\title{
DFT-Based Studies on the Jahn-Teller Effect in 3d Hexacyanometalates with Orbitally Degenerate Ground States
}

\author{
Mihial Atanasov, $*,+, *, \S$ Peter Comba, $*, \sharp$ Claude A. Daul, ${ }^{\S}$ and Andreas Hauser ${ }^{\|}$ \\ Institute of General and Inorganic Chemistry, Bulgarian Academy of Sciences, Acad. Georgi Bontchev \\ Str. Bl.11, 1113 Sofia, Bulgaria, Anorganisch-Chemisches Institut, Universität Heidelberg, \\ Im Neuenheimer Feld 270, D-69120 Heidelberg, Germany, Département de Chimie, Université de Fribourg, \\ Ch. du Musée 9, CH-1700 Fribourg, Switzerland, and Département de Chimie Physique, Université de Genève, \\ Genève, Switzerland
}

The topology of the ground-state potential energy surface of $\mathrm{M}(\mathrm{CN})_{6}$ with orbitally degenerate ${ }^{2} \mathrm{~T}_{2 \mathrm{~g}}(\mathrm{M}=$ $\mathrm{Ti}^{\mathrm{III}}\left(\mathrm{t}_{2 \mathrm{~g}}{ }^{1}\right), \mathrm{Fe}^{\mathrm{III}}$ and $\mathrm{Mn}^{\mathrm{II}}$ (both low-spin $\left.\mathrm{t}_{2 \mathrm{~g}}{ }^{5}\right)$ ) and ${ }^{3} \mathrm{~T}_{1 \mathrm{~g}}$ ground states $\left(\mathrm{M}=\mathrm{V}^{\mathrm{III}}\left(\mathrm{t}_{2 \mathrm{~g}}{ }^{2}\right), \mathrm{Mn}^{\mathrm{III}}\right.$ and $\mathrm{Cr}^{\mathrm{II}}$ (both low-spin $\mathrm{t}_{2 \mathrm{~g}}{ }^{4}$ )) has been studied with linear and quadratic Jahn-Teller coupling models in the five-dimensional space of the $\epsilon_{\mathrm{g}}$ and $\tau_{2 \mathrm{~g}}$ octahedral vibrations $\left(\mathrm{T}_{\mathrm{g}} \otimes\left(\epsilon_{\mathrm{g}}+\tau_{2 \mathrm{~g}}\right)\right.$ Jahn-Teller coupling problem $\left(\mathrm{T}_{\mathrm{g}}={ }^{2} \mathrm{~T}_{2 \mathrm{~g}},{ }^{3} \mathrm{~T}_{1 \mathrm{~g}}\right)$ ). A procedure is proposed to give access to all vibronic coupling parameters from geometry optimization with density functional theory (DFT) and the energies of a restricted number of Slater determinants, derived from electron replacements within the $\mathrm{t}_{2 \mathrm{~g}}^{1,5}$ or $\mathrm{t}_{2 \mathrm{~g}}{ }^{2,4}$ ground-state electronic configurations. The results show that coupling to the $\tau_{2 \mathrm{~g}}$ bending mode is dominant and leads to a stabilization of $D_{3 d}$ structures (absolute minima on the ground-state potential energy surface) for all complexes considered, except for $\left[\mathrm{Ti}(\mathrm{CN})_{6}\right]^{3-}$, where the minimum is of $D_{4 h}$ symmetry. The Jahn-Teller stabilization energies for the $D_{3 d}$ minima are found to increase in the order of increasing $\mathrm{CN}-\mathrm{M} \pi$ back-donation $\left(\mathrm{Ti}^{\mathrm{III}}<\mathrm{V}^{\mathrm{III}}<\mathrm{Mn}^{\mathrm{III}}<\mathrm{Fe}^{\mathrm{III}}<\mathrm{Mn}^{\mathrm{II}}<\mathrm{Cr}^{\mathrm{II}}\right.$ ). With the angular overlap model and bonding parameters derived from angular distortions, which correspond to the stable $D_{3 d}$ minima, the effect of configuration interaction and spin-orbit coupling on the ground-state potential energy surface is explored. This approach is used to correlate Jahn-Teller distortion parameters with structures from X-ray diffraction data. Jahn-Teller coupling to trigonal modes is also used to reinterpret the anisotropy of magnetic susceptibilities and $\mathbf{g}$ tensors of $\left[\mathrm{Fe}(\mathrm{CN})_{6}\right]^{3-}$, and the ${ }^{3} \mathrm{~T}_{1 \mathrm{~g}}$ ground-state splitting of $\left[\mathrm{Mn}(\mathrm{CN})_{6}\right]^{3-}$, deduced from near-IR spectra. The implications of the pseudo Jahn-Teller coupling due to $t_{2 g}-e_{g}$ orbital mixing via the trigonal modes $\left(\tau_{2 \mathrm{~g}}\right)$ and the effect of the dynamic Jahn-Teller coupling on the magnetic susceptibilities and $\mathbf{g}$ tensors of $\left[\mathrm{Fe}(\mathrm{CN})_{6}\right]^{3-}$ are also addressed.

\section{Introduction}

Hexacynometalates of $3 \mathrm{~d}$ metal ions are characterized by $\mathrm{t}_{2 \mathrm{~g}}{ }^{n}$ electronic configurations and orbitally degenerate low-spin ground states: ${ }^{3} \mathrm{~T}_{1 \mathrm{~g}}$ for $\mathrm{Mn}^{\mathrm{III}}$ and $\mathrm{Cr}^{\mathrm{II}}\left(\mathrm{d}^{4}\right)$ and ${ }^{2} \mathrm{~T}_{2 \mathrm{~g}}$ for $\mathrm{Fe}^{\mathrm{III}}$ and $\mathrm{Mn}^{\mathrm{II}}\left(\mathrm{d}^{5}\right)$. These systems as well as $\mathrm{Ti}^{\mathrm{III}}\left({ }^{2} \mathrm{~T}_{2 \mathrm{~g}}, \mathrm{~d}^{1}\right)$ and $\mathrm{V}^{\mathrm{III}}\left({ }^{3} \mathrm{~T}_{1 \mathrm{~g}}\right.$, $\mathrm{d}^{2}$ ) are Jahn-Teller (JT) active. ${ }^{1,2}$ The $\epsilon_{\mathrm{g}}$ and $\tau_{2 \mathrm{~g}}$ octahedral vibrational modes lift the orbital degeneracy and lower the energy of the system $\left(\mathrm{T}_{\mathrm{g}} \otimes\left(\epsilon_{\mathrm{g}}+\tau_{2 \mathrm{~g}}\right) \mathrm{JT}\right.$ coupling, $\left.\mathrm{T}_{\mathrm{g}}={ }^{2} \mathrm{~T}_{2 \mathrm{~g}},{ }^{3} \mathrm{~T}_{1 \mathrm{~g}}\right)$. $\mathrm{JT}$ and vibronic couplings have usually been ignored in theoretical studies of the magnetic properties of room-temperature magnets, derived from Prussian blue analogues with $\mathrm{M}(\mathrm{CN})_{6}$ as building blocks for oligonuclear complexes. ${ }^{3,4} \mathrm{~T}_{\mathrm{g}} \otimes\left(\epsilon_{\mathrm{g}}+\tau_{2 \mathrm{~g}}\right)$ JT coupling in complexes with $\pi$-bonding or -antibonding $\mathrm{T}_{\mathrm{g}}$ states is expected to be weaker than that in systems where $\mathrm{d}$ electrons occupy the $\sigma$-antibonding e subshell $\left(\mathrm{E} \otimes \epsilon_{\mathrm{g}} \mathrm{JT}\right.$ coupling). A prominent example is that of complexes of $\mathrm{Cu}^{\mathrm{II}} .^{5-7}$ However, energies involved in the $\mathrm{T}_{\mathrm{g}} \otimes\left(\epsilon_{\mathrm{g}}+\tau_{2 \mathrm{~g}}\right) \mathrm{JT}$ interaction

* To whom correspondence should be addressed at Universität Heidelberg. Fax: (+49) 6221-546617. E-mail: peter.comba@aci.uni-heidelberg.de (P.C.); mihail.atanasov@aci.uni-heidelberg.de (M.A.).

Bulgarian Academy of Sciences.

$\doteqdot$ Universität Heidelberg.

$\S$ Université de Fribourg.

"Université de Genève. are comparable to spin-orbit coupling energies and, therefore, are expected to strongly modify the magnetic behavior.

$\mathrm{T}_{\mathrm{g}} \otimes\left(\epsilon_{\mathrm{g}}+\tau_{2 \mathrm{~g}}\right) \mathrm{JT}$ coupling in octahedral complexes has been treated in the limiting case of linear and the more thorough case of quadratic JT coupling. ${ }^{8-10}$ A typical problem with these models is the large number of symmetry-independent parameters, which usually are larger than the number of observables (four harmonic force and vibronic coupling constants for linear and eight for quadratic JT coupling models). We have applied density functional theory (DFT) to the $\mathrm{T}_{\mathrm{g}} \otimes \epsilon_{\mathrm{g}}$ problem in $\mathrm{M}(\mathrm{CN})_{6}$ complexes $\left(\mathrm{M}=\mathrm{Ti}{ }^{\mathrm{III}}, \mathrm{V}^{\mathrm{III}}, \mathrm{Mn}^{\mathrm{III}}, \mathrm{Fe}^{\mathrm{III}}, \mathrm{Cr}^{\mathrm{II}}, \mathrm{Mn}^{\mathrm{II}}\right) .{ }^{11}$ DFT is used to deduce vibronic coupling parameters, which then are used for the calculation of structural distortions and JT stabilization energies. ${ }^{11}$ Here, we give an extension of this DFTbased approach, which allows us to consider all five $\epsilon_{\mathrm{g}}$ and $\tau_{2 \mathrm{~g}}$ vibrations and to explore the topology of the ground-state potential energy surface. The $\mathrm{T}_{\mathrm{g}} \otimes\left(\epsilon_{\mathrm{g}}+\tau_{2 \mathrm{~g}}\right)$ problem in octahedral $\mathrm{T}_{\mathrm{g}}$ ground states is isomorphic with the $\mathrm{T} \otimes\left(\epsilon+\tau_{2}\right)$ problem in tetrahedral complexes of $\mathrm{Cu}^{\mathrm{II}}\left({ }^{2} \mathrm{~T}_{2}\right)$ and $\mathrm{Ni}^{\mathrm{II}}\left({ }^{3} \mathrm{~T}_{1}\right)$. In a study on the symmetry aspects of the JT effect in these systems, group theoretical concepts were applied to describe the lowest and intermediate subgroups, starting from the high-symmetry (cubic) reference configuration. ${ }^{12}$ With symmetry concepts we are able to simplify the $\mathrm{T}_{\mathrm{g}} \otimes\left(\epsilon_{\mathrm{g}}+\tau_{2 \mathrm{~g}}\right)$ multimode JT problem. 
$\varepsilon_{\mathrm{g}}$

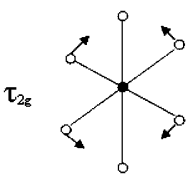

$\mathrm{Q}_{\zeta}$

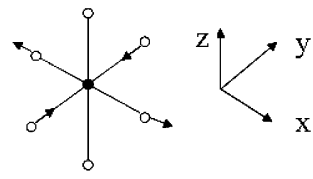

$\mathrm{Q}_{\varepsilon}$
Figure 1. Components and shapes of the $\epsilon_{\mathrm{g}}$ and $\tau_{\mathrm{g}}$ octahedral vibrations.

Our aim is to calculate all stationary points (energy minima and saddle points) on the ground-state potential energy surface in $\mathrm{M}(\mathrm{CN})_{6}\left(\mathrm{M}=\mathrm{Ti}^{\mathrm{III}}, \mathrm{V}^{\mathrm{III}}, \mathrm{Mn}^{\mathrm{III}}, \mathrm{Fe}^{\mathrm{III}}, \mathrm{Cr}^{\mathrm{II}}, \mathrm{Mn}^{\mathrm{II}}\right)$, on the basis of DFT and a $\mathrm{T}_{\mathrm{g}} \otimes\left(\epsilon_{\mathrm{g}}+\tau_{2 \mathrm{~g}}\right)$ vibronic coupling model. While energy minima are expected to dominate the low-temperature magnetic behavior, saddle points (transition states) are important for the reactivity in these and other related systems. To check the theory, we have applied this approach to experimental data of $\mathrm{K}_{3}\left[\mathrm{Fe}(\mathrm{CN})_{6}\right]$ and $\mathrm{K}_{3}\left[\mathrm{Mn}(\mathrm{CN})_{6}\right]$, for which isotropic and anisotropic susceptibility data are available. ${ }^{13-25}$ The groundstate splitting of $\left[\mathrm{Mn}(\mathrm{CN})_{6}\right]^{3-}$, derived from high-resolution spectroscopy of $\mathrm{K}_{3}\left[\mathrm{Mn}(\mathrm{CN})_{6}\right]$, and $\mathbf{g}$ tensor data of $\left[\mathrm{Fe}(\mathrm{CN})_{6}\right]^{3-}$ are also included in the analysis. ${ }^{13}$ Implications of pseudo and dynamic JT coupling have been studied with $\left[\mathrm{Fe}(\mathrm{CN})_{6}\right]^{3-}$ as a model complex.

\section{Theory}

a. Vibronic Coupling Model and Symmetry Analysis of the Topology of the $\mathbf{T}_{\mathrm{g}} \otimes\left(\epsilon_{\mathrm{g}}+\tau_{2 \mathrm{~g}}\right)$ Ground-State Adiabatic Potential Energy Surface. The Hamiltonian matrix of the $\mathrm{T}_{\mathrm{g}} \otimes\left(\epsilon_{\mathrm{g}}+\tau_{2 \mathrm{~g}}\right)$ vibronic coupling problem up to second-order vibronic coupling terms is given by ${ }^{26,27}$

$$
\begin{gathered}
\mathbf{H}=\left[\frac{1}{2} K_{\epsilon}\left(Q_{\theta}{ }^{2}+Q_{\epsilon}{ }^{2}\right)+\frac{1}{2} K_{\tau}\left(Q_{\xi}{ }^{2}+Q_{\eta}{ }^{2}+Q_{\xi}{ }^{2}\right)\right] \mathbf{I}+ \\
{\left[V_{\epsilon} Q_{\theta}+\frac{1}{2} L_{\epsilon}\left(Q_{\epsilon}{ }^{2}-Q_{\theta}{ }^{2}\right)-\frac{1}{4} L_{\tau}\left(2 Q_{\xi}{ }^{2}-Q_{\xi}{ }^{2}-Q_{\eta}{ }^{2}\right)\right] \mathbf{C}_{\theta}+} \\
{\left[V_{\epsilon} Q_{\epsilon}+L_{\epsilon} Q_{\theta} Q_{\epsilon}-\frac{\sqrt{3}}{4} L_{\tau}\left(Q_{\xi}{ }^{2}-Q_{\eta}{ }^{2}\right)\right] \mathbf{C}_{\epsilon}+\left[V_{\tau} Q_{\xi}+\right.} \\
\left.X_{\tau} Q_{\eta} Q_{\varsigma}+W\left(-\frac{1}{2} Q_{\theta}+\frac{\sqrt{3}}{2} Q_{\epsilon}\right) Q_{\xi}\right] \mathbf{C}_{\xi}+\left[V_{\tau} Q_{\eta}+\right. \\
\left.X_{\tau} Q_{\xi} Q_{\varsigma}+W\left(-\frac{1}{2} Q_{\theta}-\frac{\sqrt{3}}{2} Q_{\epsilon}\right) Q_{\eta}\right] \mathbf{C}_{\eta}+ \\
{\left[V_{\tau} Q_{\varsigma}+X_{\tau} Q_{\xi} Q_{\eta}+W Q_{\zeta} Q_{\theta}\right] \mathbf{C}_{\xi}}
\end{gathered}
$$

$Q_{\theta}$ and $Q_{\epsilon}$ and $Q_{\xi}, Q_{\eta}$, and $Q_{\zeta}$ are the $\epsilon_{\mathrm{g}}$ and $\tau_{2 \mathrm{~g}}$ vibrations, respectively (see Figure 1). With Griffith's standard notation the basis of the matrix representation is $\mathrm{T}_{1 \mathrm{~g}} \alpha, \mathrm{T}_{1 \mathrm{~g}} \beta, \mathrm{T}_{1 \mathrm{~g}} \gamma$ or $\mathrm{T}_{2 \mathrm{~g}} \xi, \mathrm{T}_{2 \mathrm{~g}} \eta, \mathrm{T}_{2 \mathrm{~g}} \xi .{ }^{28} \mathbf{I}$ is the $(3 \times 3)$ unit matrix. The $\mathbf{C}$ matrices with the appropriate coupling coefficients are defined as

$$
\begin{aligned}
\mathbf{C}_{\theta} & =\left(\begin{array}{lll}
\frac{1}{2} & 0 & 0 \\
0 & \frac{1}{2} & 0 \\
0 & 0 & -1
\end{array}\right) \\
\mathbf{C}_{\epsilon} & =\left(\begin{array}{lll}
-\frac{\sqrt{3}}{2} & 0 & 0 \\
0 & \frac{\sqrt{3}}{2} & 0 \\
0 & 0 & 0
\end{array}\right) \\
\mathbf{C}_{\xi} & =\left(\begin{array}{lll}
0 & 0 & 0 \\
0 & 0 & -1 \\
0 & -1 & 0
\end{array}\right) \\
\mathbf{C}_{\xi} & =\left(\begin{array}{lll}
0 & -1 & 0 \\
-1 & 0 & 0 \\
0 & 0 & 0
\end{array}\right) \\
\mathbf{C}_{\eta} & =\left(\begin{array}{lll}
0 & 0 & 0 \\
-1 & 0 & 0
\end{array}\right)
\end{aligned}
$$

The six parts of eq 1 correspond to the six representations $\left(A_{1 g}\right.$, $\mathrm{E}_{\mathrm{g}}$, and $\mathrm{T}_{2 \mathrm{~g}}$ ) and their components, included in the symmetrized direct products $\mathrm{T}_{1 \mathrm{~g}} \otimes \mathrm{T}_{1 \mathrm{~g}}=\mathrm{T}_{2 \mathrm{~g}} \otimes \mathrm{T}_{2 \mathrm{~g}}, K_{\epsilon}$ and $K_{\tau}$ are the harmonic force constants for the $\epsilon_{\mathrm{g}}$ and $\tau_{2 \mathrm{~g}}$ vibrational modes, $V_{\epsilon}$ and $V_{\tau}$ are the linear JT coupling constants for the $\mathrm{T}_{\mathrm{g}} \otimes \epsilon_{\mathrm{g}}$ and $\mathrm{T}_{\mathrm{g}} \otimes \tau_{2 \mathrm{~g}}$ problems, $W$ is a quadratic constant, which arises from the coupling between the $\epsilon_{\mathrm{g}}$ and $\tau_{2 \mathrm{~g}}$ vibrations, and $L_{\epsilon}, L_{\tau}$, and $X_{\tau}$ refer to quadratic coupling constants, which result from the non-totally-symmetric parts of the $\epsilon_{\mathrm{g}} \times \epsilon_{\mathrm{g}}$ and $\tau_{2 \mathrm{~g}} \times \tau_{2 \mathrm{~g}}$ symmetrized direct products $\left(\mathrm{e}_{\mathrm{g}}\left(L_{\epsilon}\right)\right.$ and $\mathrm{e}_{\mathrm{g}}\left(L_{\tau}\right)+\mathrm{t}_{2 \mathrm{~g}}\left(X_{\tau}\right)$, respectively).

It has been shown in a symmetry analysis ${ }^{12}$ that distortions along the $\epsilon_{\mathrm{g}}$ and $\tau_{2 \mathrm{~g}}$ modes lead to a decrease of the symmetry toward subgroups of $O_{h}$, in which one or more components of these modes become totally symmetric. Activation of $\epsilon_{\mathrm{g}}$ lowers the symmetry toward $D_{4 h}$ and $D_{2 h}$, where only one $\left(Q_{\theta}\right)$ and two $\left(Q_{\theta}\right.$ and $\left.Q_{\epsilon}\right)$ components, respectively, are totally symmetric (see Table 1 ). Activation of $\tau_{2 \mathrm{~g}}$ leads to $D_{3 d}, C_{2 h}$, and $C_{i}$ symmetries, where one, two, and three components of the $\tau_{2 \mathrm{~g}}$ vibration are totally symmetric. From Table 1 it follows that activation of both $\epsilon_{\mathrm{g}}$ and $\tau_{2 \mathrm{~g}}$ leads to symmetries which cannot be higher than $D_{2 h}$. The highest possible symmetry which can be achieved upon distortion along a certain vibrational mode or a combination of various modes is referred to as the epikernel symmetry. $D_{4 h}$ and $D_{3 d}$ are higher and $D_{2 h}$ and $C_{2 h}$ are lower ranking epikernels. The

TABLE 1: Symmetry Species Spanned by $t_{2 g}$ Orbitals and the $t_{2 \mathrm{~g}}$ and $e_{\mathrm{g}}$ Vibrations ${ }^{a}$ Involved in the $T_{\mathrm{g}} \otimes\left(\epsilon_{\mathrm{g}}+\tau_{2 \mathrm{~g}}\right)\left(\mathbf{T}_{\mathrm{g}}=\right.$ $\left.{ }^{2} T_{2 g}\left(t_{2 g}{ }^{1}, t_{2 g}{ }^{5}\right),{ }^{3} T_{1 g}\left(t_{2 g}{ }^{2}, t_{2 g}{ }^{4}\right)\right)$ JT Effect of Transition-Metal Complexes

\begin{tabular}{cccccc}
\hline$O_{h}$ & $D_{4 \mathrm{~h}^{z}}$ & $D_{3 d^{x y z}}$ & $D_{2 \mathrm{~h}}{ }^{x y}$ & $C_{2 \mathrm{~h}}{ }^{x y}$ & $C_{i}$ \\
\hline $\mathrm{t}_{2 \mathrm{~g}}$ & $\mathrm{~b}_{2 \mathrm{~g}}$ & $\mathrm{a}_{1 \mathrm{~g}}$ & $\mathrm{a}_{\mathrm{g}}$ & $\mathrm{a}_{\mathrm{g}}$ & $\mathrm{a}_{\mathrm{g}}$ \\
& $\mathrm{e}_{\mathrm{g}}$ & $\mathrm{e}_{\mathrm{g}}$ & $\mathrm{b}_{2 \mathrm{~g}}$ & $\mathrm{ag}_{\mathrm{g}}$ & $\mathrm{ag}_{\mathrm{g}}$ \\
& & & $\mathrm{b}_{3 \mathrm{~g}}$ & $\mathrm{~b}_{\mathrm{g}}$ & $\mathrm{ag}_{\mathrm{g}}$ \\
$\mathrm{e}_{\mathrm{g}}$ & $\mathrm{a}_{1 \mathrm{~g}}$ & $\mathrm{e}_{\mathrm{g}}$ & $\mathrm{a}_{\mathrm{g}}$ & $\mathrm{ag}_{\mathrm{g}}$ & $\mathrm{ag}_{\mathrm{g}}$ \\
& $\mathrm{b}_{1 \mathrm{~g}}$ & & $\mathrm{~b}_{1 \mathrm{~g}}$ & $\mathrm{bg}_{\mathrm{g}}$ & $\mathrm{ag}_{\mathrm{g}}$
\end{tabular}

${ }^{a}$ For species spanned by the $\mathrm{e}_{\mathrm{g}}$ and $\mathrm{t}_{2 \mathrm{~g}}$ vibrations $\left(\epsilon_{\mathrm{g}}, \tau_{2 \mathrm{~g}}\right.$, etc. $)$, Greek letters have been used in the text. 


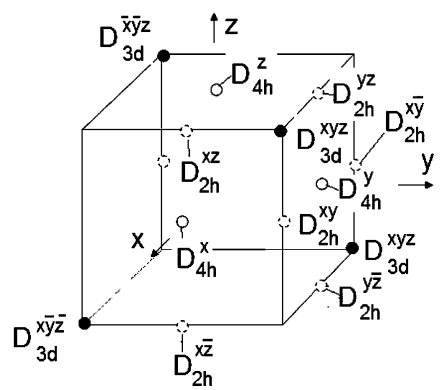

Figure 2. Stationary points of $D_{4 h}, D_{3 d}$, and $D_{2 h}$ symmetry on the ground-state potential energy surface, which originate from $\mathrm{T}_{\mathrm{g}} \otimes\left(\epsilon_{\mathrm{g}}+\tau_{2 \mathrm{~g}}\right)$ JT coupling.

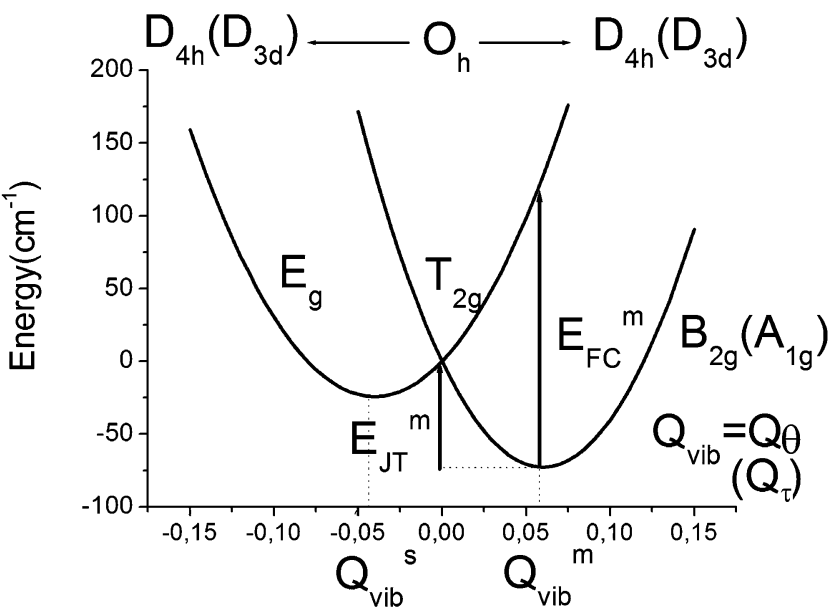

Figure 3. Energy profile for the components split from the $T_{g}=T_{2 g}$ ground states for $\mathrm{d}^{1,5}$ (and similarly for $\mathrm{d}^{2,4}$ ) transition-metal ions due to $\mathrm{T}_{\mathrm{g}} \otimes \epsilon_{\mathrm{g}}\left(\mathrm{T}_{\mathrm{g}} \otimes \tau_{2 \mathrm{~g}}\right)$ JT coupling along a distortion pathway which preserves the highest possible symmetry $D_{4 h}\left(D_{3 d}\right)$ and lifts the orbital degeneracy. The basic model parameters - the JT stabilization energy, $E_{\mathrm{JT}}{ }^{\mathrm{m}}$, the energy of the vertical (Franck-Condon) transition at the $D_{4 h}$ $\left(D_{3 d}\right)$ minimum, $E_{\mathrm{FC}}{ }^{\mathrm{m}}$, and the distortions of the active mode, $Q_{\mathrm{vib}}{ }^{\mathrm{m}}$ and $Q_{\text {vib }}{ }^{\mathrm{s}}\left(\mathrm{vib}=\epsilon_{\mathrm{g}}, \tau_{2 \mathrm{~g}}\right)$-for the minima (m) and saddle points (s) are illustrated.

lowest possible symmetry that can be achieved by the $\mathrm{T}_{\mathrm{g}} \otimes\left(\epsilon_{\mathrm{g}}+\tau_{2 \mathrm{~g}}\right)$ vibronic interaction is $C_{i}$ and is referred to as a kernel symmetry. It was demonstrated in a case study of the tetrahedral $\mathrm{T} \otimes\left(\epsilon+\tau_{2}\right) \mathrm{JT}$ effect that extrema prefer epikernels to kernels and maximal epikernels to lower ranking epikernels (epikernel principle). ${ }^{12}$

b. Linear $\mathbf{T}_{\mathrm{g}} \otimes\left(\epsilon_{\mathrm{g}}+\tau_{2 \mathrm{~g}}\right)$ Vibronic Coupling: Determination of the Vibronic Parameters from DFT. The matrix $\mathbf{H}$ of eq 1 takes the form of eq 3 . Coordinates of the stationary points

$$
\begin{array}{r}
\mathbf{H}_{\mathbf{1}}=\left[\begin{array}{lll}
V_{\epsilon} \cdot\left(\frac{1}{2} Q_{\theta}-\frac{\sqrt{3}}{2} Q_{\epsilon}\right) & -V_{\tau} Q_{\zeta} & -V_{\tau} Q_{\eta} \\
-V_{\tau} Q_{\zeta} & V_{\epsilon} \cdot\left(\frac{1}{2} Q_{\theta}+\frac{\sqrt{3}}{2} Q_{\epsilon}\right) & -V_{\tau} Q_{\xi} \\
-V_{\tau} Q_{\eta} & -V_{\tau} Q_{\xi} & -V_{\epsilon} Q_{\theta}
\end{array}\right]+ \\
{\left[\frac{1}{2} K_{\epsilon}\left(Q_{\theta}{ }^{2}+Q_{\epsilon}{ }^{2}\right)+\frac{1}{2} K_{\tau}\left(Q_{\xi}{ }^{2}+Q_{\eta}{ }^{2}+Q_{\zeta}{ }^{2}\right)\right] \mathbf{I}}
\end{array}
$$

on the ground-state potential energy surface can be derived by the method of Öpik and Price (see the Supporting Information). ${ }^{29}$ There are three, four, and six symmetry-equivalent points of $D_{4 h}, D_{3 d}$, and $D_{2 h}$ symmetry. These can be visualized as the axes, corners, and edges of a cube (Figure 2). An energy diagram plot with a single configurational coordinate (Figure 3) illustrates the basic geometric and energetic parameters of the model.
These are the tetragonal $\left(D_{4 h}\right)$ or trigonal $\left(D_{3 d}\right)$ elongations or compressions of an octahedron (tetragonal: $Q_{\theta}>0$ (elongation), $Q_{\theta}<0$ (compression); trigonal: $Q_{\tau}=Q_{\xi}=Q_{\eta}=Q_{\xi} ; Q_{\tau}<0$ (elongation), $Q_{\tau}>0$ (compression)), the Jahn-Teller stabilization energy $\left(E_{\mathrm{JT}}{ }^{\mathrm{m}}\right)$ and the energy of the vertical electronic transition from the minimum of the nondegenerate ground state to the doubly degenerate excited state $\left(E_{\mathrm{FC}} \mathrm{m}\right.$; Franck-Condon, FC). Table 2 gives for the three types of stationary points the corresponding energy functions, derived from the vibronic coupling constants. It is remarkable that in the linear coupling case only four parameters are needed to determine the groundstate topology: i.e., $V_{\epsilon}, K_{\epsilon}$ (for $D_{4 h}$ distortions) and $V_{\tau}, K_{\tau}$ (for $D_{3 d}$ distortions) (see Table 2). With the following approach one can get these parameters from DFT.

1. A geometry optimization in $D_{4 h}$ is performed by using the orbital occupations appropriate for the nondegenerate ground state of interest $\left({ }^{2} \mathrm{~B}_{2 \mathrm{~g}}\left(\mathrm{~d}^{1}\right.\right.$, low-spin $\left.\mathrm{d}^{5}\right),{ }^{3} \mathrm{~A}_{2 \mathrm{~g}}\left(\mathrm{~d}^{2}\right.$, low-spin $\left.\left.\mathrm{d}^{4}\right)\right)$; more explicitly, these are the configurations $\mathrm{b}_{2 \mathrm{~g}}{ }^{1}\left(\mathrm{Ti}^{\mathrm{III}}\right), \mathrm{e}_{\mathrm{g}}{ }^{2}\left(\mathrm{~V}^{\mathrm{III}}\right)$, $\mathrm{b}_{2 \mathrm{~g}}{ }^{2} \mathrm{e}_{\mathrm{g}}{ }^{2}\left(\mathrm{Mn}^{\mathrm{III}}, \mathrm{Cr}^{\mathrm{II}}\right)$, and $\mathrm{e}_{\mathrm{g}}{ }^{4} \mathrm{~b}_{2 \mathrm{~g}}{ }^{1}\left(\mathrm{Fe}^{\mathrm{III}}, \mathrm{Mn}^{\mathrm{II}}\right)$. As a result, the metal-ligand bond distances for the axial and equatorial bonds $\left(R_{\mathrm{ax}}{ }^{\mathrm{tt}}, R_{\mathrm{eq}}{ }^{\mathrm{tt}} ;\right.$ Figure 4$)$ are obtained and used to calculate $Q_{\theta}{ }^{\mathrm{m}}$ with the expressions from Table $4 \mathrm{a}$.

2. With the geometry of step 1 one calculates $E_{\mathrm{FC}} \mathrm{m}\left(D_{4 h}\right)$ as the difference between the energy of the excited $\left({ }^{2} \mathrm{E}_{\mathrm{g}}\right.$ or $\left.{ }^{3} \mathrm{E}_{\mathrm{g}}\right)$ and ground states $\left({ }^{2} \mathrm{~B}_{2 \mathrm{~g}}\right.$ or $\left.{ }^{3} \mathrm{~A}_{2 \mathrm{~g}}\right)$ for $\mathrm{d}^{1,5}$ and $\mathrm{d}^{2,4}$.

3. A geometry optimization in $D_{3 d}$ is then performed to yield the orbital occupations of the nondegenerate ground states of interest $\left({ }^{2} \mathrm{~A}_{1 \mathrm{~g}}\left(\mathrm{~d}^{1}\right.\right.$, low-spin $\left.\mathrm{d}^{5}\right),{ }^{3} \mathrm{~A}_{2 \mathrm{~g}}\left(\mathrm{~d}^{2}\right.$, low-spin $\left.\left.\mathrm{d}^{4}\right)\right)$; more explicitly, these are the configurations $\mathrm{a}_{1 \mathrm{~g}}{ }^{1}\left(\mathrm{Ti}^{\mathrm{III}}\right), \mathrm{e}_{\mathrm{g}}{ }^{2}\left(\mathrm{~V}^{\mathrm{III}}\right)$, $\mathrm{a}_{1 \mathrm{~g}}{ }^{2} \mathrm{e}_{\mathrm{g}}{ }^{2}\left(\mathrm{Mn}^{\mathrm{III}}, \mathrm{Cr}^{\mathrm{II}}\right)$, and $\mathrm{e}_{\mathrm{g}}{ }^{4} \mathrm{a}_{1 \mathrm{~g}}{ }^{1}\left(\mathrm{Fe}^{\mathrm{III}}, \mathrm{Mn}^{\mathrm{II}}\right)$. The distance $R_{\text {tr }}$ and the angle $\theta$ (Figure 4) quantify the trigonal distortion and are used to calculate $Q_{\tau}{ }^{\mathrm{m}}$ with the expressions from Table $4 \mathrm{~b}$.

4. With the geometry of step 3 one calculates $E_{\mathrm{FC}}{ }^{\mathrm{m}}\left(D_{3 d}\right)$ as the difference between the energy of the excited $\left({ }^{2} E_{g}\right.$ or $\left.{ }^{3} E_{g}\right)$ and ground states $\left({ }^{2} \mathrm{~A}_{1 \mathrm{~g}}\right.$ or $\left.{ }^{3} \mathrm{~A}_{2 \mathrm{~g}}\right)$ for $\mathrm{d}^{1,5}$ or $\mathrm{d}^{2,4}$.

From the equations in Table $2, V_{\epsilon}, K_{\epsilon}, V_{\tau}$, and $K_{\tau}$ are

$$
\begin{aligned}
& V_{\epsilon}=\frac{2}{3} \frac{E_{\mathrm{FC}}{ }^{\mathrm{m}}\left(D_{4 h}\right)}{Q_{\theta}{ }^{\mathrm{m}}} K_{\epsilon}=\frac{2}{3} \frac{E_{\mathrm{FC}}{ }^{\mathrm{m}}\left(D_{4 h}\right)}{\left(Q_{\theta}{ }^{\mathrm{m}}\right)^{2}} \\
& V_{\tau}=\frac{1}{3} \frac{E_{\mathrm{FC}}{ }^{\mathrm{m}}\left(D_{3 d}\right)}{Q_{\tau}^{\mathrm{m}}} K_{\tau}=\frac{2}{9} \frac{E_{\mathrm{FC}}{ }^{\mathrm{m}}\left(D_{3 d}\right)}{\left(Q_{\theta}{ }^{\mathrm{m}}\right)^{2}}
\end{aligned}
$$

After substitution in the equations of Table 2 the JT stabilization energies $\left(E_{\mathrm{JT}}{ }^{\mathrm{m}}\left(D_{4 h}\right)\right.$ and $\left.E_{\mathrm{JT}} \mathrm{m}\left(D_{3 d}\right)\right]$ and all quantities, which characterize the $D_{2 h}$ stationary points are obtained.

Note that the stabilization of the distorted geometry with respect to the regular octahedral reference $\left(E_{\mathrm{JT}}{ }^{\mathrm{m}}\right)$ does not directly emerge as a difference between the DFT energies of the two configurations but is based on explicit solutions of $\mathbf{H}_{\mathbf{1}}$. This is because Kohn-Sham DFT in its present implementations is not able to calculate the energies of electronic states in the case of orbital degeneracy $\left({ }^{2} \mathrm{~T}_{2 \mathrm{~g}}\right.$ or $\left.{ }^{3} \mathrm{~T}_{1 \mathrm{~g}}\right) .{ }^{30,31}$ For example, for $\mathrm{Ti}^{\mathrm{III}}\left(\mathrm{d}^{1}\right)$ one electron is distributed evenly between the $\mathrm{d}_{x z}, \mathrm{~d}_{y z}$, and $\mathrm{d}_{x y}$ orbitals. Such a distribution usually leads to a lower energy than the correct one-electron/one-orbital occupancy (no correction for electron self-interaction). Similarily, electronic transitions from a nondegenerate to a doubly degenerate orbital create orbitally degenerate subshells $\left(\mathrm{e}_{\mathrm{g}}{ }^{1}\right.$ in the given example; steps 2 and 4 of the procedure). For a thorough calculation one would adopt the $D_{4 h}$ (step 2) or the $D_{3 d}$ (step 4) geometry but a $D_{2 h}$ or $C_{s}$ electron distribution, where $\mathrm{e}_{\mathrm{g}}$ splits into $\mathrm{b}_{2 \mathrm{~g}}$ and $b_{3 g}$ or $a^{\prime}$ and $a^{\prime \prime}$, respectively. Thus, one imposes a single orbital 
TABLE 2: Expressions for the Coordinates of the $D_{4 h}, D_{3 d}$, and $D_{2 h}$ Stationary Points, ${ }^{a}$ the JT Stabilization Energies, and Energies of Vertical (Franck-Condon) Transitions ${ }^{b}$ for the Linear $\mathbf{T}_{\mathrm{g}} \otimes\left(\epsilon_{\mathrm{g}}+\tau_{2 \mathrm{~g}}\right)$ JT Coupling Problem

\begin{tabular}{|c|c|c|}
\hline$D_{4 h}$ & $D_{3 d}$ & $D_{2 h}$ \\
\hline $\begin{array}{l}Q_{\theta}^{\mathrm{m}}\left(D_{4 h}\right)=V_{\epsilon} / K_{\epsilon} \\
Q_{\theta} \theta^{\mathrm{m}}\left(D_{4 h}\right)=-V_{\epsilon} / 2 K_{\epsilon} \\
\rho_{\epsilon}^{\mathrm{m}}\left(D_{4 h}\right)=\left|Q_{\theta}{ }^{\mathrm{m}}\left(D_{4 h}\right)\right|\end{array}$ & $\begin{array}{l}Q_{\xi}^{\mathrm{m}}=Q_{\eta}{ }^{\mathrm{m}}=Q_{\zeta}{ }^{\mathrm{m}}=(2 / 3)\left(V_{\tau} / K_{\tau}\right) \\
Q_{\xi}^{\mathrm{s}}=Q_{\eta}{ }^{\mathrm{s}}=Q_{\zeta}^{\mathrm{s}}=-(1 / 3)\left(V_{\tau} / K_{\tau}\right) \\
\rho_{\tau}^{\mathrm{m}}\left(D_{3 d}\right)=(2 / \sqrt{3})\left|V_{\mathrm{t}} / K_{\mathrm{t}}\right|\end{array}$ & $\begin{array}{l}Q_{\theta}^{\mathrm{m}^{\prime}}\left(D_{2 h}\right)=-(1 / 2)\left(V_{\epsilon} / K_{\epsilon}\right) \\
Q_{\varsigma}^{\mathrm{m}}\left(D_{2 h}\right)=V_{\tau} / K_{\tau} \\
\rho_{\epsilon}^{\mathrm{m}}\left(D_{2 h}\right)=(1 / 2)\left[\rho_{\epsilon}^{\mathrm{m}}\left(D_{4 h}\right)\right] \\
\rho_{\tau}^{\mathrm{m}}\left(D_{2 h}\right)=(\sqrt{3} / 2)\left[\rho_{\tau}^{\mathrm{m}}\left(D_{3 d}\right)\right]\end{array}$ \\
\hline $\begin{array}{l}\mathrm{b}_{2 \mathrm{~g}} \rightarrow \mathrm{e}_{\mathrm{g}} \\
E_{\mathrm{FC}} \mathrm{m}\left(D_{4 h}\right)=(3 / 2)\left(V_{\epsilon}^{2} / K_{\epsilon}\right)\end{array}$ & $\begin{array}{l}\mathrm{A}_{1 \mathrm{~g} \rightarrow \mathrm{e}_{\mathrm{g}}} \\
E_{\mathrm{FC}}{ }^{\mathrm{m}}\left(D_{3 d}\right)=2\left(V_{\tau}^{2} / K_{\tau}\right)\end{array}$ & $\begin{array}{l}E_{\mathrm{FC}}^{\mathrm{m}}\left(D_{2 h}, \mathrm{~b}_{2 \mathrm{~g}} \rightarrow \mathrm{b}_{3 \mathrm{~g}}\right)=E_{\mathrm{FC}}{ }^{\mathrm{m}}\left(D_{3 d}\right) \\
E_{\mathrm{FC}} \mathrm{m}\left(D_{2 h}, \mathrm{~b}_{2 \mathrm{~g}} \rightarrow \mathrm{a}_{\mathrm{g}}\right)=(1 / 2)\left[E_{\mathrm{FC}}^{\mathrm{m}}\left(D_{4 h}\right)+E_{\mathrm{FC}} \mathrm{m}\left(D_{3 d}\right)\right]\end{array}$ \\
\hline$E_{\mathrm{JT}}{ }^{\mathrm{m}}\left(D_{4 h}\right)=(1 / 2)\left(V_{\epsilon}^{2} / K_{\epsilon}\right)$ & $E_{\mathrm{JT}} \mathrm{m}^{\mathrm{m}}\left(D_{3 d}\right)=(2 / 3)\left(V_{\tau}^{2} / K_{\mathrm{t}}\right)$ & $E_{\mathrm{JT}}{ }^{\mathrm{m}}\left(D_{2 h}\right)=(1 / 4)\left[E_{\mathrm{JT}}{ }^{\mathrm{m}}\left(D_{4 h}\right)\right]+(3 / 4)\left[E_{\mathrm{JT}} \mathrm{m}\left(D_{3 d}\right)\right]$ \\
\hline
\end{tabular}

${ }^{a}$ Only nonzero values for $Q_{\theta}, Q_{\epsilon}, Q_{\xi}, Q_{\eta}$, and $Q_{\xi}$ are listed. ${ }^{b}$ Specified as electronic transitions between the components split from the $\mathrm{t}_{2 \mathrm{~g}}$ orbital of the $\mathrm{t}_{2 \mathrm{~g}}{ }^{1}, \mathrm{t}_{2 \mathrm{~g}}{ }^{5}\left({ }^{2} \mathrm{~T}_{2 \mathrm{~g}}\right.$ states) or the $\mathrm{t}_{2 \mathrm{~g}}{ }^{2}, \mathrm{t}_{2 \mathrm{~g}}{ }^{4}\left({ }^{3} \mathrm{~T}_{1 \mathrm{~g}}\right.$ states) electronic configurations.

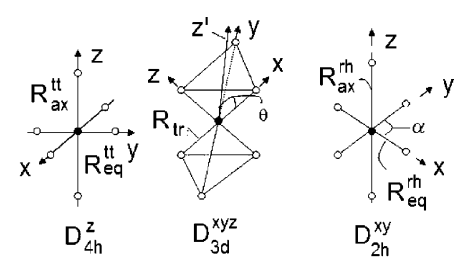

Figure 4. Geometric parameters to describe the JT distortions of $\mathrm{T}_{\mathrm{g}} \otimes \epsilon_{\mathrm{g}}$ $\left(D_{4 h^{z}}\right), \mathrm{T}_{\mathrm{g}} \otimes \tau_{2 \mathrm{~g}}\left(D_{3 d^{x z}}\right)$, and $\mathrm{T}_{\mathrm{g}} \otimes\left(\epsilon_{\mathrm{g}}+\tau_{2 \mathrm{~g}}\right)\left(D_{2 h^{x y}}\right)$ type, deduced from DFT geometry optimizations with electronic configurations with correct spin and space symmetries in $D_{4 h}\left({ }^{2} \mathrm{~B}_{2 g}\left(\mathrm{~d}^{1}\right.\right.$, low-spin $\left.\mathrm{d}^{5}\right),{ }^{3} \mathrm{~A}_{2 \mathrm{~g}}\left(\mathrm{~d}^{2}\right.$, low-spin $\left.\left.\mathrm{d}^{4}\right)\right), D_{3 d}\left({ }^{2} \mathrm{~A}_{1 \mathrm{~g}}\left(\mathrm{~d}^{1}\right.\right.$, low-spin $\left.\mathrm{d}^{5}\right),{ }^{3} \mathrm{~A}_{2 \mathrm{~g}}\left(\mathrm{~d}^{2}\right.$, low-spin $\left.\left.\mathrm{d}^{4}\right)\right)$, and $D_{2 h}$ $\left({ }^{2} \mathrm{~B}_{2 \mathrm{~g}}\left(\mathrm{~d}^{1}, \mathrm{~d}^{5}\right),{ }^{3} \mathrm{~B}_{2 \mathrm{~g}}\left(\mathrm{~d}^{2}, \mathrm{~d}^{4}\right)\right)$.

occupancy by artificially lowering the symmetry. A full list of orbital occupations derived from this procedure is given in the Supporting Information.

So far, we have considered the symmetry of the nuclear configurations and of the electronic states as well as the distortions of the nuclear coordinates of the stationary points on the ground-state potential energy surface. In order to decide if a stationary point corresponds to a minimum or to a saddle point, the Hamiltonian of eq 3 has to be reexpanded around the extrema in $D_{4 h}, D_{3 d}$, and $D_{2 h}$ to yield a new Hessian matrix. This differs from that of the octahedron, which is diagonal with the elements $K_{\epsilon}$ and $K_{\tau}$ for the $\epsilon_{\mathrm{g}}$ and $\tau_{2 \mathrm{~g}}$ vibrations. Diagonalization of the new matrix yields the force constants as the eigenvalues and the principal axes of curvature as the eigenvectors of the Hessian. A minimum implies that all five eigenvectors are positive, while saddle points (transition states for reactions) have one negative eigenvalue (the corresponding eigenvector indicates the reaction coordinate (transition vector)). In $D_{4 h}$ symmetry, the $\tau_{2 \mathrm{~g}}$ vibration splits into $\alpha_{1 \mathrm{~g}}$ and $\epsilon_{\mathrm{g}}$, and the only mode which can couple the ${ }^{2} \mathrm{~B}_{2 \mathrm{~g}}\left(\mathrm{~d}^{1}\right.$, low-spin $\left.\mathrm{d}^{5}\right)$ or ${ }^{3} \mathrm{~A}_{2 \mathrm{~g}}\left(\mathrm{~d}^{2}\right.$, low-spin $\left.\mathrm{d}^{4}\right)$ ground states with the ${ }^{2} \mathrm{E}_{\mathrm{g}}$ or ${ }^{3} \mathrm{E}_{\mathrm{g}}$ excited states and yield negative curvature is the $\epsilon_{\mathrm{g}}\left(\tau_{2 \mathrm{~g}}\right)$ mode. Its force constant, $K_{\epsilon_{\mathrm{g}}\left(\tau_{2 \mathrm{~g}}\right)}$ is given by eq 6 (see the Supporting Information).

$$
K_{\epsilon_{\mathrm{g}}\left(\tau_{2 \mathrm{~g}}\right)}=K_{\tau}\left(1-\frac{4}{3} \frac{V_{\tau}^{2} K_{\epsilon}}{V_{\epsilon}^{2} K_{\tau}}\right)
$$

Therefore, the values $V_{\epsilon}, K_{\epsilon}, V_{\tau}$, and $K_{\tau}$, obtained from DFT, are of immediate use to judge whether a given stationary point represents a minimum or a saddle point. For extrema with $D_{3 d}$ symmetry there are two vibrations of $\epsilon_{\mathrm{g}}$ symmetry, which can mix the ${ }^{2} \mathrm{~A}_{1 \mathrm{~g}}\left(\mathrm{~d}^{1}\right.$, low-spin $\left.\mathrm{d}^{5}\right)$ or the ${ }^{3} \mathrm{~A}_{2 \mathrm{~g}}$ ground state $\left(\mathrm{d}^{2}\right.$, lowspin $\left.d^{4}\right)$ with the ${ }^{2} E_{g}$ or ${ }^{3} E_{g}$ excited state. One of them arises from the $\epsilon_{\mathrm{g}}$ octahedral mode $\left(\epsilon_{\mathrm{g}}\left(\epsilon_{\mathrm{g}}\right)\right.$, which does not split in $D_{3 d}$ symmetry), the other $\left(\epsilon_{\mathrm{g}}\left(\tau_{2 \mathrm{~g}}\right)\right)$ originates from the $\tau_{2 \mathrm{~g}}$ vibrations (vide supra). Therefore, the Hessian is given by a 2 $\times 2$ matrix and a possible instability will be reflected by the negative sign of its lowest eigenvalue.

$$
\begin{aligned}
& \epsilon_{\mathrm{g}}\left(\epsilon_{\mathrm{g}}\right) \quad \epsilon_{\mathrm{g}}\left(\tau_{2 \mathrm{~g}}\right) \\
& {\left[\begin{array}{ll}
K_{\epsilon}-\frac{1}{2} K_{\tau} \frac{V_{\epsilon}^{2}}{\mathrm{~V}_{\tau}^{2}} & \frac{K_{\tau} V_{\epsilon}}{\sqrt{6} V_{\tau}} \\
\frac{K_{\tau} V_{\epsilon}}{\sqrt{6} V_{\tau}} & \frac{2}{3} K_{\tau}
\end{array}\right]}
\end{aligned}
$$

Finally, we note that $D_{2 h}$ stationary points originate from the combined action of the $\epsilon_{\mathrm{g}}\left(Q_{\theta}\right)$ and the $\tau_{2 \mathrm{~g}}\left(Q_{\zeta}\right)$ vibrations. The distortion along $Q_{\theta}$ is of opposite sign with respect to that which leads to a nondegenerate ground state. Therefore, it stabilizes an $\mathrm{E}_{\mathrm{g}}$ ground state. The role of the $\tau_{2 \mathrm{~g}}\left(Q_{\xi}\right)$ mode is to split the $\mathrm{E}_{\mathrm{g}}$ state into $\mathrm{B}_{2 \mathrm{~g}}$ or $\mathrm{B}_{3 \mathrm{~g}}$, depending on the sign of $Q_{\zeta}$. We focus here on the $B_{2 g}$ ground state; the others, derived from the $T_{g}$ term, are $\mathrm{B}_{3 \mathrm{~g}}$ and $\mathrm{A}_{\mathrm{g}}$. The $\mathrm{B}_{2 \mathrm{~g}}$ state can mix with $\mathrm{A}_{\mathrm{g}}$ via the $\beta_{2 \mathrm{~g}}$ split component of the $\tau_{2 \mathrm{~g}}\left(O_{h}\right)$ mode, or with the $\beta_{1 \mathrm{~g}}$ vibration of the $\epsilon_{\mathrm{g}}\left(O_{h}\right)$ mode. The following equations for their force constants emerge (see Supporting Information):

$$
\begin{gathered}
K_{\beta_{2 \mathrm{~g}}}=K_{\tau}\left(\begin{array}{c}
\left.1-\frac{8 K_{\epsilon}}{4 K_{\epsilon}+3 K_{\tau} \frac{V_{\epsilon}^{2}}{V_{\tau}^{2}}}\right) \\
K_{\beta_{1 \mathrm{~g}}}=K_{\epsilon}\left(1-\frac{3}{4} \frac{V_{\epsilon}^{2}}{V_{\tau}^{2}} \cdot \frac{K_{\tau}}{K_{\epsilon}}\right)
\end{array}\right.
\end{gathered}
$$

Stationary points with $D_{2 h}$ symmetry may represent genuine transition states in contrast to the extrema in $D_{4 h}$ and $D_{3 d}$ symmetry, where only $\epsilon_{\mathrm{g}}$ vibrations can contribute to instability and lead to second-order or higher order saddle points. This is of importance for the reactivity of the systems.

c. Quadratic $\mathbf{T}_{\mathrm{g}} \otimes\left(\epsilon_{\mathrm{g}}+\tau_{2 \mathrm{~g}}\right)$ Vibronic Coupling: Determination of All Parameters of the Vibronic Hamiltonian from DFT. The extension of the DFT approach to the more general case of quadratic $\mathrm{T}_{\mathrm{g}} \otimes\left(\epsilon_{\mathrm{g}}+\tau_{2 \mathrm{~g}}\right)$ JT coupling is straightforward. As in the linear case, we subdivide the procedure to get the vibronic coupling parameters into the $\mathrm{T}_{\mathrm{g}} \otimes \epsilon_{\mathrm{g}}\left(D_{4 h}\right)$ and $\mathrm{T}_{\mathrm{g}} \otimes \tau_{2 \mathrm{~g}}$ $\left(D_{3 d}\right)$ sections (steps 1 and 2), in which the $\epsilon_{\mathrm{g}}$ and $\tau_{2 \mathrm{~g}}$ vibrations are decoupled from each other, and into a combined $\mathrm{T}_{\mathrm{g}} \otimes\left(\epsilon_{\mathrm{g}}+\tau_{2 \mathrm{~g}}\right)$ $\left(D_{2 h}\right)$ problem (step 3), which allows us to get all $\mathrm{T}_{\mathrm{g}} \otimes \epsilon_{\mathrm{g}}-\mathrm{T}_{\mathrm{g}} \otimes \tau_{2 \mathrm{~g}}$ coupling terms. In step 1 , we have the following expressions for the distortion along $Q_{\theta}$ for the nondegenerate $\left({ }^{2} \mathrm{~B}_{2 \mathrm{~g}}\left({ }^{2} \mathrm{~T}_{2 \mathrm{~g}}\right)\right.$ or $\left.{ }^{3} \mathrm{~A}_{2 \mathrm{~g}}\left({ }^{3} \mathrm{~T}_{1 \mathrm{~g}}\right)\right)\left(Q_{\theta} \mathrm{m}\right)$ and the doubly degenerate $\left({ }^{2} \mathrm{E}_{\mathrm{g}}\left({ }^{2} \mathrm{~T}_{2 \mathrm{~g}}\right)\right.$ or $\left.{ }^{3} \mathrm{E}_{\mathrm{g}}\left({ }^{3} \mathrm{~T}_{1 \mathrm{~g}}\right)\right)\left(Q_{\theta^{\mathrm{s}}}\right)$ electronic states ${ }^{12}$ 


$$
\begin{gathered}
Q_{\theta}{ }^{\mathrm{m}}=\frac{V_{\epsilon}}{K_{\epsilon}+L_{\epsilon}} \\
Q_{\theta}{ }^{\mathrm{s}}=-\frac{V_{\epsilon}}{2 K_{\epsilon}-L_{\epsilon}}
\end{gathered}
$$

and in addition, for the energy of the FC transition at $Q_{\theta}{ }^{\mathrm{m}}$ $\left(E_{\mathrm{FC}}{ }^{\mathrm{m}}\left(D_{4 h}\right)\right)$

$$
E_{\mathrm{FC}}{ }^{\mathrm{m}}\left(D_{4 h}\right)=\frac{3}{2}\left(K_{\epsilon}+\frac{1}{2} L_{\epsilon}\right)\left(Q_{\theta}{ }^{\mathrm{m}}\right)^{2}
$$

Here, the parameters $V_{\epsilon}, L_{\epsilon}$, and $K_{\epsilon}$ are obtained from the values of $Q_{\theta}{ }^{\mathrm{m}}, Q_{\theta}^{\mathrm{s}}$, and $E_{\mathrm{FC}}{ }^{\mathrm{m}}\left(D_{4 h}\right)$, deduced from DFT. In step 2, we have the following expressions for the distortion along $Q_{\tau}\left(=Q_{\xi}\right.$ $\left.=Q_{\eta}=Q_{\zeta}\right)$ for the nondegenerate $\left({ }^{2} \mathrm{~A}_{1 \mathrm{~g}}\left({ }^{2} \mathrm{~T}_{2 \mathrm{~g}}\right)\right.$ or $\left.{ }^{3} \mathrm{~A}_{2 \mathrm{~g}}\left({ }^{3} \mathrm{~T}_{1 \mathrm{~g}}\right)\right)$ $\left(Q_{\tau}{ }^{\mathrm{m}}\right)$ and the doubly degenerate $\left({ }^{2} \mathrm{E}_{\mathrm{g}}\left({ }^{2} \mathrm{~T}_{2 \mathrm{~g}}\right)\right.$ or $\left.{ }^{3} \mathrm{E}_{\mathrm{g}}\left({ }^{3} \mathrm{~T}_{1 \mathrm{~g}}\right)\right)\left(Q_{\theta}{ }^{\mathrm{s}}\right)$ electronic states ${ }^{12}$

$$
\begin{gathered}
Q_{\tau}^{\mathrm{m}}=\frac{2 V_{\tau}}{3 K_{\tau}-4 X_{\tau}} \\
Q_{\tau}^{\mathrm{s}}=-\frac{V_{\tau}}{3 K_{\tau}+2 X_{\tau}}
\end{gathered}
$$

and in addition for the energy of the FC transition at $Q_{\theta}{ }^{\mathrm{m}}$ $\left(E_{\mathrm{FC}}{ }^{\mathrm{m}}\left(D_{3 \mathrm{~d}}\right)\right)$

$$
E_{\mathrm{FC}}{ }^{\mathrm{m}}\left(D_{3 d}\right)=\frac{3}{2}\left(3 K_{\tau}-2 X_{\tau}\right)\left(Q_{\tau}{ }^{\mathrm{m}}\right)^{2}
$$

The parameters $V_{\tau}, X_{\tau}$, and $K_{\tau}$ are obtained from the values of $Q_{\theta}{ }^{\mathrm{m}}, Q_{\theta}^{\mathrm{s}}$, and $E_{\mathrm{FC}}{ }^{\mathrm{m}}\left(D_{3 d}\right)$, deduced from DFT. Finally, in step 3 , we consider a DFT geometry optimization for a ${ }^{2} \mathrm{~B}_{2 \mathrm{~g}}\left({ }^{2} \mathrm{~T}_{2 \mathrm{~g}}\right)$ or a ${ }^{3} \mathrm{~B}_{2 \mathrm{~g}}\left({ }^{3} \mathrm{~T}_{1 \mathrm{~g}}\right)$ ground state, which leads to a $D_{2 h}$ distorted geometry. At this stationary point the distortions along $Q_{\theta}$ and $Q_{\zeta}\left(Q_{\theta}{ }^{\mathrm{m}^{\prime}}\right.$ and $Q_{\zeta}^{\mathrm{m}}$, respectively $)$ are given by ${ }^{12}$

$$
\begin{gathered}
Q_{\theta}{ }^{{ }^{\prime}}=\frac{-V_{\epsilon}+2 W Q_{\varsigma}{ }^{\mathrm{m}}}{2 K_{\epsilon}-L_{\epsilon}} \\
Q_{\varsigma}^{\mathrm{m}}=\frac{2 V_{\tau}+2 W Q_{\theta}{ }^{{ }^{\prime}}}{2 K_{\tau}-L_{\tau}}
\end{gathered}
$$

The distortions are calculated from structural data from DFT geometry optimizations, with bond distances to get $Q_{\theta}{ }^{\mathrm{m}^{\prime}}$ and angles to get $Q_{\zeta}{ }^{\mathrm{m}}$. With the parameters $V_{\epsilon}, V_{\tau}, K_{\epsilon}, L_{\epsilon}$, and $K_{\tau}$, available from steps 1 and 2 , the parameters $W$ and $L_{\tau}$ are obtained. Therefore, we have expressed the parameters of the Hamiltonian $\mathbf{H}$ (eq 1) in terms of data which are all based on DFT (see Appendix for the master equations). From these parameters JT stabilization energies for the $D_{4 h}, D_{3 d}$, and $D_{2 h}$ stationary points may be obtained: ${ }^{12}$

$$
\begin{gathered}
E_{\mathrm{JT}}{ }^{\mathrm{m}}\left(D_{4 h}\right)=\frac{1}{2} \frac{V_{\epsilon}^{2}}{K_{\epsilon}+L_{\epsilon}}=\frac{1}{2} V_{\epsilon} Q_{\theta}{ }^{\mathrm{m}} \\
E_{\mathrm{JT}}{ }^{\mathrm{m}}\left(D_{3 \mathrm{~d}}\right)=\frac{2 V_{\tau}^{2}}{3 K_{\tau}-4 X_{\tau}}=V_{\tau} Q_{\tau}{ }^{\mathrm{m}}
\end{gathered}
$$

$$
\begin{gathered}
E_{\mathrm{JT}}{ }^{\mathrm{m}}\left(D_{2 h}\right)=\frac{V_{\epsilon}^{2} K_{\tau}^{\prime}+4 V_{\tau}^{2} K_{\epsilon}^{\prime}-4 W V_{\epsilon} V_{\tau}}{8\left(K_{\epsilon}^{\prime} K_{\tau}^{\prime}-W^{2}\right)} \\
K_{\epsilon}^{\prime}=K_{\epsilon}-\frac{1}{2} L_{\epsilon} \quad K_{\tau}^{\prime}=K_{\tau}-\frac{1}{2} L_{\tau}
\end{gathered}
$$

An analysis of the topology of the ground-state potential energy surface in the vicinity of each stationary point of $D_{4 \mathrm{~h}}$, $D_{3 d}$, and $D_{2 h}$ symmetry is possible, as described in detail in section IIb. Analytical expressions of the noninteracting modes and their diagonal Hessian matrix elements are given in Table 3 . Vibronic mixing (distortions away from the $D_{4 h}, D_{3 d}$, and $D_{2 h}$ stationary point geometries) between electronic states induces off-diagonal matrix elements, which can cause instabilities of the kind already described in section IIb. However, analytical expressions, similar to those of eqs 6-9, are quite cumbersome in this case. For this reason, we resort to numerical calculations of the $(5 \times 5)$ Hessian matrix (see the Supporting Information).

d. Static Strain and the Dynamic Jahn-Teller Effect. Calculations of the temperature dependence of the magnetic susceptibility and the $\mathrm{g}$ tensors have been done for $\left[\mathrm{Fe}(\mathrm{CN})_{6}\right]^{3-}$ (section $\mathrm{Vb}$ ). The Hamiltonian of the problem is written as a sum (eq 18) where the first to fourth terms are the ligand

$$
\hat{H}=\hat{H}_{\mathrm{LF}}+\hat{H}_{\mathrm{IER}}+\hat{H}_{\mathrm{SO}}+\hat{H}_{\mathrm{Z}}+\hat{H}_{\mathrm{vib}}+\hat{H}_{\mathrm{JT}}+\hat{H}_{\mathrm{str}}
$$

field, interelectronic repulsion, spin-orbit coupling, and Zeeman energy operators. These have been parametrized with the cubic ligand field splitting $\left(10 D q, \hat{\mathrm{H}}_{\mathrm{LF}}\right)$, the interelectronic repulsion $\left(B\right.$ and $\left.C, \hat{\mathrm{H}}_{\mathrm{IER}}\right)$, the spin-orbit coupling $\left(\zeta, \hat{\mathrm{H}}_{\mathrm{SO}}\right)$, and the covalent reduction parameters $\left(k, \hat{\mathrm{H}}_{\mathrm{Z}}=\mu_{\mathrm{B}} \mathbf{B}(\mathbf{S}+k \mathbf{L})\right)$, respectively. As will be shown in section IVa, vibronic coupling to the $\tau_{2 \mathrm{~g}}$ mode dominates and $\hat{H}_{\text {vib }}$ is

$$
\hat{H}_{\mathrm{vib}}=\frac{1}{2} \hbar \omega_{\tau}\left(\hat{P}_{\xi}^{2}+\hat{P}_{\eta}^{2}+\hat{P}_{\zeta}^{2}+{Q_{\xi}^{\prime 2}}^{\prime 2}{Q_{\eta}}^{\prime 2}+Q_{\xi}{ }^{\prime 2}\right)
$$

where $\hbar \omega_{\tau}$ is the energy of the three-dimensional harmonic oscillator and $\hat{P}_{\mathrm{i}}$ and $Q_{\mathrm{i}}{ }^{\prime}$ are dimensionless operators, related to the observables for momentum and position. ${ }^{32}$

$$
\begin{gathered}
\hat{P}_{\mathrm{i}}=\frac{1}{\sqrt{\mu \hbar \omega}} \hat{p}_{\mathrm{i}} \\
Q_{\mathrm{i}}^{\prime}=\sqrt{\frac{\mu \omega}{\hbar}} Q_{\mathrm{i}} \\
\mathrm{i}=\xi, \eta, \zeta
\end{gathered}
$$

Up to the vibronic eigenvalue problem, we restrict the treatment to linear $\mathrm{T}_{2 \mathrm{~g}} \otimes \tau_{2 \mathrm{~g}}$ terms in $\hat{H}_{\mathrm{JT}}\left(Q_{\theta}=Q_{\epsilon}=0\right.$ in eq 3$)$.

We use the distortions given by the geometric lattice strain $\left(Q_{\xi}^{\mathrm{s}}, Q_{\eta}^{\mathrm{s}}\right.$, and $Q_{\zeta}^{\mathrm{s}}$, deduced from structural data) and the vibronic coupling constants (up to second order) for $\left[\mathrm{Fe}(\mathrm{CN})_{6}\right]^{3-}$ to approximate the strain matrix $\mathbf{H}_{\text {str }}$ : 


$$
\begin{aligned}
& \mathbf{H}_{\text {str }}=
\end{aligned}
$$

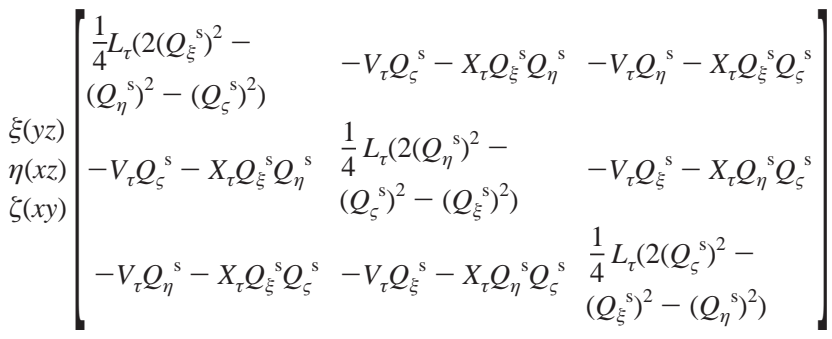

The following procedure was adopted to set up the vibronic Hamiltonian. All matrices, which represent $\hat{H}$ (eq 18, excluding $\hat{\mathrm{H}}_{\mathrm{vib}}$ ), are calculated with the basis of all 256 Slater determinants of the $\mathrm{d}^{5}$ configuration of $\left[\mathrm{Fe}(\mathrm{CN})_{6}\right]^{3-}$. The matrix $\mathbf{H}_{\mathbf{L F}}+\mathbf{H}_{\text {IER }}$ $+\mathbf{H}_{\text {So }}+\mathbf{H}_{\text {str }}$ was diagonalized first. The lowest six eigenvectors and eigenvalues, related to the parent octahedral ${ }^{2} \mathrm{~T}_{2 \mathrm{~g}}$ term, take the configuration interaction (CI) into account. This is important for all complexes (except for $\left[\mathrm{Ti}(\mathrm{CN})_{6}\right]^{3-}$; see section $\mathrm{IVb})$. The $(256 \times 6)$ matrix of the lowest six eigenvectors $\mathbf{C}$ is used to reduce the size of $\mathbf{H}_{\mathbf{J T}}$ and $\mathbf{H}_{\mathbf{Z}}(256 \times 256)$ to $6 \times 6$ matrices $\mathbf{H}_{\mathbf{J T}}{ }^{\mathbf{r}}$ and $\mathbf{H}_{\mathbf{Z}}{ }^{\mathbf{r}}$, written within the subspace of the three lowest Kramers doublets:

$$
\begin{aligned}
\mathbf{H}_{\mathrm{JT}}{ }^{\mathbf{r}} & =\boldsymbol{C}^{+} \boldsymbol{H}_{\mathrm{JT}} \boldsymbol{C} \\
\mathbf{H}_{\mathbf{Z}}{ }^{\mathbf{r}} & =\boldsymbol{C}^{+} \boldsymbol{H}_{\mathrm{Z}} \boldsymbol{C}
\end{aligned}
$$

Calculations of the $\mathbf{g}$ and susceptibility tensors in this step yield the results in section Vb.1. For the dynamic JT effect we express the vibronic eigenfunctions of the total Hamiltonian $\mathbf{H}, \Psi$ as a linear combination of products of the lowest six exact electronic eigenfunctions of $\mathbf{H}_{\mathbf{L F}}+\mathbf{H}_{\mathbf{I E R}}+\mathbf{H}_{\mathbf{S O}}+\mathbf{H}_{\text {str }}, \varphi_{\mathrm{i}}$, and the states of the three-dimensional harmonic oscillator $\left[\chi_{j}\left(Q_{\xi}{ }^{\prime}\right)\right]\left[\chi_{k}\left(Q_{\eta}{ }^{\prime}\right)\right]$ $\left[\chi_{\xi}\left(Q_{\xi}{ }^{\prime}\right)\right]$ up to the level $n_{\mathrm{v}}$ :

$$
\Psi=\sum_{i=1}^{6} \sum_{j} \sum_{k} \sum_{l} \sum_{j+k+l=0}^{n_{\mathrm{v}}} c_{i j k l} \varphi_{i} \chi_{j}\left(Q_{\xi}{ }^{\prime}\right) \chi_{k}\left(Q_{\eta}{ }^{\prime}\right) \chi_{l}\left(Q_{\xi}{ }^{\prime}\right)
$$

The total basis size $N_{\mathrm{v}}$ without exploitation of the vibronic symmetries is given by:

$$
N_{\mathrm{v}}=6\left[\frac{n_{\mathrm{v}}\left(n_{\mathrm{v}}{ }^{2}+6 n_{\mathrm{v}}+11\right)}{6}+1\right]
$$

For the moderate vibronic coupling strength, obtained for $\left[\mathrm{Fe}(\mathrm{CN})_{6}\right]^{3-}$ (section IVa), accurate $\mathbf{g}$ tensor values and magnetic susceptibilities $(\leq 2 \%)$ are achieved with $n_{\mathrm{v}}=10$, leading to a total dimension of the vibronic matrix of $1716 \times 1716$.

e. Effect of Pseudo Jahn-Teller Coupling. Vibronic parameters are deduced from DFT geometry optimizations. Therefore, they include possible contributions from pseudo JT mixing. Without loss of generality, we take $\left[\mathrm{Ti}(\mathrm{CN})_{6}\right]^{3-}$ as an example and consider the vibronic mixing (via the $\tau_{2 \mathrm{~g}}$ distortions) of its ${ }^{2} \mathrm{~T}_{2 \mathrm{~g}}(\xi, \eta, \xi)$ electronic ground state with the ${ }^{2} \mathrm{E}_{\mathrm{g}}(\theta, \epsilon)$ excited state, quantified by the matrix elements ${ }^{33}$

$$
\left[\begin{array}{cccc}
\left|\mathrm{T}_{2 \mathrm{~g}}(\xi)\right\rangle & \left|\mathrm{T}_{2 \mathrm{~g}}(\eta)\right\rangle & \left|\mathrm{T}_{2 \mathrm{~g}}(\xi)\right\rangle \\
\left\langle\mathrm{E}_{\mathrm{g}}(\theta)\right| & -\frac{1}{2} P_{\tau} Q_{\xi} & -\frac{1}{2} P_{\tau} Q_{\eta} & P_{\tau} Q_{\eta} \\
\left\langle\mathrm{E}_{\mathrm{g}}(\epsilon)\right| & \frac{\sqrt{3}}{2} P_{\tau} Q_{\xi} & -\frac{\sqrt{3}}{2} P_{\tau} Q_{\xi} & 0
\end{array}\right]
$$

$P_{\tau}$ is the pseudo JT vibronic coupling parameter, defined as

$$
P_{\tau}=\left\langle\zeta\left|\left(\frac{\partial V}{\partial Q_{\varsigma}}\right)_{\mathrm{o}}\right| \theta\right\rangle
$$

\begin{tabular}{|c|c|c|c|c|}
\hline $\begin{array}{l}\text { extremal } \\
\text { points }\end{array}$ & $\begin{array}{l}\text { ground } \\
\text { state }\end{array}$ & $\begin{array}{l}\text { excited } \\
\text { states }\end{array}$ & $\begin{array}{l}\text { normal modes and expressions for the associated force } \\
\text { constants at the position of the } D_{4 h}, D_{3 d} \text {, and } D_{2 h} \\
\text { extremal points }{ }^{a}\end{array}$ & $\begin{array}{c}\text { distortions causing } \\
\text { eventual instabilities }\end{array}$ \\
\hline$D_{4 h}$ & $\mathrm{~B}_{2 \mathrm{~g}}\left(\mathrm{~A}_{2 \mathrm{~g}}\right)$ & $E_{g}$ & $\begin{array}{l}\alpha_{1 \mathrm{~g}}, Q_{\theta} ; K_{\epsilon}+L_{\epsilon} \\
\beta_{1 \mathrm{~g}}, Q_{\epsilon} ; K_{\epsilon}-L_{\epsilon} \\
\beta_{2 \mathrm{~g}}, Q_{\zeta} ; K_{\tau}+L_{\tau} \\
\epsilon_{\mathrm{g}},\left(Q_{\xi}, Q_{\eta}\right) ; K_{\tau}-L_{\tau} / 2\end{array}$ & $\begin{array}{l}\text { none } \\
\text { none } \\
\text { none } \\
\epsilon_{\mathrm{g}}\left(\tau_{2 \mathrm{~g}}\right)\end{array}$ \\
\hline$D_{3 d}$ & $A_{1 g}\left(A_{2 g}\right)$ & $\mathrm{E}_{\mathrm{g}}$ & $\begin{array}{l}\epsilon_{\mathrm{g}},\left(Q_{\theta}, Q_{\epsilon}\right) ; K_{\epsilon} \\
\alpha_{1 \mathrm{~g}},(1 / \sqrt{ } 3)\left(Q_{\xi}+Q_{\eta}+Q_{\zeta}\right) ; K_{\tau}-(4 / 3) X_{\tau} \\
\epsilon_{\mathrm{g}},(1 / \sqrt{ } 6)\left(2 Q_{\zeta}-Q_{\xi}-Q_{\eta}\right) ; K_{\tau}+(2 / 3) X_{\tau} \\
(1 / \sqrt{ } 2)\left(Q_{\xi}-Q_{\eta}\right) ; K_{\tau}+(2 / 3) X_{\tau}\end{array}$ & $\begin{array}{l}\epsilon_{\mathrm{g}}\left(\epsilon_{\mathrm{g}}\right) \\
\text { none } \\
\epsilon_{\mathrm{g}}\left(\tau_{2 \mathrm{~g}}\right)\end{array}$ \\
\hline \multirow[t]{2}{*}{$D_{2 h}$} & $\mathrm{~B}_{2 \mathrm{~g}}$ & $\mathrm{~B}_{3 \mathrm{~g}}, \mathrm{~A}_{1 \mathrm{~g}}$ & $\begin{array}{l}\beta_{1 \mathrm{~g}}, Q_{\epsilon} ; K_{\epsilon}^{\prime}+L_{\epsilon} \\
\left.\left.\alpha_{\mathrm{g}}\left(Q_{\theta}\right)\right]\right\} \frac{K_{\epsilon}^{\prime}+K_{\tau}^{\prime}}{2} \pm \frac{1}{2} \sqrt{\left(K_{\epsilon}^{\prime}-K_{\tau}^{\prime}\right)^{2}+4 W^{2}} \\
\left.\left.\alpha_{\mathrm{g}}\left(Q_{\zeta}\right)\right]\right\} \\
\beta_{2 \mathrm{~g}},(1 / 2)\left(Q_{\xi}+Q_{\eta}\right) ; K_{\tau}^{\prime}+(3 / 4) L_{\tau}-X_{\tau} \\
\beta_{3 \mathrm{~g}},(1 / 2)\left(Q_{\xi}-Q_{\eta}\right) ; K_{\tau}^{\prime}+(3 / 4) L_{\tau}+X_{\tau}\end{array}$ & $\begin{array}{l}\beta_{1 \mathrm{~g}} \\
\text { none } \\
\text { none } \\
\beta_{2 \mathrm{~g}} \\
\text { none }\end{array}$ \\
\hline & $\mathrm{B}_{3 \mathrm{~g}}$ & $\mathrm{~B}_{2 \mathrm{~g}}, \mathrm{~A}_{1 \mathrm{~g}}$ & $\begin{array}{l}\beta_{1 \mathrm{~g}}, Q_{\epsilon} ; K_{\epsilon}^{\prime}+L_{\epsilon} \\
\left.\left.\alpha_{\mathrm{g}}\left(Q_{\theta}\right)\right]\right\} \frac{K_{\epsilon}^{\prime}+K_{\tau}^{\prime}}{2} \pm \frac{1}{2} \sqrt{\left(K_{\epsilon}^{\prime}-K_{\tau}^{\prime}\right)^{2}+4 W^{2}} \\
\left.\left.\alpha_{\mathrm{g}}\left(Q_{\zeta}\right)\right]\right\} \\
\beta_{2 \mathrm{~g}},(1 / 2)\left(Q_{\xi}+Q_{\eta}\right) ; K_{\tau}^{\prime}+(3 / 4) L_{\tau}+X_{\tau} \\
\beta_{3 \mathrm{~g}},(1 / 2)\left(\mathrm{Q}_{\xi}-\mathrm{Q}_{\eta}\right) ; K_{\tau}^{\prime}+(3 / 4) L_{\tau}-X_{\tau}\end{array}$ & $\begin{array}{l}\beta_{1 \mathrm{~g}} \\
\text { none } \\
\text { none } \\
\text { none } \\
\beta_{3 \mathrm{~g}}\end{array}$ \\
\hline
\end{tabular}

$\mathrm{CN}^{-}$is a strong-field ligand (Table 7), i.e. the energy difference ${ }^{2} \mathrm{E}_{\mathrm{g}}-{ }^{2} \mathrm{~T}_{2 \mathrm{~g}}(\Delta=10 D q)$ is large, and it is possible to apply perturbation theory to obtain the following matrix to describe the pseudo JT effect within the ${ }^{2} \mathrm{~T}_{2 \mathrm{~g}}(\xi, \eta, \zeta)$ electronic state:

TABLE 3: Normal-Mode Analysis of the $D_{4 h}, D_{3 d}$, and $D_{2 h}$ Stationary Points of the $\mathrm{T}_{\mathrm{g}} \otimes\left(\epsilon_{\mathrm{g}}+\tau_{2 \mathrm{~g}}\right) \mathrm{J}$ T Surface

\footnotetext{
${ }^{a} K_{\epsilon}{ }^{\prime}=K_{\epsilon}-L_{\epsilon} / 2 ; K_{\tau}{ }^{\prime}=K_{\tau}-L_{\tau} / 2 .{ }^{b}$ Possible transition states (first-order saddle points) are underlined.
} 


$$
\begin{aligned}
& \left|\mathrm{T}_{2 \mathrm{~g}}(\xi)\right\rangle \quad\left|\mathrm{T}_{2 \mathrm{~g}}(\eta)\right\rangle \quad\left|\mathrm{T}_{2 \mathrm{~g}}(\xi)\right\rangle \\
& {\left[\begin{array}{ccc}
-\frac{P_{\tau}^{2}}{\Delta} Q_{\xi}^{2} & 0 & 0 \\
0 & -\frac{P_{\tau}^{2}}{\Delta} Q_{\eta}{ }^{2} & 0 \\
0 & 0 & -\frac{P_{\tau}^{2}}{\Delta} Q_{\zeta}{ }^{2}
\end{array}\right]}
\end{aligned}
$$

It follows that the pseudo JT coupling modifies the diagonal quadratic JT coupling terms of the $\mathrm{T}_{\mathrm{g}} \otimes \tau_{2 \mathrm{~g}}$ problem $\left(L_{\tau}\right.$ term in eq 1). To obtain an estimate for the value of $P_{\tau}$, we will focus on $\left[\mathrm{Fe}(\mathrm{CN})_{6}\right]^{3-}$ and try to exclude the contribution from the $\mathrm{T}_{2 \mathrm{~g}} \otimes \tau_{2 \mathrm{~g}} \mathrm{JT}$ coupling. We achieve this by addition of an electron to the $\mathrm{t}_{2 \mathrm{~g}}{ }^{5}$ configuration, leading to a ${ }^{1} \mathrm{~A}_{1 \mathrm{~g}}\left(\mathrm{t}_{2 \mathrm{~g}}{ }^{6}\right)$ ground state. We restrict the analysis to trigonal $\left(D_{3 d}\right)$ elongations or compressions (component of the $\tau_{2 \mathrm{~g}}$ mode, $\alpha_{1 \mathrm{~g}}=1 / \sqrt{3}\left(Q_{\xi}+\right.$ $Q_{\eta}+Q_{\zeta}$ ); it will be shown in section IVa that these distortions are energetically preferred). The mixing between the ${ }^{1} \mathrm{~A}_{1 \mathrm{~g}}\left(\mathrm{t}_{2 \mathrm{~g}}{ }^{6}\right)$ ground state with the ${ }^{1} \mathrm{~A}_{1 \mathrm{~g}}\left(\mathrm{t}_{2 \mathrm{~g}}{ }^{5} \mathrm{e}_{\mathrm{g}}{ }^{1}\right)$ excited state $\left({ }^{1} \mathrm{~T}_{1 \mathrm{~g}}\left(\mathrm{t}_{2 \mathrm{~g}}{ }^{5} \mathrm{e}_{\mathrm{g}}{ }^{1}\right)\right)$ is described by the matrix:

$$
\begin{aligned}
& \left|{ }^{1} \mathrm{~A}_{1 \mathrm{~g}}\left(\mathrm{t}_{2 \mathrm{~g}}{ }^{6}\right\rangle \quad\right|{ }^{1} \mathrm{~A}_{1 \mathrm{~g}}\left(\mathrm{t}_{2 \mathrm{~g}}{ }^{5} \mathrm{e}_{\mathrm{g}}{ }^{1}\right\rangle \\
& {\left[\begin{array}{ll}
E_{\mathrm{g}} & N_{\tau} \\
N_{\tau} & E_{\mathrm{e}}
\end{array}\right]}
\end{aligned}
$$

$E_{\mathrm{g}}$ and $E_{\mathrm{e}}$ are the ground- and excited-state energies $\left(E_{\mathrm{g}}\right.$ is zero in $O_{h}$ geometry), and $N_{\tau}$ describes their mixing. A method has been proposed to derive these energies from DFT. ${ }^{34,35} \mathrm{We}$ focus on the lowest eigenvalue $E_{-}$of eq 29 and can represent it as

$$
E_{-}=E_{\mathrm{rf}}-E_{\mathrm{vib}}
$$

$E_{\mathrm{rf}}\left(=E_{\mathrm{g}}\right)$ and $E_{\mathrm{vib}}$ are the restoring elastic and the vibronic stabilization energies (both defined to be positive), which oppose and support the $\alpha_{1 \mathrm{~g}}\left(\tau_{2 \mathrm{~g}}\right) D_{3 d}$ distortion, respectively. A series of DFT calculations have been performed to obtain $E_{-}, E_{\mathrm{rf}}$, and $E_{\text {vib }}$ for this model example. They are represented in Figure 5 and suggest the absence of the pseudo JT instability. From these calculations we have also derived the value of $N_{\tau}$ (see Figure 5):

$$
N=P_{\alpha_{1 g}} Q_{\alpha_{1 g}}=3 P_{\tau} Q_{\tau}
$$

$N_{\tau}$ is found to depend linearly on $Q_{\tau}$ with a resulting value of $P_{\tau}=3827 \mathrm{~cm}^{-1} / \AA$. With $\Delta=34950 \mathrm{~cm}^{-1}$ (Table 7) we obtain a value of $419 \mathrm{~cm}^{-1} / \AA$ for the pseudo JT coupling energy $\left(P_{\tau}^{2} /\right.$ $\Delta)$. This may be considered as included in an efficient way in the vibronic coupling constant $L_{\tau}\left(1584 \mathrm{~cm}^{-1} / \AA^{2}\right.$; see Table 5). The second-order terms (JT and pseudo JT) do not yield leading contributions to the topology of the ground-state potential energy surface (see section IVa).

\section{Computational and Experimental Details}

All DFT calculations were carried out with the Amsterdam Density Functional program (ADF). ${ }^{36}$ In a case study on $\left[\mathrm{Mn}(\mathrm{CN})_{6}\right]^{3-}\left(\mathrm{T}_{\mathrm{g}} \otimes \epsilon_{\mathrm{g}} \text { problem }\right)^{11}$ it was shown that vibronic coupling constants do not significantly depend on the functional. Since the LDA-VWN functional ${ }^{37}$ is known to perform better than GGA for geometries of transition-metal complexes, in particular for metal-ligand bond distances, we have chosen LDA in all calculations. Large Slater-type orbital basis sets

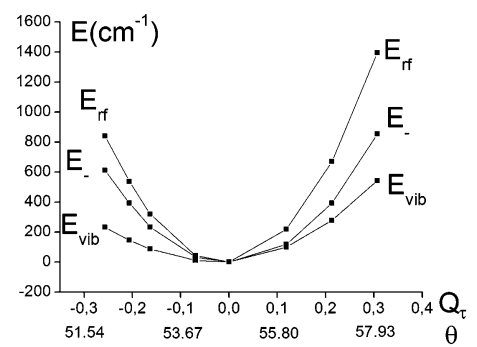

Figure 5. Dependence of $E_{-}, E_{\mathrm{rf}}$, and $E_{\mathrm{vib}}$ on the trigonal distortion parameters $Q_{\tau}$ and $\theta$ for $\left[\mathrm{Fe}(\mathrm{CN})_{6}\right]^{4-}$. Numerical values of the $\left(Q_{\tau}, N_{\tau}\right)$ pairs (in units of $\AA$ and $\mathrm{cm}^{-1}$, respectively, not shown, but calculated) are as follows: $(-0.257,2951) ;(-0.206,2350) ;(-0.163,1817)$; $(-0.069 ; 609)$; $(0.119,-1953) ;(0.213,-3247) ;(0.307,-4526)$.

(STO, triple- $\zeta$ ) with one polarization function (p type for $\mathrm{H}, \mathrm{d}$ type for $\mathrm{C}$ and $\mathrm{N}$ ) and the frozen-core approximation up to $3 \mathrm{p}$ for metal ions and $1 \mathrm{~s}$ for carbon and nitrogen were used. To account for the negative charges, calculations on chargecompensated species $\left(\left[\mathrm{M}^{\mathrm{III}}(\mathrm{CN})_{6}\right]^{3-}\right.$ solv and $\left[\mathrm{M}^{\mathrm{II}}(\mathrm{CN})_{6}\right]^{4-}$ solv $)$ were done with the conductor-like screening model COSMO, ${ }^{38}$ implemented in ADF. ${ }^{39}$ The dielectric constant of water $(\epsilon=$ 78.4) was used with the solvent radii of $1.00 \AA(\mathrm{M}=\mathrm{Cr}, \mathrm{Mn}$, $\mathrm{Fe}), 2.10 \AA(\mathrm{C})$, and $1.40 \AA(\mathrm{N})$.

Synthesis. $\mathrm{K}_{3}\left[\mathrm{Mn}(\mathrm{CN})_{6}\right]$ was prepared as described in the literature. ${ }^{40}$ Large single crystals were grown by slow evaporation from an aqueous solution.

Vis-Near-IR Spectroscopy. A single crystal $(d \approx 3 \mathrm{~mm})$ was placed to cover a small aperture on a copper plate, which was attached to the sample holder of an optical closed cycle cryosystem (Oxford Instruments, CCC1100T), capable of reaching sample temperatures of $11 \mathrm{~K}$ with the sample sitting in a helium exchange gas atmosphere for efficient cooling. Absorption spectra were recorded on a Fourier transform spectrometer (Bruker IFS 66), equipped with light sources, beam splitters, and detectors to cover the spectral range from 6000 to 30000 $\mathrm{cm}^{-1}$ at a spectral resolution of better than $2 \mathrm{~cm}^{-1}$.

\section{Results and Discussion}

a. Topology of the Ground-State Potential Energy Surface of $\mathbf{M}(\mathbf{C N})_{6}$ Complexes with JT-Active $\mathbf{T}_{g}$ Ground States. A collection of geometric data of JT-distorted structures in $D_{4 h}$, $D_{3 d}$, and $D_{2 h}$ symmetry from DFT geometry optimizations is given in Table 4. The parameters which describe these distortions are defined in Figure 4. There are two types of bond lengths for $D_{4 h}$ geometries (axial and equatorial, $R_{\mathrm{ax}}{ }^{\mathrm{tt}}, R_{\mathrm{eq}}{ }^{\mathrm{tt}}$ ), the trigonal angle $\theta$ and the bond distance $\mathrm{R}_{\mathrm{tr}}$ for $D_{3 d}$ geometries and the two bond lengths $\left(R_{\mathrm{eq}}{ }^{\text {rh }}\right.$ and $\left.R_{\mathrm{ax}}{ }^{\mathrm{rh}}\right)$ and the angle $\alpha$ for the $D_{2 h}$ geometries. Distortions of the same sign are predicted for $D_{4 h}$ and $D_{3 d}$ : i.e., tetragonally and trigonally elongated octahedra for $\mathrm{Ti}^{\mathrm{III}}, \mathrm{Mn}^{\mathrm{III}}$, and $\mathrm{Cr}^{\mathrm{II}}$ and compressed octahedra for $\mathrm{V}^{\mathrm{III}}, \mathrm{Fe}^{\mathrm{III}}$, and $\mathrm{Mn}^{\mathrm{II}}$. There is a strict correspondence between the electron count and the sign of the distortion (i.e., elongations for $\mathrm{d}^{1,4}$ and compressions for $\mathrm{d}^{2,5}$ ), and the magnitude of the distortion correlates with the $\pi$-back-bonding character of the metal-cyanide bond. For a given oxidation state, $\pi$-backdonation increases from left to right of the $3 \mathrm{~d}$ series, ${ }^{41}$ and it also increases with the decrease of the oxidation state for a given metal ion. The $\left|Q_{\tau}{ }^{\mathrm{m}}\right|$ vs $\mathrm{e}_{\pi}$ plot in Figure 6 illustrates this correlation. Geometric distortions for complexes of the same ions with $\pi$-donor ligands such as $\mathrm{F}^{-}$and $\mathrm{Cl}^{-}$are found to follow the opposite trend: $D_{4 h}$ and $D_{3 d}$ compressed octahedra are predicted for $\left[\mathrm{TiF}_{6}\right]^{3-} .^{42} \mathrm{DFT}$ geometries and energies have been used to obtain vibronic coupling parameters and JT stabilization energies $E_{\mathrm{JT}}\left(D_{4 h}\right), E_{\mathrm{JT}}\left(D_{3 d}\right)$ and $E_{\mathrm{JT}}\left(D_{2 h}\right)$, as de- 
TABLE 4: Bond Distances (in $\AA$ ) and Angles (in deg) from $D_{4 h}, D_{3 d}$, and $D_{2 h}$ Symmetry-Constrained DFT Geometry Optimizations and Energies (in $\mathrm{cm}^{-1}$ ) of Vertical (Franck-Condon, FC) Electronic Transitions from the Nondegenerate into the Doubly Degenerate (for $D_{4 h}$ and $D_{3 d}$ ) Split Components of the ${ }^{2} T_{2 g}$ or ${ }^{3} T_{1 g}$ Octahedral Terms at the Energy Minima (m), Used to Calculate the Vibronic Parameters of the $T_{2 g} \otimes\left(e_{g}+t_{2 g}\right)$ Potential Energy Surface up to First- and Second-Order Vibronic Coupling

\begin{tabular}{|c|c|c|c|c|c|c|c|c|}
\hline \multicolumn{9}{|c|}{ (a) $D_{4 h}$ Stationary Points } \\
\hline \multirow[b]{2}{*}{ complex } & \multicolumn{2}{|c|}{${ }^{2} \mathrm{~B}_{2 \mathrm{~g}}\left({ }^{2} \mathrm{~T}_{2 \mathrm{~g}}\right)$ or $\left.{ }^{3} \mathrm{~A}_{2 \mathrm{~g}}{ }^{(3} \mathrm{T}_{1 \mathrm{~g}}\right)$ state } & \multicolumn{2}{|c|}{${ }^{2} \mathrm{E}_{\mathrm{g}}\left({ }^{2} \mathrm{~T}_{2 \mathrm{~g}}\right)$ or ${ }^{3} \mathrm{E}_{\mathrm{g}}\left({ }^{3} \mathrm{~T}_{1 \mathrm{~g}}\right)$ state } & \multirow[b]{2}{*}{$Q_{\theta}{ }^{\mathrm{m} a}$} & \multirow[b]{2}{*}{$Q_{\theta^{\mathrm{s} a}}$} & \multirow[b]{2}{*}{$\left|r_{\epsilon}\right|^{b}$} & \multirow{2}{*}{$\begin{array}{c}E_{\mathrm{FC}}{ }^{\mathrm{m}} \\
{ }^{2} \mathrm{~B}_{2 \mathrm{~g}} \rightarrow{ }^{2} \mathrm{E}_{\mathrm{g}}\left({ }^{2} \mathrm{~T}_{2 \mathrm{~g}}\right) \text { or } \\
{ }^{3} \mathrm{~A}_{2 \mathrm{~g}} \rightarrow{ }^{3} \mathrm{E}_{\mathrm{g}}\left({ }^{3} \mathrm{~T}_{1 \mathrm{~g})}\right.\end{array}$} \\
\hline & $R_{\mathrm{eq}}{ }^{\mathrm{tt}}$ & $R_{\mathrm{ax}}{ }^{\mathrm{tt}}$ & $R_{\mathrm{eq}}{ }^{\mathrm{t}}$ & $R_{\mathrm{ax}}{ }^{\mathrm{tt}}$ & & & & \\
\hline$\left[\mathrm{Ti}(\mathrm{CN})_{6}{ }^{3-}\right]_{\text {solv }}$ & 2.168 & 2.199 & 2.184 & 2.168 & 0.036 & -0.018 & 2.0 & 173 \\
\hline$\left[\mathrm{V}(\mathrm{CN}) 6^{3-}\right]_{\text {solv }}$ & 2.096 & 2.079 & 2.088 & 2.097 & -0.020 & 0.010 & 2.0 & 48 \\
\hline$\left[\mathrm{Mn}(\mathrm{CN})_{6}{ }^{3-}\right]_{\text {solv }}$ & 1.948 & 1.973 & 1.961 & 1.948 & 0.029 & -0.015 & 1.9 & 158 \\
\hline$\left[\mathrm{Fe}(\mathrm{CN})_{6}{ }^{3-}\right]_{\text {solv }}$ & 1.907 & 1.897 & 1.902 & 1.908 & $-0.011_{5}$ & 0.007 & 1.6 & 14 \\
\hline$\left[\mathrm{Cr}(\mathrm{CN})_{6}{ }^{4-}\right]_{\text {solv }}$ & 1.991 & 2.032 & 2.011 & 1.991 & 0.047 & -0.023 & 2.0 & 552 \\
\hline$\left[\mathrm{Mn}(\mathrm{CN})_{6}{ }^{4-}\right]_{\text {solv }}$ & 1.940 & 1.912 & 1.926 & 1.940 & -0.032 & 0.016 & 2.0 & 190 \\
\hline \multicolumn{9}{|c|}{ (b) $D_{3 d}$ Stationary Points } \\
\hline & \multicolumn{2}{|c|}{${ }^{2} \mathrm{~A}_{1 \mathrm{~g}}\left({ }^{2} \mathrm{~T}_{2 \mathrm{~g}}\right)$ or ${ }^{3} \mathrm{~A}_{2 \mathrm{~g}}{ }^{\left({ }^{3} \mathrm{~T}_{1 \mathrm{~g}}\right)}$} & \multicolumn{2}{|c|}{${ }^{2} \mathrm{E}_{\mathrm{g}}\left({ }^{2} \mathrm{~T}_{2 \mathrm{~g}}\right)$ or ${ }^{3} \mathrm{E}_{\mathrm{g}}\left({ }^{3} \mathrm{~T}_{1 \mathrm{~g}}\right)$} & \multirow[b]{2}{*}{$Q_{\tau}^{\mathrm{m} c}$} & \multirow[b]{2}{*}{$Q_{\tau}^{\mathrm{s} c}$} & \multirow[b]{2}{*}{$\left|r_{\tau}\right|^{d}$} & \multirow{2}{*}{$\begin{array}{c}E_{\mathrm{FC}}{ }^{\mathrm{m}} \\
{ }^{2} \mathrm{~A}_{1 \mathrm{~g}} \rightarrow{ }^{2} \mathrm{E}_{\mathrm{g}}\left({ }^{2} \mathrm{~T}_{2 \mathrm{~g}}\right) \text { or } \\
{ }^{3} \mathrm{~A}_{2 \mathrm{~g}} \rightarrow{ }^{3} \mathrm{E}_{\mathrm{g}}\left({ }^{3} \mathrm{~T}_{1 \mathrm{~g}}\right)\end{array}$} \\
\hline complex & $\theta$ & $R_{\mathrm{tr}}$ & $\theta$ & $R_{\mathrm{tr}}$ & & & & \\
\hline$\left[\mathrm{Ti}(\mathrm{CN})_{6}^{3-}\right]_{\text {solv }}$ & 54.30 & 2.178 & 55.38 & 2.180 & -0.047 & 0.069 & 0.7 & 31 \\
\hline$\left[\mathrm{V}(\mathrm{CN}) 6^{3-}\right]_{\text {solv }}$ & 55.82 & 2.089 & 54.52 & 2.092 & 0.112 & -0.022 & 5.1 & 206 \\
\hline$\left[\mathrm{Mn}(\mathrm{CN})_{6}{ }^{3-}\right]_{\text {solv }}$ & 53.53 & 1.956 & 55.60 & 1.956 & -0.116 & 0.083 & 1.4 & 265 \\
\hline$\left[\mathrm{Fe}(\mathrm{CN})_{6}{ }^{3-}\right]_{\text {solv }}$ & 56.10 & 1.904 & 54.15 & 1.905 & 0.128 & -0.055 & 2.3 & 427 \\
\hline$\left[\mathrm{Cr}(\mathrm{CN})_{6}{ }^{4-}\right]_{\text {solv }}$ & 52.89 & 2.004 & 55.81 & 2.003 & -0.182 & 0.106 & 1.7 & 1865 \\
\hline$\left[\mathrm{Mn}(\mathrm{CN})_{6}{ }^{4-}\right]_{\text {solv }}$ & 56.47 & 1.932 & 53.94 & 1.932 & 0.165 & -0.076 & 2.2 & 969 \\
\hline
\end{tabular}

\begin{tabular}{|c|c|c|c|c|c|c|c|}
\hline \multirow[b]{2}{*}{ complex } & \multicolumn{3}{|c|}{${ }^{2} B_{2 g}\left({ }^{2} T_{2 g}\right)$ or $\left.{ }^{3} B_{2 g}{ }^{(3} T_{1 g}\right)$ state } & \multirow[b]{2}{*}{$Q_{\theta}^{\mathrm{m}^{\prime} e}$} & \multirow[b]{2}{*}{$Q_{\zeta}^{\mathrm{m} e}$} & \multirow[b]{2}{*}{$r_{\epsilon}^{\prime f}$} & \multirow[b]{2}{*}{$r_{\tau}{ }^{f}$} \\
\hline & $R_{\mathrm{eq}}^{\text {rh }}$ & $R_{\mathrm{a} \times}{ }^{\text {rh }}$ & $\alpha$ & & & & \\
\hline$\left[\mathrm{Ti}(\mathrm{CN})_{6}^{3-}\right]_{\text {solv }}$ & 2.182 & 2.168 & 88.86 & -0.016 & -0.087 & 0.9 & 1.8 \\
\hline$\left[\mathrm{V}(\mathrm{CN})_{6}{ }^{3-}\right]_{\text {solv }}$ & 2.087 & 2.097 & 87.98 & $0.011_{5}$ & 0.147 & 1.2 & 1.3 \\
\hline$\left[\mathrm{Mn}(\mathrm{CN})_{6}{ }^{3-}\right]_{\text {solv }}$ & 1.961 & 1.948 & 88.00 & -0.015 & -0.137 & 1.0 & 1.2 \\
\hline$\left[\mathrm{Fe}(\mathrm{CN}) 6^{3-}\right]_{\text {solv }}$ & 1.902 & 1.908 & 87.00 & 0.007 & 0.199 & 1.0 & 1.6 \\
\hline$\left[\mathrm{Cr}(\mathrm{CN})_{6}{ }^{4-}\right]_{\text {solv }}$ & 2.011 & 1.992 & 85.82 & -0.022 & -0.292 & 1.0 & 1.6 \\
\hline$\left[\mathrm{Mn}(\mathrm{CN})_{6}{ }^{4-}\right]_{\text {solv }}$ & 1.928 & 1.942 & 86.34 & 0.016 & 0.247 & 1.0 & 1.5 \\
\hline
\end{tabular}

${ }^{a}$ Calculated with the $R_{\mathrm{eq}}{ }^{\mathrm{tt}}$ and $R_{\mathrm{ax}}{ }^{\mathrm{tt}}$ values and the following set of equations: $Q_{\theta}=2\left(\mathrm{~d} R_{\mathrm{ax}}-\mathrm{d} R_{\mathrm{eq}}\right) / \sqrt{ } 3 ; \mathrm{d} R_{\mathrm{ax}}=R_{\mathrm{ax}}-R_{\mathrm{av}} ; \mathrm{d} R_{\mathrm{eq}}=R_{\mathrm{eq}}-R_{\mathrm{av}} ; R_{\mathrm{av}}$ $=\left(2 R_{\mathrm{eq}}+R_{\mathrm{ax}}\right) / 3{ }^{b} r_{\epsilon}=Q_{\theta}{ }^{\mathrm{m}} / Q_{\theta}^{\mathrm{s}} ; r_{\epsilon}=-2$ in the case of linear vibronic coupling. ${ }^{c}$ Calculated with $Q_{\tau}=2 \sqrt{ } 2 R_{\mathrm{tr}}\left(\theta-54.7356^{\circ}\right)(\pi / 180) .{ }^{d} r_{\tau}=$ $Q_{\tau}{ }^{\mathrm{m}} / Q_{\tau}^{\mathrm{s}} ; r_{\tau}=-2$ in the case of linear vibronic coupling. ${ }^{e}$ Calculated with $Q_{\theta}=2\left(\mathrm{~d} R_{\mathrm{ax}}{ }^{\mathrm{rh}}-\mathrm{d} R_{\mathrm{eq}}{ }^{\mathrm{rh}}\right) / \sqrt{ } 3 ; \mathrm{d} R_{\mathrm{ax}}{ }^{\text {rh }}=R_{\mathrm{ax}}{ }^{\mathrm{rh}}-R_{\mathrm{av}}{ }^{\mathrm{rh}} ; \mathrm{d} R_{\mathrm{eq}}{ }^{\text {rh }}=R_{\mathrm{eq}}{ }^{\mathrm{rh}}-R_{\mathrm{av}}{ }^{\text {rh }}$ $R_{\mathrm{av}}{ }^{\mathrm{rh}}=\left(2 R_{\mathrm{eq}}{ }^{\mathrm{rh}}+R_{\mathrm{ax}}{ }^{\mathrm{rh}}\right) / 3 ; Q_{\zeta}=\left|2 R_{\mathrm{av}}{ }^{\mathrm{rh}}\left(\alpha-90^{\circ}\right)(\pi / 180)\right| \operatorname{sign}\left(V_{\tau}\right) .{ }^{f} r_{\epsilon}{ }^{\prime}=Q_{\theta}{ }^{\mathrm{m}} / Q_{\theta}{ }^{\mathrm{s}} ; r_{\epsilon}{ }^{\prime}=1$ in the case of linear vibronic coupling; $r_{\tau}{ }^{\prime}=Q_{\zeta}{ }^{\mathrm{m}} / Q_{\tau}{ }^{\mathrm{m}} ; r_{\tau}{ }^{\prime}$ $=3 / 2$ in the case of linear vibronic coupling.

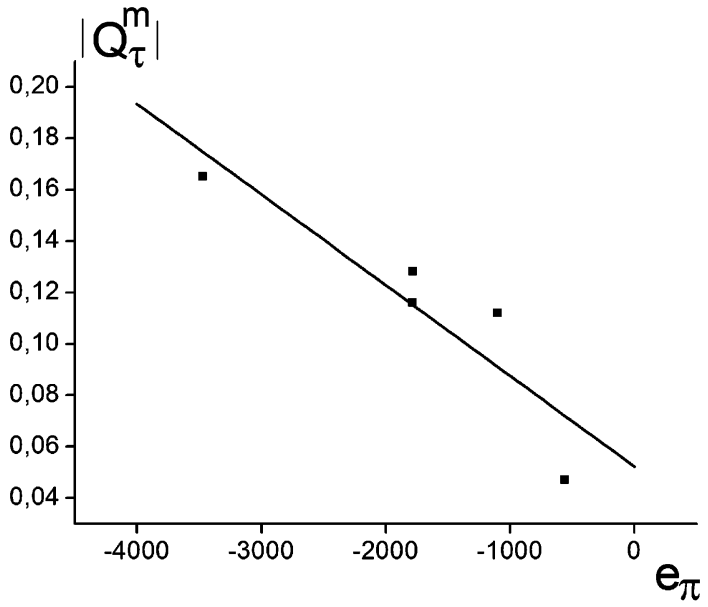

Figure 6. Correlation between the trigonal distortion $\left|Q_{\tau}{ }^{\mathrm{m}}\right|$ and the $\pi$ boding energy $e_{\pi}$. Negative values of $e_{\pi}$ imply dominating metal-ligand $\pi$-back-bonding for the $\left[\mathrm{M}(\mathrm{CN})_{6}\right]^{3-}$ complexes: $e_{\pi}=-556,-1101$, $-1783,-1779,-3470 \mathrm{~cm}^{-1}\left(\mathrm{M}=\mathrm{Ti}^{\mathrm{III}}, \mathrm{V}^{\mathrm{III}}, \mathrm{Mn}^{\mathrm{III}}, \mathrm{Fe}^{\mathrm{III}}, \mathrm{Mn}^{\mathrm{II}}\right)$. Corresponding $\sigma$ antibonding energies $e_{\sigma}$ are 6694, 6376, 8976, 9304, and $5415 \mathrm{~cm}^{-1}$, respectively (the cubic ligand splitting $\Delta=10 \mathrm{Dq}$ is given by $\left.\Delta=3 e_{\sigma}-4 e_{\pi}\right) ; \Delta=22300,23500,34000,34950$, and $30000 \mathrm{~cm}^{-1} .{ }^{41}$ The line drawn corresponds to a least-squares fit: $\left|Q_{\tau}{ }^{\mathrm{m}}\right|$ $=0.0523-0.00003526 e_{\pi}$; standard deviation 0.018 . scribed in section II (see Table 5 and Figure 7). From a comparison of the JT stabilization energies it follows that the $D_{3 d}$ stationary points are deepest in energy, followed by those of $D_{2 h}$ and $D_{4 h}$ symmetry; a $D_{4 h}$ structure is obtained as the lowest energy minimum for $\left[\mathrm{Ti}(\mathrm{CN})_{6}\right]^{3-}$. A good correlation between $E_{\mathrm{JT}}\left(D_{3 d}\right)$ and the negative $\mathrm{e}_{\pi}$ value of each complex is obtained (Figure 8), in agreement with the $V_{\tau}$ vs $e_{\pi}$ expression obtained with the angular overlap model: ${ }^{43,44}$

$$
V_{\tau}=e_{\pi} / R
$$

In Table 5 we compare results from the linear and quadratic approximations to the $\mathrm{T}_{\mathrm{g}} \otimes\left(\epsilon_{\mathrm{g}}+\tau_{2 \mathrm{~g}}\right) \mathrm{JT}$ coupling. All essential features, the order and magnitude of the stabilization, and structural distortions are correctly reproduced in the simple linear approximation. There are only small contributions from quadratic terms for the stationary points of $D_{4 h}$ and $D_{2 h}$ symmetry (see Table $4 ; r_{\epsilon}$ and $r_{\tau}$ ). Only in the case of the $D_{3 d}$ minima are the deviations of $r_{\tau}=Q_{\tau}{ }^{\mathrm{m}} / Q_{\tau} \mathrm{s}$ from the value for linear coupling $\left(r_{\tau}=-2\right)$ large (see Table $\left.4 \mathrm{~b}\right)$. The use of the quadratic $\mathrm{T}_{\mathrm{g}} \otimes\left(\epsilon_{\mathrm{g}}+\tau_{2 \mathrm{~g}}\right)$ JT coupling model is recommended here.

The parameters of Table 5 allow us to judge the vibronic coupling strength $\lambda$ due to the $\epsilon_{\mathrm{g}}$ and $\tau_{2 \mathrm{~g}}$ vibrations, defined by the equations 


$$
\begin{gathered}
\lambda_{\epsilon}=E_{\mathrm{JT}}\left(D_{4 h}\right) / \hbar \omega_{\epsilon} \\
\lambda_{\tau}=2 E_{\mathrm{JT}}\left(D_{4 h}\right) / 3 \hbar \omega_{\tau}
\end{gathered}
$$

The values of $\lambda_{\epsilon}$ and $\lambda_{\tau}$ in Table 5 show that vibronic coupling with the $\epsilon_{\mathrm{g}}$ modes is weak for all complexes. A weak vibronic coupling with the $\tau_{2 \mathrm{~g}}$ mode is also obtained for $\left[\mathrm{Ti}(\mathrm{CN})_{6}\right]^{3-}$ and $\left[\mathrm{V}(\mathrm{CN})_{6}\right]^{3-}$. However, for $\left[\mathrm{Mn}(\mathrm{CN})_{6}\right]^{4-}$ and $\left[\mathrm{Cr}(\mathrm{CN})_{6}\right]^{4-}$, a strong vibronic coupling with the $\tau_{2 \mathrm{~g}}$ mode is predicted. $\left[\mathrm{Fe}(\mathrm{CN})_{6}\right]^{3-}$ and $\left[\mathrm{Mn}(\mathrm{CN})_{6}\right]^{3-}$ represent intermediate cases (values of $\lambda_{\tau}$ are close to 1; see Table 5). For these ions, spinorbit coupling is comparable with the $\mathrm{T}_{\mathrm{g}} \otimes \tau_{2 \mathrm{~g}} \mathrm{JT}$ coupling. This will be analyzed in section IVc.

So far, we have focused on energies and geometries of stationary points on the ground-state potential energy surface. The parameters in Table 5 can also be used to assign the extrema of $D_{4 h}, D_{3 d}$, and $D_{2 h}$ symmetry to minima or saddle points. Starting from the $\epsilon_{\mathrm{g}}$ and $\tau_{2 \mathrm{~g}}$ force constants $\left(K_{\epsilon}\right.$ and $\left.K_{\tau}\right)$, we note that their values are modified by second-order vibronic coupling (see Table 3). Numerical values of the force constants for the diagonal (noninteracting) modes are given in Table 6a, where $K_{\epsilon}$ and $K_{\tau}$ for each complex, as well as their changes, are presented. In agreement with the small values of $L_{\epsilon}$, these changes are negligible for the $\epsilon_{\mathrm{g}}$ stretching mode $(\leq 4 \%$ in the case of $\alpha_{1 \mathrm{~g}}$ and $\beta_{\lg }\left(D_{4 h}\right)$ ), except for Fe $\mathrm{Fe}^{\mathrm{III}}( \pm 12 \%)$, and $\alpha_{\mathrm{lg}}(1)$ and $\beta_{1 \mathrm{~g}}\left(D_{2 h}\right)$. In contrast, for vibrations arising from the $\tau_{2 \mathrm{~g}}$ bending modes, the changes of the force constants can be very large $\left(120 \%\right.$, negative sign for $\left.\left[\mathrm{Mn}(\mathrm{CN})_{6}\right]^{3-}\right)$; these force constants are affected by $L_{\tau}$ (for $D_{4 h}$ ), by $X_{\tau}$ (for $D_{3 d}$ ), and by combinations of $L_{\tau}$ and $X_{\tau}$ (for $D_{2 h}$; see Table 3). However, second-order vibronic coupling and the underlying forces are not large enough to change the sign of $K_{\tau}$ and to induce instability. Only in the case of $\left[\mathrm{Mn}(\mathrm{CN})_{6}\right]^{3-}$ is a large and negative value of $L_{\tau}$ calculated to lead to a negative force constant and instability along $\beta_{2 \mathrm{~g}}\left(\tau_{2 \mathrm{~g}}, Q_{\xi}\right)$ at the $D_{4 h}$ stationary point.

In addition to the diagonal changes of the force field due to the $\epsilon_{\mathrm{g}}$ and $\tau_{2 \mathrm{~g}}$ vibrations, vibronic mixing between the electronic states, induced by distortions away from the $D_{4 h}, D_{3 d}$, and $D_{2 h}$ stationary points, can cause dramatic changes, as shown by numerical calculations of the Hessian (see Table 6b, for the

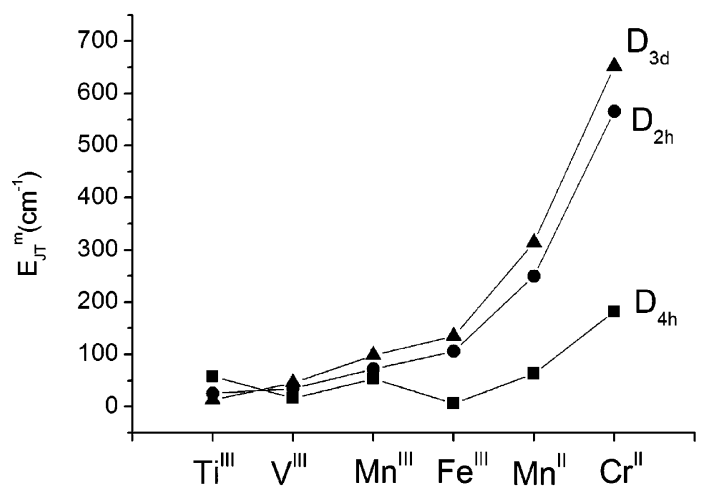

Figure 7. JT stabilization energies in hexacyanometalates of the $3 \mathrm{~d}$ series in orbitally degenerate octahedral ground states in their $D_{4 h}, D_{3 d}$, and $D_{2 h}$ minima of the ground-state potential energy surface.

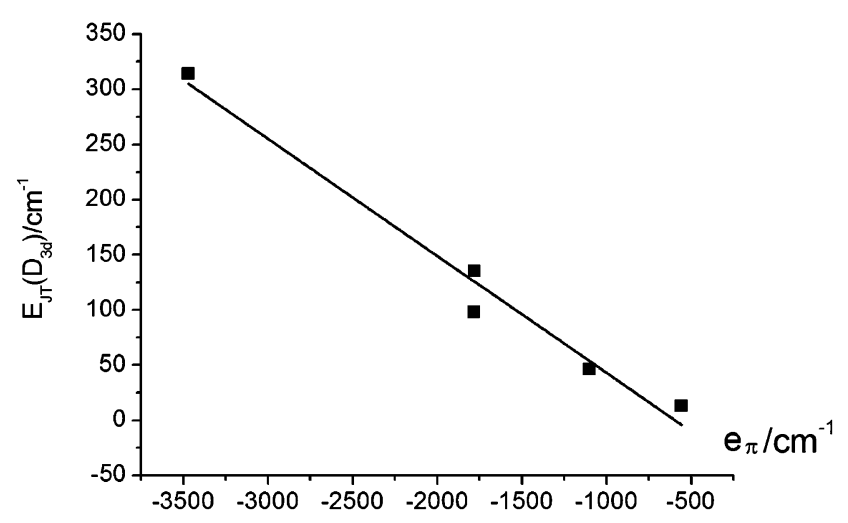

Figure 8. Correlation between the JT stabilization energies for the deepest minima of $D_{3 d}$ symmetry $\left(\left[\mathrm{V}(\mathrm{CN})_{6}\right]^{3-},\left[\mathrm{Mn}(\mathrm{CN})_{6}\right]^{3-},\left[\mathrm{Fe}(\mathrm{CN})_{6}\right]^{3-}\right.$, $\left[\mathrm{Mn}(\mathrm{CN})_{6}\right]^{4-},\left[\mathrm{Cr}(\mathrm{CN})_{6}\right]^{4-}$ in the order of increasing $E_{\mathrm{JT}}\left(D_{3 d}\right)$ energy) and the value of the parameter $\mathrm{e}_{\pi}$ dominated by $\pi$-back-bonding. $E_{\mathrm{JT}}\left(D_{3 d}\right)=-0.106 e_{\pi}-62.92$, with a standard deviation of 18.08 and a correlation coefficient of -0.9881 .

negative Hessian eigenvalues). A number of zero such eigenvalues indicates an absolute minimum. This is shown to be the case in $D_{4 h}$ for $\left[\mathrm{Ti}(\mathrm{CN})_{6}\right]^{3-}$ and in $D_{3 d}$ for $\mathrm{M}=\mathrm{V}^{\mathrm{IIII}}, \mathrm{Mn}^{\mathrm{III}}$, $\mathrm{Fe}^{\mathrm{III}}, \mathrm{Cr}^{\mathrm{II}}, \mathrm{Mn}^{\mathrm{II}}$. With the exception of $\mathrm{M}=\mathrm{Ti}^{\mathrm{III}}, D_{3 d}$ is the preferred geometry and $D_{4 h}$ extrema are found to be instable

TABLE 5: Vibronic Couling Parameters of the Quadratic and Linear ${ }^{a} \mathbf{T}_{\mathrm{g}} \otimes\left(\epsilon_{\mathrm{g}}+\tau_{2 \mathrm{~g}}\right)$ JT Problem in 3d Hexacyanometalates in Orbitally Degenerate $T_{g}={ }^{2} T_{2 g}\left(t_{2 g}{ }^{1} t_{2 g}{ }^{5}\right)$ or ${ }^{3} T_{1 g}\left(t_{2 g}{ }^{2}, t_{2 g}{ }^{4}\right)$ Ground States, as Deduced from DFT as Well as JT Stabilization Energies for the $D_{4 h}, D_{3 d}$, and $D_{2 h}$ Stationary Points and Vibronic Coupling Strengths, $\lambda=2 E_{\mathrm{JT}} /\left(n_{\Gamma} h v_{\Gamma}\right)$, for the T $T_{\mathrm{g}} \otimes \epsilon_{\mathrm{g}}\left(\Gamma=\epsilon_{\mathrm{g}}\right.$,

\begin{tabular}{|c|c|c|c|c|c|c|}
\hline & \multicolumn{6}{|c|}{ complex } \\
\hline & {$\left[\mathrm{Ti}(\mathrm{CN})_{6}{ }^{3-}\right]_{\text {solv }}$} & {$\left[\mathrm{V}(\mathrm{CN})_{6}{ }^{3-}\right]_{\text {solv }}$} & {$\left[\mathrm{Mn}(\mathrm{CN})_{6}{ }^{3-}\right]_{\text {solv }}$} & {$\left[\mathrm{Fe}(\mathrm{CN}) 6^{3-}\right]_{\text {solv }}$} & {$\left[\mathrm{Cr}(\mathrm{CN})_{6}{ }^{4-}\right]_{\text {solv }}$} & {$\left[\mathrm{Mn}(\mathrm{CN})_{6}{ }^{4-}\right]_{\text {solv }}$} \\
\hline$V_{\epsilon}\left(\mathrm{cm}^{-1} / \AA\right)$ & 3256 [3222] & $-1661[-1630]$ & 3696 [3649] & $-855[-808]$ & 7709 [7773] & $-3918[-3918]$ \\
\hline$L_{\mathrm{e}}\left(\mathrm{cm}^{-1} / \AA^{2}\right)$ & 1895 & 3134 & 3283 & 8235 & -2714 & 0 \\
\hline$K_{\epsilon}\left(\mathrm{cm}^{-1} / \AA^{2}\right)$ & 89063 [90010] & 81478 [83045] & 124758 [126400] & $65882[70000]$ & 165545 [164188] & 121173 [121173] \\
\hline$V_{\tau}\left(\mathrm{cm}^{-1} / \AA\right)$ & $-283[-221]$ & $408[614]$ & $-844[-759]$ & $1052[1110]$ & $-3572[-3405]$ & 1896 [1953] \\
\hline$X_{\tau}\left(\mathrm{cm}^{-1} / \AA^{2}\right)$ & -1335 & 1839 & -731 & 449 & -917 & 344 \\
\hline$K_{\tau}\left(\mathrm{cm}^{-1} / \AA^{2}\right)$ & $2251[3140]$ & $4887[3661]$ & 3858 [4345] & $6069[5770]$ & $11820[12432]$ & 8099 [7870] \\
\hline$L_{\tau}\left(\mathrm{cm}^{-1} / \AA^{2}\right)$ & -1158 & 4135 & -4640 & 1584 & -686 & 842 \\
\hline$W\left(\mathrm{~cm}^{-1} / \AA^{2}\right)$ & -2349 & 626 & 0 & 0 & -659 & 0 \\
\hline$E_{\mathrm{JT}}\left(D_{4 h}\right)\left(\mathrm{cm}^{-1}\right)$ & $58[58]$ & $16[16]$ & $53[53]$ & $5[5]$ & $182[184]$ & $63[63]$ \\
\hline$E_{\mathrm{JT}}\left(D_{3 d}\right)\left(\mathrm{cm}^{-1}\right)$ & $13[10]$ & $46[69]$ & $98[88]$ & $135[142]$ & $652[622]$ & 314 [322] \\
\hline$E_{\mathrm{JT}}\left(D_{2 h}\right)\left(\mathrm{cm}^{-1}\right)$ & $25[22]$ & $35[55]$ & $72[79]$ & $106[108]$ & $565[512]$ & $250[258]$ \\
\hline$\hbar \omega_{\epsilon}^{b}\left(\mathrm{~cm}^{-1}\right)$ & 340 & 325 & 402 & 292 & 463 & 396 \\
\hline$\hbar \omega_{\tau}^{b}\left(\mathrm{~cm}^{-1}\right)$ & 50 & 76 & 72 & 93 & 124 & 106 \\
\hline$\lambda_{\epsilon}=E_{\mathrm{JT}}\left(D_{4 h}\right) / \hbar \omega_{\epsilon}$ & 0.171 & 0.049 & 0.132 & 0.017 & 0.393 & 0.160 \\
\hline$\lambda_{\tau}=2\left[E_{\mathrm{JT}}\left(D_{3 d}\right)\right] /\left(3 \hbar \omega_{\tau}\right)$ & 0.178 & 0.399 & 0.905 & 0.965 & 3.519 & 1.971 \\
\hline
\end{tabular}
$\left.n_{\Gamma}=2\right)$ and $T_{g} \otimes \tau_{2 g}\left(\Gamma=\tau_{2 g}, n_{\Gamma}=3\right)$ Jahn-Teller Problems

${ }^{a}$ Given in brackets. ${ }^{b}$ Calculated from the values of $K=K_{\epsilon}, K_{\tau}\left(\right.$ in $\left.\mathrm{cm}^{-1} / \AA^{2}\right)$ and the equation $\hbar \omega=1302.83(G \cdot K / 50350)^{1 / 2}$. $G$ is the diagonal element of the $\mathbf{G}$ matrix given by $G_{\epsilon}=1 /\left(m_{\mathrm{C}}+m_{\mathrm{N}}\right)=1 / 26 ; G_{\tau}=4 /\left(m_{\mathrm{C}}+m_{\mathrm{N}}\right) R_{\mathrm{tr}}^{2}, m_{\mathrm{C}}$ and $m_{\mathrm{N}}$ are the atomic masses of $\mathrm{C}$ and $\mathrm{N}$, and $R_{\mathrm{tr}}=$ the distance from Table $4 \mathrm{~b}$. A DFT calculation of $\hbar \omega_{\epsilon}$ and $\hbar \omega_{\tau}$ for $\left[\mathrm{Cr}(\mathrm{CN})_{6}{ }^{3-}\right]_{\text {solv }}$ yields values of 315 and $78 \mathrm{~cm}^{-1}$, respectively; the experimental value for $\hbar \omega_{\epsilon}$ is $339 \mathrm{~cm}^{-1}$. 
TABLE 6: (a) Normal Mode Force Constants and Their Changes ${ }^{a}$ in Comparison with the Octahedral Values $K_{\epsilon}$ and $K_{\tau}$ (Noninteracting Modes) for the $D_{4 h}, D_{3 d}$, and $D_{2 h}$ Stationary Points on the $T_{\mathrm{g}} \otimes\left(\epsilon_{\mathrm{g}}+\tau_{2 \mathrm{~g}}\right)$ Ground-State Potential Energy Surface and (b) Eigenvalues (in $\mathrm{cm}^{-1} / \AA^{2}$ ) and Eigenvectors of the Hessian, Corresponding to Distortion Modes, Which Contribute to the Eventual Configurational Instabilities at the $D_{4 h}, D_{3 d}$, and $D_{2 h}$ Stationary Points of $\mathrm{M}(\mathrm{CN})_{6}$ Complexes $^{b}$

\begin{tabular}{lllllll}
\hline $\operatorname{sym}_{\operatorname{mode}}{ }^{c}$ & $\mathrm{Ti}^{\mathrm{III}}$ & $\mathrm{V}^{\mathrm{III}}$ & $\mathrm{Mn}^{\mathrm{III}}$ & $\mathrm{Cr}^{\mathrm{II}}$ & $\mathrm{Mn}^{\mathrm{II}}$ \\
\hline
\end{tabular}

(a) Normal Mode Force Constants

\begin{tabular}{|c|c|c|c|c|c|c|}
\hline \multirow{3}{*}{$\begin{array}{l}\epsilon_{\mathrm{g}} ; K_{\epsilon} \\
\tau_{2 \mathrm{~g}}: K_{\tau}\end{array}$} & \multicolumn{5}{|c|}{$O_{h}$} & \multirow{3}{*}{$\begin{array}{l}121173 \\
8099\end{array}$} \\
\hline & 89063 & 81478 & 124758 & 65882 & 165545 & \\
\hline & 2251 & 4887 & 3858 & 6069 & 11820 & \\
\hline $\begin{array}{l}\alpha_{1 \mathrm{~g}}\left(\epsilon_{\mathrm{g}}\right)^{d} \\
\beta_{1 \mathrm{~g}}\left(\epsilon_{\mathrm{g}}\right)^{d} \\
\beta_{2 \mathrm{~g}}\left(\tau_{2 \mathrm{~g}}\right)^{d} \\
\epsilon_{\mathrm{g}}\left(\tau_{2 \mathrm{~g}}\right)^{d}\end{array}$ & $\begin{array}{l}90958(\mathbf{2}) \\
87168(-\mathbf{2}) \\
1093(\mathbf{- 5 1}) \\
2830(\mathbf{2 5})\end{array}$ & $\begin{array}{l}84612(\mathbf{4}) \\
78344(-\mathbf{4}) \\
9022(\mathbf{8 5}) \\
2820(-\mathbf{4 2})\end{array}$ & $\begin{array}{l}\quad D_{4 h} \\
128042(\mathbf{3}) \\
121475(-\mathbf{3}) \\
-782(-\mathbf{1 2 0}) \\
6178(\mathbf{6 0})\end{array}$ & $\begin{array}{l}74118(\mathbf{1 2}) \\
57647(-\mathbf{1 2}) \\
7653(\mathbf{2 6}) \\
5277(-\mathbf{1 3})\end{array}$ & $\begin{array}{l}162831(-2) \\
168259(2) \\
11134(-6) \\
12164(3)\end{array}$ & $\begin{array}{l}121173(\mathbf{0}) \\
121173(\mathbf{0}) \\
8941(\mathbf{1 0}) \\
7678(-\mathbf{5})\end{array}$ \\
\hline $\begin{array}{l}\epsilon_{\mathrm{g}}\left(\epsilon_{\mathrm{g}}\right)^{d} \\
\alpha_{1 \mathrm{~g}}\left(\tau_{2 \mathrm{~g}}\right)^{d} \\
\epsilon_{\mathrm{g}}\left(\tau_{2 \mathrm{~g}}\right)^{d}\end{array}$ & $\begin{array}{l}89063(\mathbf{0}) \\
4030(\mathbf{7 9}) \\
1361(\mathbf{- 3 9})\end{array}$ & $\begin{array}{l}81478(\mathbf{0}) \\
2434(-\mathbf{5 0}) \\
6113(\mathbf{2 5})\end{array}$ & $\begin{array}{l}\quad D_{3 d} \\
124758(\mathbf{0}) \\
4833(\mathbf{2 5}) \\
3370(\mathbf{- 1 3})\end{array}$ & $\begin{array}{l}65882(\mathbf{0}) \\
5470(-10) \\
6369(\mathbf{5})\end{array}$ & $\begin{array}{l}165545(\mathbf{0}) \\
13044(\mathbf{1 0}) \\
11209(-\mathbf{5})\end{array}$ & $\begin{array}{l}121173(\mathbf{0}) \\
7640(-\mathbf{6}) \\
8328(\mathbf{3})\end{array}$ \\
\hline $\begin{array}{l}\beta_{1 \mathrm{~g}}\left(\epsilon_{\mathrm{g}}\right)^{d} \\
\beta_{2 \mathrm{~g}}\left(\tau_{2 \mathrm{~g}}\right)^{d} \\
\beta_{3 \mathrm{~g}}\left(\tau_{2 \mathrm{~g}}\right)^{d} \\
\alpha_{1 \mathrm{~g}}(1)\left(\epsilon_{\mathrm{g}}, \tau_{2 \mathrm{~g}}\right)^{d} \\
\alpha_{1 \mathrm{~g}}(2)\left(\epsilon_{\mathrm{g}}, \tau_{2 \mathrm{~g}}\right)^{d}\end{array}$ & $\begin{array}{l}90010(\mathbf{1}) \\
3296(\mathbf{4 6}) \\
627(-\mathbf{7 2}) \\
88180(\mathbf{- 1}) \\
2765(\mathbf{2 3})\end{array}$ & $\begin{array}{l}83045(\mathbf{2}) \\
4081(-\mathbf{1 6}) \\
7760(\mathbf{5 9}) \\
79916(-\mathbf{2}) \\
2814(-\mathbf{4 2})\end{array}$ & $\begin{array}{l}\quad D_{2 h} \\
126400(\mathbf{1}) \\
3429(-\mathbf{1 1}) \\
1967(-\mathbf{4 9}) \\
123117(-\mathbf{1}) \\
6178(\mathbf{6 0})\end{array}$ & $\begin{array}{l}70000(\mathbf{6}) \\
6016(-\mathbf{1}) \\
6915(\mathbf{1 4}) \\
61765(-\mathbf{6}) \\
5277(-\mathbf{1 3})\end{array}$ & $\begin{array}{l}164188(-\mathbf{1}) \\
12566(\mathbf{6}) \\
10732(-9) \\
166905(\mathbf{1}) \\
12161(\mathbf{3})\end{array}$ & $\begin{array}{l}121173(\mathbf{0}) \\
7966(-2) \\
8653(7) \\
121173(\mathbf{0}) \\
7678(-\mathbf{5})\end{array}$ \\
\hline
\end{tabular}

$\begin{array}{ll}\epsilon_{\mathrm{g}}\left(\tau_{2 \mathrm{~g}}\right) & {[1351]} \\ & 2158 \\ Q_{\theta} & 0.00,0.00 \\ Q_{\epsilon} & 0.00,0.00 \\ Q_{\xi} & -0.71,0.71 \\ Q_{\eta} & 0.71,0.71 \\ Q_{\zeta} & 0.00,0.00 \\ & (0)^{e}\end{array}$

(b) Eigenvalues and Eigenvectors

\begin{tabular}{|c|c|c|c|c|c|c|}
\hline \multicolumn{7}{|c|}{$D_{3 d}$} \\
\hline \multirow[t]{2}{*}[\epsilon_{\mathrm{g}}(\epsilon_{\mathrm{g}})/\epsilon_{\mathrm{g}}(\tau_{2\mathrm{g}})]{} & {$[-61521]$} & [1589] & [2017] & [3978] & [7052] & [4927] \\
\hline & -232780 & 2821 & 3308 & 3658 & 5720 & 5000 \\
\hline$Q_{\theta}$ & $0.81,-0.58$ & $0.04,-0.09$ & $-0.01,0.02$ & $0.03,-0.01$ & $0.07,-0.05$ & $-0.03,-0.06$ \\
\hline$Q_{\epsilon}$ & $-0.58,-0.81$ & $0.09,0.04$ & $-0.02,-0.01$ & $-0.01,-0.03$ & $-0.05,-0.07$ & $-0.06,0.03$ \\
\hline$Q_{\xi}$ & $-0.06,-0.03$ & $0.47,0.66$ & $-0.51,-0.64$ & $-0.65,-0.49$ & $-0.72,-0.37$ & $-0.41,0.70$ \\
\hline$Q_{\eta}$ & $0.01,0.07$ & $-0.81,0.08$ & $0.81,-0.12$ & $-0.10,0.81$ & $0.04,0.81$ & $0.81,0.01$ \\
\hline$Q_{\zeta}$ & $\begin{array}{l}0.06,-0.04 \\
(2)^{e}\end{array}$ & $\begin{array}{l}0.34,-0.74 \\
(0)^{e}\end{array}$ & $\begin{array}{l}-0.30,0.76 \\
(0)^{e}\end{array}$ & $\begin{array}{l}0.75,-0.32 \\
(0)^{e}\end{array}$ & $\begin{array}{l}0.68,-0.44 \\
(0)^{e}\end{array}$ & $\begin{array}{l}-0.40,-0.71 \\
(0)^{e}\end{array}$ \\
\hline \multicolumn{7}{|c|}{$D_{2 h}$} \\
\hline \multirow[t]{2}{*}{$\beta_{1 \mathrm{~g}}\left(\epsilon_{\mathrm{g}}\right)$} & {$[-134156]$} & [20844] & {$[69254]$} & [62871] & [124262] & [95233] \\
\hline & -277250 & 50723 & 39870 & 67719 & 120700 & 96580 \\
\hline$Q_{\theta}$ & 0.00 & 0.00 & 0.00 & 0.00 & 0.00 & 0.00 \\
\hline$Q_{\epsilon}$ & 1.00 & 1.00 & 1.00 & 1.00 & 1.00 & 1.00 \\
\hline$Q_{\xi}$ & 0.00 & 0.00 & 0.00 & 0.00 & 0.00 & 0.00 \\
\hline$Q_{\eta}$ & 0.00 & 0.00 & 0.00 & 0.00 & 0.00 & 0.00 \\
\hline$Q_{\zeta}$ & 0.00 & 0.00 & 0.00 & 0.00 & 0.00 & 0.00 \\
\hline \multirow[t]{2}{*}{$\beta_{2 \mathrm{~g}}\left(\tau_{2 \mathrm{~g}}\right)$} & [967] & {$[-717]$} & {$[-1482]$} & {$[-5539]$} & {$[-7102]$} & {$[-5243]$} \\
\hline & 2560 & -1712 & -4830 & -3779 & -4990 & -5080 \\
\hline$Q_{\theta}$ & 0.00 & 0.00 & 0.00 & 0.00 & 0.00 & 0.00 \\
\hline$Q_{\epsilon}$ & 0.00 & 0.00 & 0.00 & 0.00 & 0.00 & 0.00 \\
\hline$Q_{\xi}$ & 0.71 & 0.71 & 0.71 & 0.71 & 0.71 & 0.71 \\
\hline$Q_{\eta}$ & 0.71 & 0.71 & 0.71 & 0.71 & 0.71 & 0.71 \\
\hline \multirow{2}{*}{$Q_{\zeta}$} & 0.00 & 0.00 & 0.00 & 0.00 & 0.00 & 0.00 \\
\hline & $(1)^{e}$ & $(1)^{e}$ & $(1)^{e}$ & $(1)^{e}$ & $(1)^{e}$ & $(1)^{e}$ \\
\hline
\end{tabular}

${ }^{a}$ Changes (in percentages), with respect to the corresponding values of $K_{\epsilon}$ and $K_{\tau}$, are given in parenthesis in boldface type. ${ }^{b}$ Entries in brackets are based on the linear $T_{\mathrm{g}} \otimes\left(\epsilon_{\mathrm{g}}+\tau_{2 \mathrm{~g}}\right)$ vibronic coupling model (eqs 3 and 6-9); the other entries are obtained by a numerical calculation of the Hessian at the $D_{4 h}, D_{3 d}$, and $D_{2 h}$ equilibrium points, using eq 1 and vibronic coupling parameters from Table 5. ${ }^{c}$ The origin of each mode from the corresponding $O_{h}$ normal vibration is given in parentheses. ${ }^{d}$ Calculated from the expressions in Table 3 and vibronic coupling parameters from Table 5. ${ }^{e}$ The total number of negative eigenvalues of the Hessian is given in parentheses. Legend: (0) minimum; (1) first-order saddle point, a reactive transition state; (2) second-order saddle point; (3) exotic type of instability (monkey saddle). The eigenvalue not listed for $\left[\mathrm{Mn}(\mathrm{CN})_{6}\right]^{3-}$ is that of $\beta_{2 \mathrm{~g}}\left(\tau_{2 \mathrm{~g}}\right)\left(-782 \mathrm{~cm}^{-1} / \AA^{2}\right.$, see part a).

for all these cases. The latter is a rare situation of a secondorder saddle point for this geometry (two negative Hessian eigenvalues for the $\epsilon_{\mathrm{g}}\left(\tau_{2 \mathrm{~g}}\right)$ mode). An extraordinary case is $\left[\mathrm{Mn}(\mathrm{CN})_{6}\right]^{3-}$, where the eigenvalues due to all three components of the $\tau_{2 \mathrm{~g}}$ mode $\left(\epsilon_{\mathrm{g}}\right.$ and $\beta_{2 \mathrm{~g}}$ ) are negative. Vibronic mixing is responsible for this in the case of $\epsilon_{\mathrm{g}}$, and a diagonal modification by second-order JT forces is the origin in the case of $\beta_{2 \mathrm{~g}}$. A $D_{3 d}$ saddle point with an instability, caused by the $\epsilon_{\mathrm{g}}$ stretching 


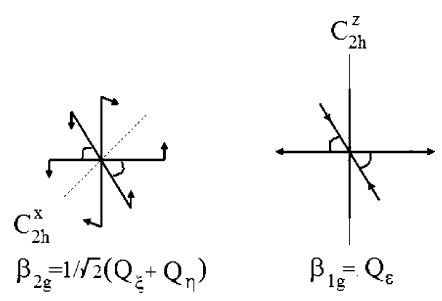

Figure 9. Vibrations $\beta_{2 \mathrm{~g}}$ (component of $\tau_{2 \mathrm{~g}}$ ) and $\beta_{1 \mathrm{~g}}$ (component of $\epsilon_{\mathrm{g}}$ ), which lead to a mixing between the $\mathrm{B}_{2 \mathrm{~g}}$ ground state of the $D_{2 h}$ minimum with the $\mathrm{A}_{1 \mathrm{~g}}$ and $\mathrm{B}_{3 \mathrm{~g}}$ states, respectively. The $\beta_{2 \mathrm{~g}}$ mode drives the system into a $D_{3 d^{x y z}}$ minimum via a continuous line of $C_{2 h}{ }^{x}$ structures, while the $\beta_{1 \mathrm{~g}}$ mode leads to a $D_{4 h^{x}}$ stationary point via a $C_{2 h^{z}}$ distortion path.
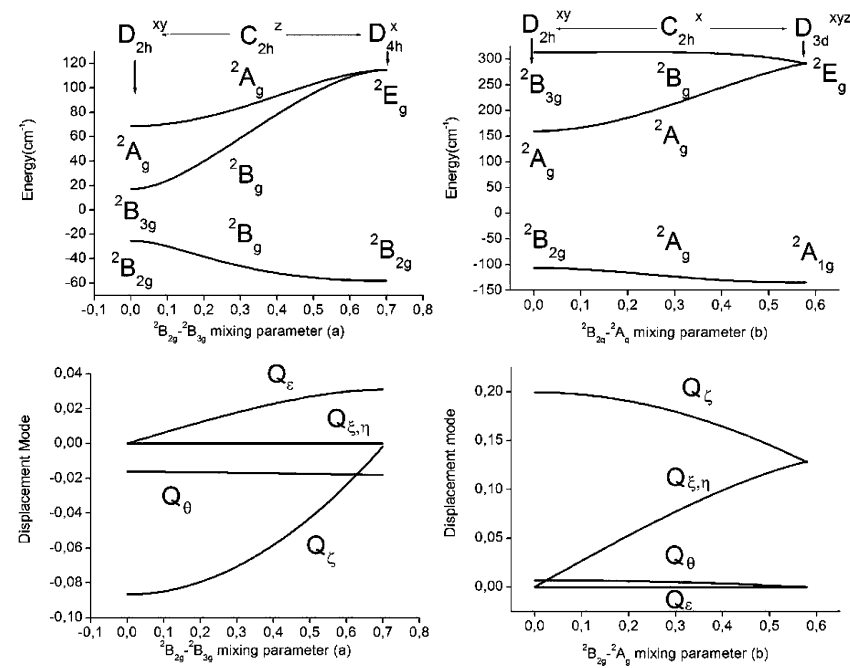

Figure 10. Distortion paths due to $\mathrm{B}_{2 \mathrm{~g}} \otimes \beta_{1 \mathrm{~g}} \otimes \mathrm{B}_{3 \mathrm{~g}}\left(\left[\mathrm{Ti}(\mathrm{CN})_{6}\right]^{3-}\right.$, left) and $\mathrm{B}_{2 \mathrm{~g}} \otimes \beta_{2 \mathrm{~g}} \otimes \mathrm{A}_{\mathrm{g}}\left(\left[\mathrm{Fe}(\mathrm{CN})_{6}\right]^{3-}\right.$, right) vibronic interactions starting from the $D_{2 h}{ }^{x y}$ stationary point expressed in terms of the single electronic mixing parameters $(a)$ and $(b)$, respectively. The top curves represent the electronic energies of the components of the ${ }^{2} T_{2 g}$ ground state. The bottom curves display the concomitant changes of the components of the five $\epsilon_{\mathrm{g}}+\tau_{2 \mathrm{~g}}$ vibrational modes. The data have been obtained by varying $(a)$ and $(b)$, calculating $Q_{\theta}, Q_{\epsilon}, Q_{\xi}, Q_{\eta}$, and $Q_{\xi}$, using the stationary conditions (method of Öpik and Price ${ }^{29}$ ), and solving the secular equation with these values. Vibronic coupling parameters used to construct the diagram are those for $\left[\mathrm{Ti}(\mathrm{CN})_{6}\right]^{3-}$ (left) and $\left[\mathrm{Fe}(\mathrm{CN})_{6}\right]^{3-}$ (right) (Table 5). As the method of Öpik and Price is, in a strict sense, only applicable at special points of high symmetry (for which electronic eigenfunctions are known by symmetry; initial and final points on the abscissa on each diagram), intermediate points should be viewed with care, and these serve only as a tool for interpolation between the $D_{2 h}$ and $D_{4 h}$ (left) and $D_{2 h}$ and $D_{3 d}$ (right) limiting cases.

mode, is calculated for $\left[\mathrm{Ti}(\mathrm{CN})_{6}\right]^{3-}$ with a $D_{4 h}$ stable minimum. That is, the vibration that drives the systems into the absolute minimum, i.e., $\epsilon_{\mathrm{g}}\left(O_{h}\right)$ for $\left[\mathrm{Ti}(\mathrm{CN})_{6}\right]^{3-}\left(D_{4 h}\right)$ and $\tau_{2 \mathrm{~g}}$ for $\mathrm{M}=$ $\mathrm{V}^{\mathrm{III}}, \mathrm{Mn}^{\mathrm{III}}, \mathrm{Fe}^{\mathrm{III}}, \mathrm{Cr}^{\mathrm{II}}, \mathrm{Mn}^{\mathrm{II}}\left(D_{3 d}\right)$, causes instability in the alternative symmetry, $D_{3 d}$ and $D_{4 h}$, respectively. The $\beta_{1 \mathrm{~g}}\left(\epsilon_{\mathrm{g}}\right)$ mode for $\left[\mathrm{Ti}^{\mathrm{III}}(\mathrm{CN})_{6}\right]^{3-}$ and the $\beta_{2 \mathrm{~g}}\left(\tau_{2 \mathrm{~g}}\right)$ mode for all other complexes are the distortion modes responsible for the instabilities at the $D_{2 h}$ stationary points (Figure 9).

One negative root of the Hessian (reactive transition state) is obtained in all these complexes. In Figure 10, we visualize the changes of the electronic energy and the concomitant changes of the $Q_{\theta}, Q_{\epsilon}, Q_{\xi}, Q_{\eta}$, and $Q_{\zeta}$ nuclear coordinates with a single variable parameter, which describes the mixing of the ground state $\mathrm{B}_{2 \mathrm{~g}}$ with $\mathrm{B}_{3 \mathrm{~g}}\left(\left[\mathrm{Ti}(\mathrm{CN})_{6}\right]^{3-}\right.$, left) and $\mathrm{A}_{\mathrm{g}}$ excited states $\left(\left[\mathrm{Fe}(\mathrm{CN})_{6}\right]^{3-}\right.$, right) by virtue of the $\beta_{1 \mathrm{~g}}\left(\epsilon_{\mathrm{g}}\right)$ and $\beta_{2 \mathrm{~g}}\left(\tau_{2 \mathrm{~g}}\right)$ stretching and bending vibrations. Starting from the $D_{2 h}{ }^{x y}$ stationary point, $\beta_{1 \mathrm{~g}}\left(\epsilon_{\mathrm{g}}\right)$ and $\beta_{2 \mathrm{~g}}\left(\tau_{2 \mathrm{~g}}\right)$ distortions drive the system via a continuous distortion path of $C_{2 h^{z}}$ and $C_{2 h^{x}}$ symmetry into the $D_{4 h}{ }^{x}$ (or $D_{4 h} h^{y}$, depending on the sign of $\left.\beta_{1 \mathrm{~g}}\left(\epsilon_{\mathrm{g}}\right)\right)$ and $D_{3 d^{x y z}}$ absolute minima for $\left[\mathrm{Ti}(\mathrm{CN})_{6}\right]^{3-}$ and $\left[\mathrm{Fe}(\mathrm{CN})_{6}\right]^{3-}$, respectively.

The linear vibronic coupling model (Table 6b, entries given in brackets) is able to reproduce the topology of the groundstate potential energy surface due to $T_{\mathrm{g}} \otimes\left(\epsilon_{\mathrm{g}}+\tau_{2 \mathrm{~g}}\right)$ vibronic coupling. With one exception $\left(\left[\mathrm{Mn}(\mathrm{CN})_{6}\right]^{3-}\right.$; see Table 6a) all minima and saddle points are correctly predicted. It appears from our DFT-based analysis that the instabilities at the $D_{4 h}, D_{3 d}$, and $D_{2 h}$ stationary points on the ground-state potential energy surface of the complexes discussed here are mainly due to vibronic mixing between electronic states, and this is correctly described at the level of the linear JT coupling.

b. Effect of Configurational Interaction (CI) on the Ground-State $\mathbf{T}_{\mathrm{g}} \otimes\left(\epsilon_{\mathrm{g}}+\tau_{2 \mathrm{~g}}\right)$ JT Coupling. We have considered ${ }^{2} \mathrm{~T}_{2 \mathrm{~g}}$ and ${ }^{3} \mathrm{~T}_{1 \mathrm{~g}}$ ground states and focus on a single $\mathrm{t}_{2 \mathrm{~g}}{ }^{n}$ configuration. Strictly, this is only valid for $\mathrm{t}_{2 \mathrm{~g}}{ }^{1}\left(\mathrm{Ti}^{\mathrm{III}}\right)$, and it is an approximation for $\mathrm{d}^{5}$ and the $\mathrm{d}^{2,4}$ metal ions. The ${ }^{2} \mathrm{~T}_{2 \mathrm{~g}}$ and ${ }^{3} \mathrm{~T}_{1 \mathrm{~g}}$ ground states of $\left[\mathrm{Fe}(\mathrm{CN})_{6}\right]^{3-}$ and $\left[\mathrm{Mn}(\mathrm{CN})_{6}\right]^{3-}$ are mixtures of as much as $10\left(\mathrm{~T}_{2 \mathrm{~g}}\right)$ and $7\left(\mathrm{~T}_{1 \mathrm{~g}}\right)$ species of the same symmetry, which differ in their electron configurations of the MOs of $d$ character. These terms mix with each other via interelectronic repulsion (CI) and split because of excited-state JT coupling, due to $\pi$-type vibronic mixing (via the $\tau_{2 \mathrm{~g}}$ mode, splitting of the $t_{2 \mathrm{~g}}$ orbitals). For $\left[\mathrm{Fe}(\mathrm{CN})_{6}\right]^{3-}$ and $\left[\mathrm{Mn}(\mathrm{CN})_{6}\right]^{3-}$ (strong ligand field), the $\mathrm{t}_{2 \mathrm{~g}}{ }^{5}$ and $\mathrm{t}_{2 \mathrm{~g}}{ }^{4}$ configurations are expected to dominate the ground-state wavefunction but the excited-state configurations might still be important for the ground-state vibronic coupling. Unfortunately, there are no DFT methods for the explicit geometry optimization of electronic states of multiconfigurational character. In DFT, one assumes that a single configuration dominates the electronic and geometric structures. To trace the effect of CI on the ground-state JT effect of these ions, we resort to ligand field theory (LFT) and focus on the $D_{3 d}$ minima of the ground-state potential energy surface. For some of the complexes studied here, approximate values of $10 D q, B$, and $C$ are known (Table 7). ${ }^{41}$ They have been used in a CI calculation of the ground state ${ }^{2} \mathrm{~T}_{2 \mathrm{~g}}\left(\mathrm{Fe}^{\mathrm{III}}, \mathrm{Mn}^{\mathrm{II}}\right)$ and ${ }^{3} \mathrm{~T}_{1 \mathrm{~g}}$ (VIII, Mn ${ }^{\mathrm{III}}$ ) terms. From the known values of the trigonal distortion angle $\theta$, the energy $E_{\mathrm{FC}}{ }^{\mathrm{m}}$, and $10 D q$, we deduce the angular overlap parameters from one-electron calculations and then switch to a many-electron CI treatment. The ground-state splitting which results from such a calculation is $E_{\mathrm{FC}}{ }^{\mathrm{CI}}$. Since the energies $E_{\mathrm{FC}}$ and $E_{\mathrm{JT}}$ are interrelated (see section II), we can use eq 35 to obtain an approximation of the JT stabilization energy.

$$
E_{\mathrm{JT}}{ }^{\mathrm{Cl}}=E_{\mathrm{JT}}{ }^{\mathrm{m}}\left(E_{\mathrm{FC}}{ }^{\mathrm{Cl}} / E_{\mathrm{FC}}{ }^{\mathrm{m}}\right)
$$

The results in Table 7 show that CI mixing is essential and leads to an enhancement of the ground-state splitting and an increase of the magnitude of $E_{\mathrm{FC}}$ by about a factor of 2 for $\left[\mathrm{Fe}(\mathrm{CN})_{6}\right]^{3-}$ and $\left[\mathrm{V}(\mathrm{CN})_{6}\right]^{3-}$. For the latter complex the effect of $\mathrm{CI}$ is opposite to complexes with $\pi$-donor ligands $\left(\mathrm{VF}_{6}{ }^{3-}\right)$, where it was found with structural and spectroscopic data that CI reduces the ${ }^{3} \mathrm{~T}_{1}$ ground-state JT coupling. ${ }^{42}$

c. Effect of the Combination of the $\mathbf{T}_{\mathrm{g}} \otimes\left(\epsilon_{\mathrm{g}}+\tau_{2 \mathrm{~g}}\right) \mathbf{J T}$ and Spin-Orbit Coupling on the Ground-State Potential Energy Surface. Spin-orbit coupling (quantified by the spin-orbit coupling constant $\zeta$ ) leads to a first-order splitting of the octahedral ${ }^{2} \mathrm{~T}_{2 \mathrm{~g}}$ and ${ }^{3} \mathrm{~T}_{1 \mathrm{~g}}$ ground states with the following energies of the twofold $\left(\Gamma_{7}\right)$ and fourfold $\left(\Gamma_{8}\right)$ degenerate states (for ${ }^{2} \mathrm{~T}_{2 \mathrm{~g}} \mathrm{~d}^{1}\left(\mathrm{~d}^{5}\right)$ ) and of the nondegenerate $\left(\mathrm{A}_{1}\right)$ and threefold $\left(T_{1}\right)$ and fivefold degenerate $\mathrm{E}, \mathrm{T}_{2}$ states (accidental degeneracy) for $\left({ }^{3} \mathrm{~T}_{1 \mathrm{~g}} \mathrm{~d}^{2}\left(\mathrm{~d}^{4}\right)\right)(\xi>0)$ : 


$$
\left[\mathrm{Ti}(\mathrm{CN})_{6}\right]^{3-}\left(\mathrm{d}^{1}\right): \Gamma_{8}[-(1 / 2) \xi]<\Gamma_{7}[\xi]
$$

$\left[\mathrm{Fe}(\mathrm{CN})_{6}\right]^{3-}, \mathrm{Mn}(\mathrm{CN})_{6}{ }^{4-}\left(\mathrm{d}^{5}\right): \Gamma_{7}[-\zeta]<\Gamma_{8}[(1 / 2) \zeta]$

$$
\left[\mathrm{V}(\mathrm{CN})_{6}\right]^{3-}\left(\mathrm{d}^{2}\right):\left(\mathrm{T}_{2}, \mathrm{E}\right)[-(1 / 2) \xi]<\mathrm{T}_{1}[(1 / 2) \xi]<\mathrm{A}_{1}[\xi]
$$

$$
\begin{array}{r}
{\left[\mathrm{Mn}(\mathrm{CN})_{6}\right]^{3-},\left[\mathrm{Cr}(\mathrm{CN})_{6}\right]^{4-}\left(\mathrm{d}^{4}\right): \mathrm{A}_{1}[-\zeta]<} \\
\left(\mathrm{T}_{1}[-(1 / 2) \xi]<\right. \\
\left(\mathrm{T}_{2}, \mathrm{E}\right)[(1 / 2) \zeta](39)
\end{array}
$$

While spin-orbit coupling lifts the orbital degeneracy and, therefore, opposes the JT forces for $\left[\mathrm{Fe}(\mathrm{CN})_{6}\right]^{3-},\left[\mathrm{Mn}(\mathrm{CN})_{6}\right]^{4-}$, $\left[\mathrm{Mn}(\mathrm{CN})_{6}\right]^{3-}$, and $\left[\mathrm{Cr}(\mathrm{CN})_{6}\right]^{4-}$, this is not the case for $\left.\mathrm{Ti}(\mathrm{CN})_{6}\right]^{3-}$ and $\left[\mathrm{V}(\mathrm{CN})_{6}\right]^{3-}$, where the ground states remain fourfold and (accidentally) fivefold degenerate, respectively. Values of $\xi$ for these ions (Table 7) from relativistic two-component (ZORA) DFT calculations (reduced by metal-ligand covalency ${ }^{45,46}$ ) have been used to calculate the stabilization by spin-orbit coupling on the ground-state energy ( $E_{\mathrm{SOC}}$, Table 7). On the basis of the comparison between $E_{\mathrm{SOC}}$ and $E_{\mathrm{JT}}{ }^{\mathrm{m}}$, we can conclude that spinorbit coupling and JT coupling are of comparable magnitude, except for $\mathrm{Mn}^{\mathrm{II}}$ and $\mathrm{Cr}^{\mathrm{II}}$ (not listed). In Figure 11 we present contour plot diagrams for $\left[\mathrm{Mn}(\mathrm{CN})_{6}\right]^{3-}$ and $\left[\mathrm{Fe}(\mathrm{CN})_{6}\right]^{3-}$ with trigonal distortion modes and take $Q_{\zeta}$ and $\mathrm{Q}_{\xi}=\mathrm{Q}_{\eta}$ as independent variables: i.e., the subspace of all distortions compatible with the symmetry $C_{2 h}{ }^{x}$ (see Figure 10). In the upper part of Figure 11 spin-orbit coupling is set to zero, and the $D_{3 d}$ minima and $D_{2 h}$ saddle points are easily recognizable. As seen from the lower part of Figure 11, the inclusion of spinorbit coupling leads to specific changes. The JT stabilization $\left(E_{\mathrm{JT}}{ }^{\mathrm{m}}=98, \zeta=0\right)$ vanishes $\left(E_{\mathrm{JT}}{ }^{\mathrm{m}}=0, \zeta=284\right)$ for $\left[\mathrm{Mn}(\mathrm{CN})_{6}\right]^{3-}$, and it becomes strongly reduced for $\left[\mathrm{Fe}(\mathrm{CN})_{6}\right]^{3-}$ (from $E_{\mathrm{JT}}{ }^{\mathrm{m}}=135 \mathrm{~cm}^{-1}, \zeta=0$ to $E_{\mathrm{JT}}{ }^{\mathrm{m}}=12 \mathrm{~cm}^{-1}, \zeta=347$ $\left.\mathrm{cm}^{-1}\right) . E_{\mathrm{JT}}{ }^{\mathrm{CI}}$ is nonzero for $\left[\mathrm{Fe}(\mathrm{CN})_{6}\right]^{3-}$, but it is sufficiently reduced by spin-orbit coupling to suppress the JT coupling via the zero-point energy of the $\tau_{2 \mathrm{~g}}$ vibration.

Contour plot diagrams for $\left[\mathrm{Ti}(\mathrm{CN})_{6}\right]^{3-}$ and $\left[\mathrm{V}(\mathrm{CN})_{6}\right]^{3-}$ are presented in Figure 12. The orbital degeneracy is not lifted by spin-orbit coupling, and the effect of spin-orbit coupling on the ground-state potential energy surface is less pronounced than with $\left[\mathrm{Mn}(\mathrm{CN})_{6}\right]^{3-}$ and $\left[\mathrm{Fe}(\mathrm{CN})_{6}\right]^{3-}$. Nevertheless, there is a significant reduction of $E_{\mathrm{JT}}{ }^{\mathrm{m}}$ (from $E_{\mathrm{JT}}{ }^{\mathrm{m}}=58 \mathrm{~cm}^{-1}, \zeta=0$ to $E_{\mathrm{JT}}{ }^{\mathrm{m}}=24 \mathrm{~cm}^{-1}, \zeta=147 \mathrm{~cm}^{-1}$ for $\left[\mathrm{Ti}(\mathrm{CN})_{6}\right]^{3-}$; from $E_{\mathrm{JT}}{ }^{\mathrm{m}}=$ $46 \mathrm{~cm}^{-1}, \zeta=0$ to $E_{\mathrm{JT}} \mathrm{T}^{\mathrm{m}}=31 \mathrm{~cm}^{-1}, \zeta=190 \mathrm{~cm}^{-1}$ for $\left.\left[\mathrm{V}(\mathrm{CN})_{6}\right]^{3-}\right)$. Our results show that JT coupling is larger than spin-orbit coupling for $\left[\mathrm{Mn}(\mathrm{CN})_{6}\right]^{4-}\left(E_{\mathrm{JT}}{ }^{\mathrm{m}}\left(D_{3 d}\right)=314 \mathrm{~cm}^{-1}\right.$, $\left.E_{\mathrm{SOC}}=243 \mathrm{~cm}^{-1}\right)$ and much larger for $\left[\mathrm{Cr}(\mathrm{CN})_{6}\right]^{4-}\left(E_{\mathrm{JT}^{\mathrm{m}}}^{\mathrm{m}}\left(D_{3 d}\right)\right.$ $\left.=652 \mathrm{~cm}^{-1}, E_{\mathrm{SOC}}=193 \mathrm{~cm}^{-1}\right)$. Therefore, for these complexes and dynamic JT coupling, it is expected that spin-orbit coupling
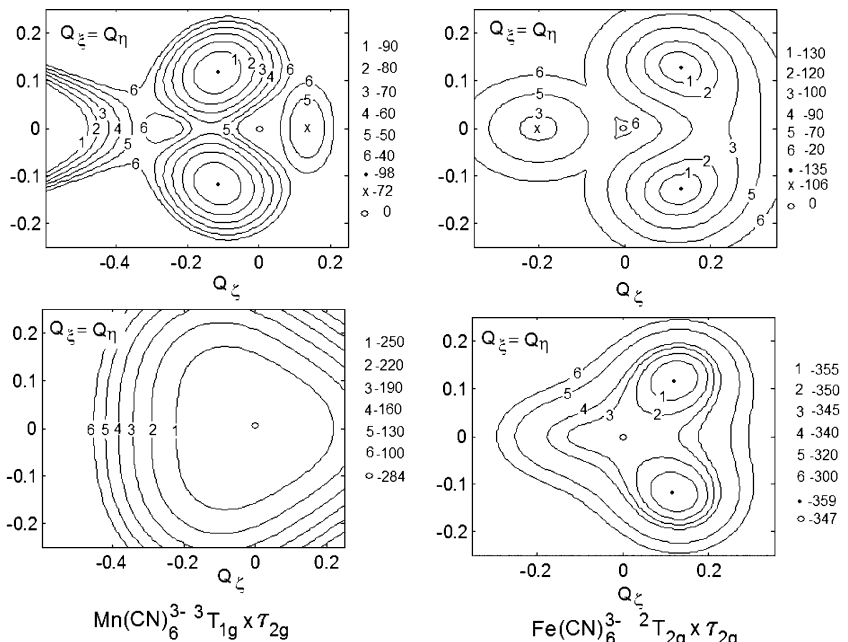

Figure 11. Contour plot diagrams of $\left[\mathrm{Fe}(\mathrm{CN})_{6}\right]^{3-}$ (top right, $\zeta=0$; bottom right, $\zeta=347 \mathrm{~cm}^{-1}$ ) and $\left[\mathrm{Mn}(\mathrm{CN})_{6}\right]^{3-}$ (top left, $\zeta=0$; bottom left, $\left.\zeta=284 \mathrm{~cm}^{-1}\right) . D_{2 h}$ and $D_{3 d}$ minima are indicated by $\times$ and $\bullet$, respectively; vibronic coupling parameters used to construct the plot are those given in Table 5 (quadratic JT coupling).
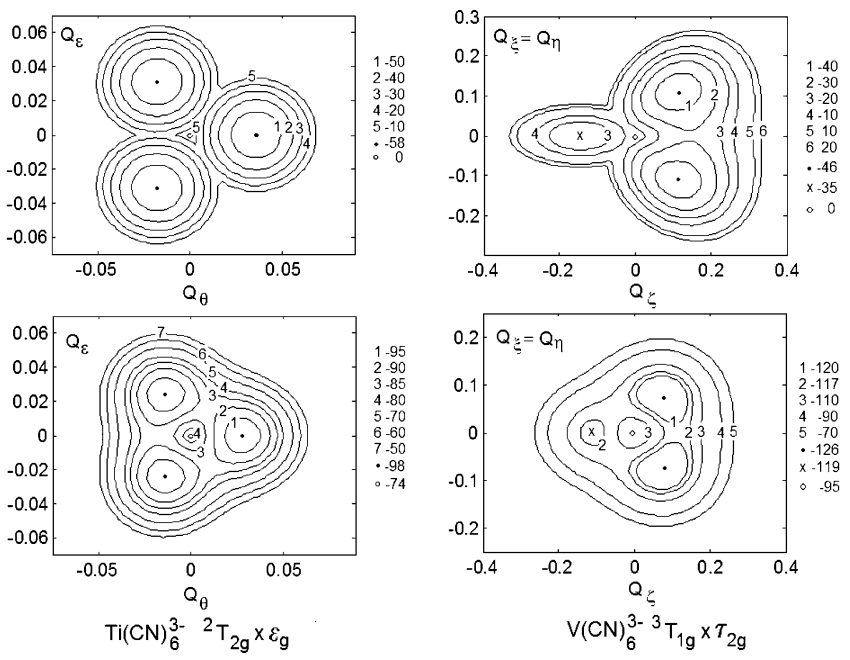

Figure 12. Contour plot diagrams of $\left[\mathrm{V}(\mathrm{CN})_{6}\right]^{3-}$ (top right, $\zeta=0$; bottom right, $\zeta=95 \mathrm{~cm}^{-1} ; D_{2 h}$ and $D_{3 d}$ minima are indicated by $\times$ and $\bullet$, respectively) and $\left[\mathrm{Ti}(\mathrm{CN})_{6}\right]^{3-}$ (top left, $\zeta=0$; bottom left, $\zeta=$ $74 \mathrm{~cm}^{-1} ; D_{4 h}$ minima are indicated by $\bullet$ ). Vibronic coupling parameters used to construct the plots are those given in Table 5 (quadratic JT coupling).

will be strongly reduced by vibronic coupling (Ham effect; see section Vb.2). JT coupling and spin-orbit coupling counteract in the case of $\left[\mathrm{Mn}(\mathrm{CN})_{6}\right]^{3-}$ and $\left[\mathrm{Fe}(\mathrm{CN})_{6}\right]^{3-}$ to an extent to

\begin{tabular}{|c|c|c|c|c|c|c|c|c|c|c|c|c|}
\hline complex & $10 D q^{d}$ & $E_{\mathrm{FC}}{ }^{\mathrm{m}}$ & $E_{\mathrm{FC}}{ }^{\mathrm{CI}}$ & $\theta$ & $e_{\sigma}$ & $e_{\pi}$ & $E_{\mathrm{JT}}$ & $E_{\mathrm{JT}}{ }^{\mathrm{CI}}$ & $B^{d}$ & $C^{d}$ & $\xi^{f}$ & $E_{\mathrm{SOC}}{ }^{e}$ \\
\hline$\left[\mathrm{Ti}(\mathrm{CN})_{6}\right]^{3-}$ & 22300 & 31 & & 54.30 & 6694 & -556 & 13 & & & & 147 & 74 \\
\hline$\left[\mathrm{V}(\mathrm{CN})_{6}\right]^{3-}$ & 23500 & 206 & 342 & 55.82 & 6376 & -1101 & 46 & 74 & 375 & 2700 & 190 & 95 \\
\hline$\left[\mathrm{Mn}(\mathrm{CN})_{6}\right]^{3-}$ & 34000 & 265 & 397 & 53.53 & 8976 & -1783 & 98 & 147 & 675 & 3120 & 284 & 284 \\
\hline$\left[\mathrm{Fe}(\mathrm{CN})_{6}\right]^{3-}$ & 34950 & 427 & 830 & 56.10 & 9304 & -1779 & 135 & 262 & 720 & 3290 & 347 & 347 \\
\hline$\left[\mathrm{Mn}(\mathrm{CN})_{6}\right]^{4-}$ & 30000 & 969 & 1196 & 56.47 & 5415 & -3470 & 314 & 387 & 425 & 1800 & 243 & 243 \\
\hline
\end{tabular}
nearly suppress minima on the ground-state potential energy

TABLE 7: Angular Overlap Model Parameters ${ }^{a}$ and the Trigonal Angles $\left(\theta^{b}\right)$ for CI Calculations of the Effect of Configurational Mixing on the JT Energies: $E_{\mathrm{FC}}{ }^{\mathrm{m}}\left(\mathrm{JT}\right.$ Splitting) and $\boldsymbol{E}_{\mathrm{JT}}\left(\mathrm{JT}\right.$ Stabilization Energy ${ }^{c}$

${ }^{a}$ Deduced from a fit of $e_{\sigma}$ and $e_{\pi}$ to the $\mathrm{t}_{2 \mathrm{~g}}$ splitting $\left(E_{\mathrm{FC}}{ }^{\mathrm{m}}\right)$ and the value of $10 \mathrm{Dq}$ using the angles $\theta .{ }^{b}$ Values of $\theta$ correspond to the $D_{3 d}$ minima (see Table $4 \mathrm{~b}) .{ }^{c} E_{\mathrm{JT}}$ values accounting for CI, $E_{\mathrm{JT}}{ }^{\mathrm{CI}}$, are calculated using $E_{\mathrm{JT}}{ }^{\mathrm{CI}}=E_{\mathrm{JT}}{ }^{\mathrm{m}}\left(E_{\mathrm{FC}}{ }^{\mathrm{Cl}} / E_{\mathrm{FC}}{ }^{\mathrm{m}}\right) .{ }^{d}$ From ref $41 .{ }^{e}$ Calculated from the energy expression for states split from ${ }^{2} \mathrm{~T}_{2 \mathrm{~g}}$ and ${ }^{3} \mathrm{~T}_{1 \mathrm{~g}}$ due to spin-orbit coupling $\left(\zeta\right.$ is defined to be positive in all cases). Ti $(\mathrm{CN})_{6}{ }^{3-}: \Gamma_{8},-(1 / 2) \zeta, \Gamma_{7}, \zeta$. $\mathrm{V}(\mathrm{CN})_{6}{ }^{3-}:\left(\mathrm{T}_{2}, \mathrm{E}\right),-(1 / 2) \xi ; \mathrm{T}_{1},(1 / 2) \xi ; \mathrm{A}_{1}, \zeta . \mathrm{Mn}(\mathrm{CN})_{6}{ }^{3-}: \mathrm{A}_{1},-\xi ; \mathrm{T}_{1},-(1 / 2) \xi ;\left(\mathrm{T}_{2}, \mathrm{E}\right),(1 / 2) \xi . \mathrm{Fe}(\mathrm{CN})_{6}{ }^{3-}$ and $\mathrm{Mn}(\mathrm{CN})_{6}{ }^{4-}: \Gamma_{7},-\xi ; \Gamma_{8},(1 / 2) \xi$ ${ }^{f}$ Deduced from two-component relativistic (ZORA) calculations on the $\mathrm{M}^{3+}\left(\mathrm{Ti}, 200 \mathrm{~cm}^{-1} ; \mathrm{V}, 264 \mathrm{~cm}^{-1} ; \mathrm{Mn}, 429 \mathrm{~cm}^{-1} ; \mathrm{Fe}, 548 \mathrm{~cm}^{-1}\right)$ and M $\mathrm{M}^{2+}$ $\left(\mathrm{Mn}, 368 \mathrm{~cm}^{-1} ; \mathrm{Cr}, 284 \mathrm{~cm}^{-1}\right.$ ) ions after a proper reduction by covalency; the value of the spin-orbit coupling constant for $\mathrm{Cr}^{\mathrm{II}}$ (not listed) is $\zeta=$ $193 \mathrm{~cm}^{-1}$. 
TABLE 8: Comparison of Experimental and Computed Radial $\left(\rho_{\epsilon}\right)$ and Angular $\left(\rho_{\tau}\right)$ Distortions ${ }^{a}$ from the Regular Octahedral Geometries of 3d Hexacyanometalate Complexes

\begin{tabular}{|c|c|c|c|c|c|c|}
\hline \multirow[b]{2}{*}{ complex } & \multirow[b]{2}{*}{ counterion } & \multicolumn{2}{|c|}{ exptl } & \multicolumn{2}{|c|}{ theor $^{b}$} & \multirow[b]{2}{*}{ ref } \\
\hline & & $\rho_{\epsilon}$ & $\rho_{\tau}$ & $\rho_{\epsilon}$ & $\rho_{\tau}$ & \\
\hline$\left[\mathrm{Mn}(\mathrm{CN})_{6}\right]^{3-}$ & $3\left[\mathrm{~N}\left(\mathrm{PPh}_{3}\right)_{2}\right]^{+}$ & $0.012(2)$ & $0.148(6)$ & 0.029 & 0.116 & 47 \\
\hline$\left[\mathrm{Mn}(\mathrm{CN})_{6}\right]^{3-}$ & $3 \mathrm{~K}^{+}$ & $0.044(14)$ & $0.040(40)$ & 0.029 & 0.116 & $48 \mathrm{a}$ \\
\hline$\left[\mathrm{Fe}(\mathrm{CN})_{6}\right]^{3-}$ & $3\left[\mathrm{~N}\left(\mathrm{PPh}_{3}\right)_{2}\right]^{+}$ & $0.021(7)$ & $0.202(20)$ & 0.012 & 0.128 & 49 \\
\hline$\left[\mathrm{Fe}(\mathrm{CN})_{6}\right]^{3-c}$ & $3 \mathrm{~K}^{+}$ & $0.016(3)$ & $0.088(7)$ & 0.012 & 0.128 & 20 \\
\hline$\left[\mathrm{Fe}(\mathrm{CN})_{6}\right]^{3-d}$ & $3 \mathrm{~K}^{+}$ & $0.000(6)$ & $0.103(20)$ & 0.012 & 0.128 & 20 \\
\hline$\left[\mathrm{Co}(\mathrm{CN})_{6}\right]^{3-}$ & $3 \mathrm{~K}^{+}$ & $0.040(11)$ & $0.014(31)$ & 0 & 0 & $48 b$ \\
\hline$\left[\mathrm{Cr}(\mathrm{CN})_{6}\right]^{4-}$ & $4 \mathrm{Na}^{+}$ & $0.029(6)$ & $0.169(14)$ & 0.047 & 0.182 & 50 \\
\hline
\end{tabular}

${ }^{a}$ Calculated using $\rho_{\epsilon}=\left(\sum_{i=1}{ }^{6} \Delta R_{i}^{2}\right)^{1 / 2}$, where $\Delta R_{i}=R_{i}-R_{\mathrm{av}}$ and $R_{\mathrm{av}}$ is the average $\mathrm{M}-\mathrm{CN}$ bond distance, and $\rho_{\tau}=R_{\mathrm{av}}\left(\sum_{i=1}^{12} \Delta \alpha_{i}^{2}\right)^{1 / 2}$, where $\Delta \alpha_{i}=\pi\left(\alpha_{i}-90\right) / 180$ and $\alpha_{i}$ denotes the 12 cis-C-M-C bond angles in a hexacoordinate complex. ${ }^{b}$ Calculated for the $D_{4 h}\left(\rho_{\epsilon}\right)$ and $D_{3 d}\left(\rho_{\tau}\right)$ minima of the ground-state potential energy surface. ${ }^{c}$ Monoclinic form. ${ }^{d}$ Orthorhombic form.

surface, calculated to be of $D_{3 d}$ symmetry. The JT coupling may still manifest itself on potential energy surfaces, which are very flat along distortional modes of $\tau_{2 \mathrm{~g}}$ symmetry. These ions are expected to be susceptible to angular distortions.

\section{Comparison with Experiment}

a. Structural Data. Hexacyanometalates of the $3 \mathrm{~d}$ metals are anionic species, and crystal and molecular structures of their compounds with alkali-metal ions have been reported. ${ }^{20,47-50}$ The $\mathrm{M}(\mathrm{CN})_{6}$ units are nearly octahedral, with small distortions in bond lengths and angles. To quantify these distortions and to facilitate comparison between the predicted and observed structures, we introduce JT radii for the $\epsilon_{\mathrm{g}}$ and $\tau_{2 \mathrm{~g}}$ modes, defined in eqs 40 and 41, and use reported bond lengths and

$$
\begin{gathered}
\rho_{\epsilon}=\left(Q_{\theta}{ }^{2}+\mathrm{Q}_{\epsilon}{ }^{2}\right)^{1 / 2}=\left(\sum_{i=1}^{6} \Delta R_{\mathrm{i}}{ }^{2}\right)^{1 / 2} \\
\Delta R_{i}=R_{i}-R_{\mathrm{av}} \\
\rho_{\tau}=\left(Q_{\xi}{ }^{2}+\mathrm{Q}_{\eta}{ }^{2}+Q_{\zeta}{ }^{2}\right)^{1 / 2}=R_{\mathrm{av}}\left(\sum_{i=1}^{12} \Delta \alpha_{i}^{2}\right)^{1 / 2} \\
\Delta \alpha_{i}=\pi\left(\alpha_{i}-90\right) / 180
\end{gathered}
$$

angles to approximate their values. In eqs 40 and $41 R_{\mathrm{av}}$ is the average $\mathrm{M}-\mathrm{CN}$ distance, while $\alpha_{i}$ values give the $12 \mathrm{cis}-\mathrm{C}-$ $\mathrm{M}-\mathrm{C}$ angles. In Table 8 , values of $\rho_{\epsilon}$ and $\rho_{\tau}$ from X-ray diffraction data of $\left[\mathrm{Mn}(\mathrm{CN})_{6}\right]^{3-},\left[\mathrm{Fe}(\mathrm{CN})_{6}\right]^{3-}$, and $\left[\mathrm{Cr}(\mathrm{CN})_{6}\right]^{4-}$ are compared with those deduced from the $D_{4 h}\left(\rho_{\epsilon}\right)$ and $D_{3 d}$ $\left(\rho_{\tau}\right)$ DFT geometry optimizations. There is good agreement between the orders of magnitude of $\rho_{\epsilon}$ and $\rho_{\tau}$ from DFT and experimental data. In agreement with the predicted larger JT coupling of the trigonal $\left(\tau_{2 \mathrm{~g}}\right)$ compared with the tetragonal modes $\left(\epsilon_{\mathrm{g}}\right)$, we obtain $\rho_{\tau} \gg \rho_{\epsilon}$. However, from a comparison of the $\rho_{\epsilon}$ and $\rho_{\tau}$ values of $\left[\mathrm{Fe}(\mathrm{CN})_{6}\right]^{3-}\left(\right.$ or $\left.\left[\mathrm{Mn}(\mathrm{CN})_{6}\right]^{3-}\right)$ in crystal lattices with various counterions or from different crystal structural analyses (orthorhombic vs monoclinic), it follows that there is a significant matrix effect. This conclusion also emerges from the observed small distortions of the JT-inert $\left[\mathrm{Co}(\mathrm{CN})_{6}\right]^{3-}$ complex.

b. The $g$ Tensor Values and the Anisotropic Susceptibility of $\mathbf{K}_{3}\left[\mathbf{F e}(\mathbf{C N})_{6}\right]$. b.1. Static Strain along the $\tau_{2 g}$ Distortions. The electronic structure of $\left[\mathrm{Fe}(\mathrm{CN})_{6}\right]^{3-}$ has been extensively studied, starting with the early work on the paramagnetic resonance of $\left[\mathrm{Fe}(\mathrm{CN})_{6}\right]^{3-}$ and its theoretical interpretation. ${ }^{13,14}$ In addition, magnetic susceptibility $(\chi)$ studies, including crystal anisotropies and crystal structures, have been reported. ${ }^{15,18,21}$ Efforts to rationalize these data were based on the assumption of an orthorhombic symmetry with orthorhombic axes parallel to the three $\mathrm{Fe}-\mathrm{CN}$ bond directions. A reasonable fit with three parameters (two crystal field energies, which define the splitting of the $x y, y z$, and $x z$ orbitals $(A(x y), B(y z)$, and $C(x z)$, respectively; $A+B+C=0$ and the spin-orbit coupling constant) could reproduce both the $\mathbf{g}$ tensors and the anisotropic susceptibility. However, the Mössbauer data of $\left[\mathrm{Fe}(\mathrm{CN})_{6}\right]^{3-16,17,19}$ could not be explained. The room-temperature (295 K) crystal structures of $\mathrm{K}_{3}\left[\mathrm{Fe}(\mathrm{CN})_{6}\right]$ in its monoclinic and orthorhombic forms have been determined with high precision. ${ }^{20}$ As follows from the $\mathrm{C}-\mathrm{Fe}-\mathrm{C}$ angles (Table $9 \mathrm{a} ; \alpha_{\xi}, \alpha_{\eta}$, and $\alpha_{\xi}$ ), $\left[\mathrm{Fe}(\mathrm{CN})_{6}\right]^{3-}$ is found in a trigonally elongated geometry with the $C_{3}$ axis approximately parallel to the crystallographic axis $(a)$, superimposed by an additional orthorhombic distortion. We have used the distortions to get an estimate of the geometric strain, described by $Q_{\xi}$, $Q_{\eta}{ }^{\mathrm{s}}$, and $Q_{\varsigma}^{\mathrm{s}}$ (see Table 9), and the vibronic coupling constants of $\left[\mathrm{Fe}(\mathrm{CN})_{6}\right]^{3-}$ to approximate the strain matrix according to eq 21 , to calculate the $\mathbf{g}$ and susceptibility tensors of $\left[\mathrm{Fe}(\mathrm{CN})_{6}\right]^{3-}$ from a full LF calculation. With this matrix, we could not reproduce the sign of the magnetic anisotropy. Apparently, the geometry of $\left[\mathrm{Fe}(\mathrm{CN})_{6}\right]^{3-}$ doped into $\mathrm{K}_{3}\left[\mathrm{Co}(\mathrm{CN})_{6}\right]$ is not the same as that given by the roomtemperature structure of $\mathrm{K}_{3}\left[\mathrm{Fe}(\mathrm{CN})_{6}\right]$, and the latter may change going to lower temperatures. Here, probably a geometric distortion, dominated by a trigonal compression, takes place. This is compatible with the stabilization of a nondegenerate (JT stable) ${ }^{2} \mathrm{~A}_{1 \mathrm{~g}}$ ground state. If we adopt the values of $Q_{\xi}$ s,$Q_{\eta}{ }^{\mathrm{s}}$, and $Q_{\varsigma}{ }^{\mathrm{s}}$, deduced from $\mathrm{X}$-ray data of the two modifications, and change their sign, accurate computed anisotropic g-tensor components and low-temperature magnetic susceptibility are obtained. The results are given in Table 9a and plotted in Figure 13. Readjustment of the values of $-Q_{\xi}^{\mathrm{s}},-Q_{\eta}^{\mathrm{s}}$, and $-Q_{\varsigma}^{\mathrm{s}}$ did not further strongly improve the agreement with experiment. From the data in Table $9 \mathrm{~b}$, the orientation of the principal axes of the $\mathbf{g}$ tensor with respect to the two sets of axes, the octahedral $\mathrm{Fe}-\mathrm{C}$ bond directions, and the crystallographic $a, b$, and $c$ axes also emerge. The orientations yield the $(1,1,1)(0,-1,1)$ and $(2,-$ $1,-1)$ trigonal directions for $g_{1}, g_{2}$, and $g_{3}$. These orientations show that $g_{1}, g_{2}$, and $g_{3}$ are (within angles of 11,8 , and $17^{\circ}$ ) parallel to the $(a),(c)$, and $(b)$ crystal axes in the orthorhombic lattice. In the monoclinic form, the axis of $g_{1}$ is parallel to $(a)$ but the directions of $g_{2}$ and $g_{3}$ interchange and become aligned along $(b)$ and $(c)$, respectively. This phenomenon has been described before. ${ }^{17}$ There is a misfit between the directions of $g_{1}$ and $\chi_{1}$ (both $\| a$, see the entries for (II) and (V) in Table 9b) and the orientation of $g_{1}$ reported in ref 13 , where the crystal structure of $\mathrm{K}_{3}\left[\mathrm{Fe}(\mathrm{CN})_{6}\right]$ was not known. In agreement with the susceptibility data, the magnetic anisotropies of $\left[\mathrm{Fe}(\mathrm{CN})_{6}\right]^{3-}$ in the two crystallographic forms of $\mathrm{K}_{3}\left[\mathrm{Fe}(\mathrm{CN})_{6}\right]$ are very similar and only compatible with a trigonally compressed geometry, as indicated by the JT coupling model. A change of the angle $\theta=54.7350^{\circ}$ by only $1^{\circ}$ is large enough to account for the observed anisotropy of $\mathrm{g}$ and $\chi$.

b.2. Dynamic Jahn-Teller Coupling. The $\tau_{2 \mathrm{~g}}$ vibrational frequencies of $\left[\mathrm{Mn}(\mathrm{CN})_{6}\right]^{3-}$ and $\left[\mathrm{Fe}(\mathrm{CN})_{6}\right]^{3-}$ are comparable with the JT stabilization energies $E_{\mathrm{JT}}\left(D_{3 d}\right)$. Therefore, dynamic JT coupling can take place. The ${ }^{2} \mathrm{~T}_{2 \mathrm{~g}}$ electronic state of $\left[\mathrm{Fe}(\mathrm{CN})_{6}\right]^{3-}$ undergoes mixing with vibrational states, and this leads to a total vibronic state of the same symmetry. Spinorbit coupling splits this ${ }^{2} \mathrm{~T}_{2 \mathrm{~g}}$ vibronic state into a $\Gamma_{7}$ ground 
TABLE 9: (a) Geometric and g tensor Values for $\left[\mathrm{Fe}(\mathrm{CN})_{6}\right]^{3-}$ in Its Orthorhombic and Monoclinic Forms Given by Experiment and Simulated with a Vibronic JT Coupling Model and (b) Directional Cosines of the Principal Axes of the g Tensor with Respect to the Octahedral $\mathrm{Fe}-\mathrm{C}$ bond Directions $(x, y, z)$ and the Crystallographic $a, b, c$ (Orthorhombic Setting) As Deduced from Experiment (III) and Simulated (Best Fit of Geometric Parameters) for [ $\left[\mathrm{Fe}(\mathrm{CN})_{6}\right]^{3-}$ in Its Orthorhombic (II) and Monoclinic (V) Forms

(a) Geometric and $\mathbf{g}$ Tensor Values

\begin{tabular}{|c|c|c|c|c|c|}
\hline & \multicolumn{2}{|c|}{ orthorhombic $^{b}$} & \multirow[b]{2}{*}{$\begin{array}{c}g_{\text {exptl }}{ }^{13} \\
\text { III }\end{array}$} & \multicolumn{2}{|c|}{ monoclinic $^{c}$} \\
\hline & $\begin{array}{l}\text { X-ray struct }{ }^{20}(\text { exptl }) \\
\text { I }\end{array}$ & $\begin{array}{l}\text { geom from a fit } \\
\text { to } \mathbf{g} \text { tensor values } \\
\text { II }\end{array}$ & & $\begin{array}{l}\text { X-ray struct }{ }^{20}(\text { exptl }) \\
\text { IV }\end{array}$ & $\begin{array}{l}\text { geom from a fit } \\
\text { to } \mathbf{g} \text { tensor values } \\
\mathrm{V}\end{array}$ \\
\hline \multicolumn{6}{|c|}{$\angle \mathrm{CFeC}$} \\
\hline$\alpha_{\xi}$ & $90.8^{e}\left(89.2^{d}\right)$ & 90.6 & & $90.9^{e}(89.1)$ & 91.1 \\
\hline$\alpha_{\eta}$ & $90.7^{e}\left(89.3^{d}\right)$ & 91.0 & & $90.8^{e}(89.2)$ & 91.0 \\
\hline$\alpha_{\xi}$ & $91.1^{e}\left(88.9^{d}\right)$ & 91.1 & & $90.5^{e}(89.5)$ & 90.6 \\
\hline$Q_{\xi}$ & $0.054(-0.054)$ & 0.041 & & $0.061(-0.061)$ & 0.077 \\
\hline$Q_{\eta}$ & $0.047(-0.047)$ & 0.069 & & $0.054(-0.054)$ & 0.069 \\
\hline$Q_{\zeta}$ & $0.074(-0.074)$ & 0.076 & & $0.034(-0.034)$ & 0.041 \\
\hline$Q\left(\alpha_{1 \mathrm{~g}}\right)$ & $0.101(-0.101)$ & 0.105 & & $0.086(-0.086)$ & 0.105 \\
\hline$Q\left(\epsilon_{\mathrm{g}}: x\right)$ & $0.019(-0.019)$ & 0.017 & & $-0.019(0.019)$ & -0.025 \\
\hline$Q\left(\epsilon_{\mathrm{g}}: y\right)$ & $0.005(-0.005)$ & -0.019 & & $0.005(-0.005)$ & 0.005 \\
\hline \multicolumn{6}{|c|}{ g Tensor } \\
\hline$g_{1}$ & $1.053(1.413)$ & 0.994 & 0.915 & $1.186(1.462)$ & 0.994 \\
\hline$g_{2}$ & $2.193(1.642)$ & 2.179 & 2.100 & $2.139(1.702)$ & 2.180 \\
\hline$g_{3}$ & $2.376(2.597)$ & 2.429 & 2.350 & $2.332(2.512)$ & 2.429 \\
\hline $\mathrm{SD}^{a}$ & $0.084(0.360)$ & 0.068 & & $0.137(0.348)$ & 0.069 \\
\hline \multicolumn{6}{|c|}{ Trigonal Orbital Splittings } \\
\hline$a_{1}$ & $120(-126)$ & 128 & $e(x y)=25$ & $103(-108)$ & 129 \\
\hline $\mathrm{e}$ & $-42,-78(48,78)$ & $-39,-89$ & $\begin{array}{l}e(y z)=-99 \\
e(x z)=65\end{array}$ & $-33,-70(38,70)$ & $-39,-90$ \\
\hline
\end{tabular}

(b) Directional Cosines

\begin{tabular}{|c|c|c|c|c|c|c|c|c|c|}
\hline \multirow[b]{2}{*}{ axis } & \multicolumn{3}{|c|}{ II } & \multicolumn{3}{|c|}{ III } & \multicolumn{3}{|c|}{ V } \\
\hline & $g_{1}$ & $g_{2}$ & $g_{3}$ & $g_{1}$ & $g_{2}$ & $g_{3}$ & $g_{1}$ & $g_{2}$ & $g_{3}$ \\
\hline & 0.994 & 2.179 & 2.429 & 0.915 & 2.100 & 2.350 & 0.991 & 2.181 & 2.430 \\
\hline$x$ & 0.630 & -0.059 & -0.774 & 0.002 & 0.573 & -0.819 & 0.535 & 0.759 & -0.371 \\
\hline$y$ & 0.561 & -0.655 & 0.506 & 0.710 & 0.567 & 0.418 & 0.563 & -0.648 & -0.514 \\
\hline$z$ & 0.537 & 0.754 & 0.379 & -0.694 & 0.581 & 0.423 & 0.630 & -0.066 & 0.774 \\
\hline$a$ & 0.981 & 0.031 & 0.250 & 0.000 & 0.500 & 0.866 & 0.988 & -0.147 & 0.005 \\
\hline$b$ & 0.255 & -0.075 & -0.956 & 0.000 & 0.866 & 0.500 & 0.142 & 0.896 & -0.404 \\
\hline$c$ & -0.007 & 0.990 & -0.084 & 1.000 & 0.000 & 0.000 & 0.058 & 0.404 & 0.906 \\
\hline
\end{tabular}

${ }^{a}$ Legend: SD, standard deviation between calculated and experimental $g$ values; $k=0.79 ; \zeta=345 \mathrm{~cm}^{-1} ; B=720 ; C=3290 \mathrm{~cm}^{-1}$. ${ }^{b}$ Crystallographic axes: $a=13.422 \AA ; b=10.399 \AA ; c=8.381 \AA$ (Pnca space group). ${ }^{c}$ Pseudo orthorhombic. ${ }^{d}$ Angles along the approximate $C_{3}$ direction running nearly parallel to the crystallographic $a$ axis; the other angles (cis to the listed ones) are $90.88,90.87,92.02,90.87,90.90$, and 89.54. ${ }^{e}$ Adopted from the reported bond angles $\alpha$ after changing the sign of $\left(\alpha-90^{\circ}\right)$ from negative to positive (see text).

vibronic state and a $\Gamma_{8}$ state at higher energy. The $\mathbf{g}$ tensor of the ground vibronic state $\Gamma_{7}$ is given by

$$
\mathbf{g}\left(\Gamma_{7}\right)=\frac{1}{3}(2+4 k)
$$

The orbital reduction factor $k$ can be expressed as

$$
k=k_{\mathrm{cov}} \cdot k_{\mathrm{CI}} \cdot\left[K_{\mathrm{T}_{2}}\left(\mathrm{~T}_{1}\right)\right]
$$

$k_{\text {cov }}$ is the covalent reduction factor, $k_{\mathrm{CI}}$ arises from configurational mixing between the $\Gamma_{7}\left({ }^{2} \mathrm{~T}_{2 \mathrm{~g}}\left(\mathrm{t}_{2 \mathrm{~g}}{ }^{5}\right)\right)$ ground state and all other excited states of the same symmetry. ${ }^{51} K_{\mathrm{T}_{2}}\left(\mathrm{~T}_{1}\right)$ is the vibronic (Ham) reduction factor, which includes all information about the vibronic nature of the $\Gamma_{7}$ ground state. ${ }^{52}$ Approximate expressions for these factors as a function of the strength of the ${ }^{2} \mathrm{~T}_{2 \mathrm{~g}} \otimes \tau_{2 \mathrm{~g}}$ JT coupling have been reported. ${ }^{32,53-55}$ In the usual treatment of the dynamic JT effect, one assumes that vibronic coupling is stronger than spin-orbit coupling, and the latter is modified according to $K_{\mathrm{T}_{2}}\left(\mathrm{~T}_{1}\right)$. In Figure 14 the lowest vibronic levels and $K_{\mathrm{T}_{2}}\left(\mathrm{~T}_{1}\right)$ are plotted vs the vibronic coupling strength $\lambda_{\tau}$. Small values of $\lambda_{\tau}$ (weak vibronic coupling) lead already to a strong reduction of the ${ }^{2} \mathrm{~A}_{1 \mathrm{~g}}-{ }^{2} \mathrm{~T}_{2 \mathrm{~g}}$ energy gap and of $K_{\mathrm{T}_{2}}\left(\mathrm{~T}_{1}\right)$
( $\delta$ is the tunneling splitting in the strong vibronic coupling limit). For octahedral $\left[\mathrm{Fe}(\mathrm{CN})_{6}\right]^{3-}$ and with neglect of influences from spin-orbit coupling and strain $\lambda_{\tau}=0.965$ (Table 5), $\delta$ drops from its initial value $\left(\delta=\hbar \omega_{\tau}=93 \mathrm{~cm}^{-1}\right)$ to $30 \mathrm{~cm}^{-1}$, accompanied by a nearly total quenching of $k\left(K_{\mathrm{T}_{2}}\left(\mathrm{~T}_{1}\right)=0.138\right)$. The situation drastically changes when dynamic Jahn-Teller coupling and spin-orbit coupling are accounted for on the same footing. This should be done because the two effects are comparable in magnitude (see section IVc). In this case $\delta$ is equal to the energy difference between the first excited state $\Gamma_{8}$ and the ground-state vibronic level $\Gamma_{7}$ (Figure 14a), i.e., 70 $\mathrm{cm}^{-1}$, in comparison to its nominal value of $93 \mathrm{~cm}^{-1}$. In line with this, the vibronic reduction for $\left[\mathrm{Fe}(\mathrm{CN})_{6}\right]^{3-}$ remains only $12 \%\left(K_{\mathrm{T}_{2}}\left(\mathrm{~T}_{1}\right)=0.876\right.$; see Figure $\left.14 \mathrm{~b}\right)$, therefore leaving the value of $g$ only weakly affected by vibronic coupling $\left(g\left(\Gamma_{7}\right)=\right.$ $1.835)$, in comparison to the static octahedral limit $\left(g\left(\Gamma_{7}\right)=\right.$ 1.918).

We now discuss the combined effect of geometric strain and dynamic JT coupling. In Figure 15 are presented the $\lambda_{\tau}$ dependence of the magnetic susceptibility $\left(\Delta \chi_{\mathrm{i}}, \mathrm{i}=a, b, c ; T\right.$ $=5 \mathrm{~K})$ and the $\mathbf{g}$ tensor $\left(\mathrm{g}_{\mathrm{i}}\right)$ for the vibronic ground state of $\left[\mathrm{Fe}(\mathrm{CN})_{6}\right]^{3-}$ in its monoclinic form (set $\mathrm{V}$ in Table 9). In these 


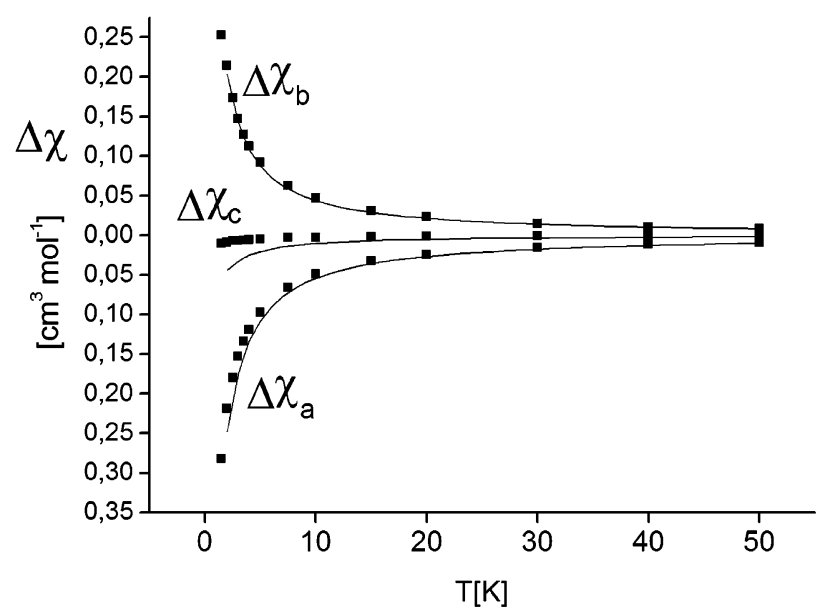

Figure 13. Experimental (black squares) ${ }^{21}$ and theoretical anisotropic magnetic susceptibilities for $\left[\mathrm{Fe}(\mathrm{CN})_{6}\right]^{3-}$. The notations $\Delta \chi_{a}, \Delta \chi_{b}$, and $\Delta \chi_{c}$ are defined as $\Delta \chi_{a}=\chi_{1}-\chi_{3}, \Delta \chi_{b}=\chi_{2}-\chi_{1}$, and $\Delta \chi_{c}=\chi_{2}-\chi_{3}$. $\chi_{1}, \chi_{2}$, and $\chi_{3}$ are the principal crystal susceptibilities with orientations along the $a, b$, and $c$ crystallographic axes, respectively; these coincide (within an angle of $\left.\pm 5^{\circ}\right)$ with the $(1,1,1),(2,-1,-1)$, and $(0,1,-1)$ $D_{3 d}$ directions of the $\left[\mathrm{Fe}(\mathrm{CN})_{6}\right]^{3-}$ complex (in the coordinate system $x$, $y, z$, defined by the $\mathrm{Fe}-\mathrm{C}$ bond vectors) and with principal axes of the molecular $\mathbf{g}$ tensor $0.915,2.100$, and $2.350\left(T=12 \mathrm{~K}^{13}\right)$, respectively. The following set of ligand field parameters describing the effect due to the geometrical strain (in $\mathrm{cm}^{-1}$ ) have been used (set V, Table 9, in combination with eq 21): $\left\langle x y\left|V_{\mathrm{LF}}\right| x y\right\rangle=-3,\left\langle x y\left|V_{\mathrm{LF}}\right| y z\right\rangle=70$, $\left\langle y z\left|V_{\mathrm{LF}}\right| y z\right\rangle=2,\left\langle x z\left|V_{\mathrm{LF}}\right| x y\right\rangle=79,\left\langle y z\left|V_{\mathrm{LF}}\right| x z\right\rangle=41,\left\langle x z\left|V_{\mathrm{LF}}\right| x z\right\rangle=1 ;$ $\left\langle x^{2}-y^{2}\left|V_{\mathrm{LF}}\right| x^{2}-y^{2}\right\rangle=\left\langle z^{2}\left|V_{\mathrm{LF}}\right| z^{2}\right\rangle=34950 ; B=720, C=3290 ; \xi=$ $345 \mathrm{~cm}^{-1} ; k=0.79$.

calculations, we have assumed that the energy of the $\tau_{2 \mathrm{~g}}$ mode $\left(\hbar \omega_{\tau}=93 \mathrm{~cm}^{-1}\right)$ remains unchanged, when the free $\left[\mathrm{Fe}(\mathrm{CN})_{6}\right]^{3-}$ complex is embedded in its crystal surrounding. In contrast to $\Delta \chi_{\mathrm{i}}$, which is not found to be sensitive to $\lambda_{\tau}, \mathbf{g}_{\mathrm{i}}$ shows a clear dependence on $\lambda_{\tau}$, particularly pronounced for the smaller component $g_{1}$. When $\lambda_{\tau}$ increases, starting from the static strain induced geometry, there is a strong reduction of $g_{1}$ from its initial value (0.994; Table 9, set V) to 0.197. Apparently, there is an enhancement of the geometric strain by dynamic JT coupling. We also calculate a clear temperature effect on all $\mathbf{g}$ tensor values; the smaller component $g_{1}$ increases (by 20\%), while the larger $g_{2}$ and $g_{3}$ values decrease (by $4 \%$ and $3 \%$, respectively), when the temperature $(T)$ is increased from 0 to $50 \mathrm{~K}$. That is, the increase of the temperature counteracts the changes induced by the dynamic JT effect. The calculated strain induced changes of the $\mathbf{g}$ tensor are comparable with those reported (both experimental and calculated) for other strainaffected dynamic JT coupling systems, such as $\mathrm{CuF}_{6}{ }^{2-}, 56$ $\mathrm{Cu}\left(\mathrm{H}_{2} \mathrm{O}\right)_{6}{ }_{6}^{2+}, 57$ (including temperature dependencies for both, see ref 58), $\mathrm{TiCl}_{6}{ }^{3-}, 59$ and aqua complexes of $\mathrm{Ti}^{\mathrm{III}}\left(\mathrm{t}_{2 \mathrm{~g}}\right)^{1}{ }^{60-63}$ and $\mathrm{V}^{\mathrm{III}}\left(\mathrm{t}_{2 \mathrm{~g}}{ }^{2}\right) .{ }^{64,65}$ When we compare the results presented here with the $\mathrm{g}$ tensor values of $\left[\mathrm{Fe}(\mathrm{CN})_{6}\right]^{3-}$ from experiment (Table 9), we conclude that dynamic JT coupling is prohibited in the $\mathrm{K}_{3} \mathrm{Fe}(\mathrm{CN})_{6}$ crystal lattice. However, the results obtained may stimulate further experiments on this and other related systems, such as $\mathrm{Cs}_{2} \mathrm{KFe}(\mathrm{CN})_{6}$, for which temperature-dependent structural and EPR data are still missing. ${ }^{66}$

c. Near-IR Spectra and the Anisotropic Susceptibility of $\mathbf{K}_{3}\left[\mathbf{M n}(\mathbf{C N})_{6}\right]$. Potassium hexacyanomanganate(III) is isomorphic with the corresponding cobalt salt. Unfortunately, the structures of neither of the two compounds are known with good accuracy (see Table 8). Single-crystal susceptibilities of $\mathrm{K}_{3}[\mathrm{Mn}-$ $\left.(\mathrm{CN})_{6}\right]$ have been reported, and a distinct anisotropy between 80 and $300 \mathrm{~K}$ has been found. ${ }^{24}$ To interpret these data, a crystal field model with tetragonal $D_{4 h}$ symmetry has been adopted. ${ }^{24}$
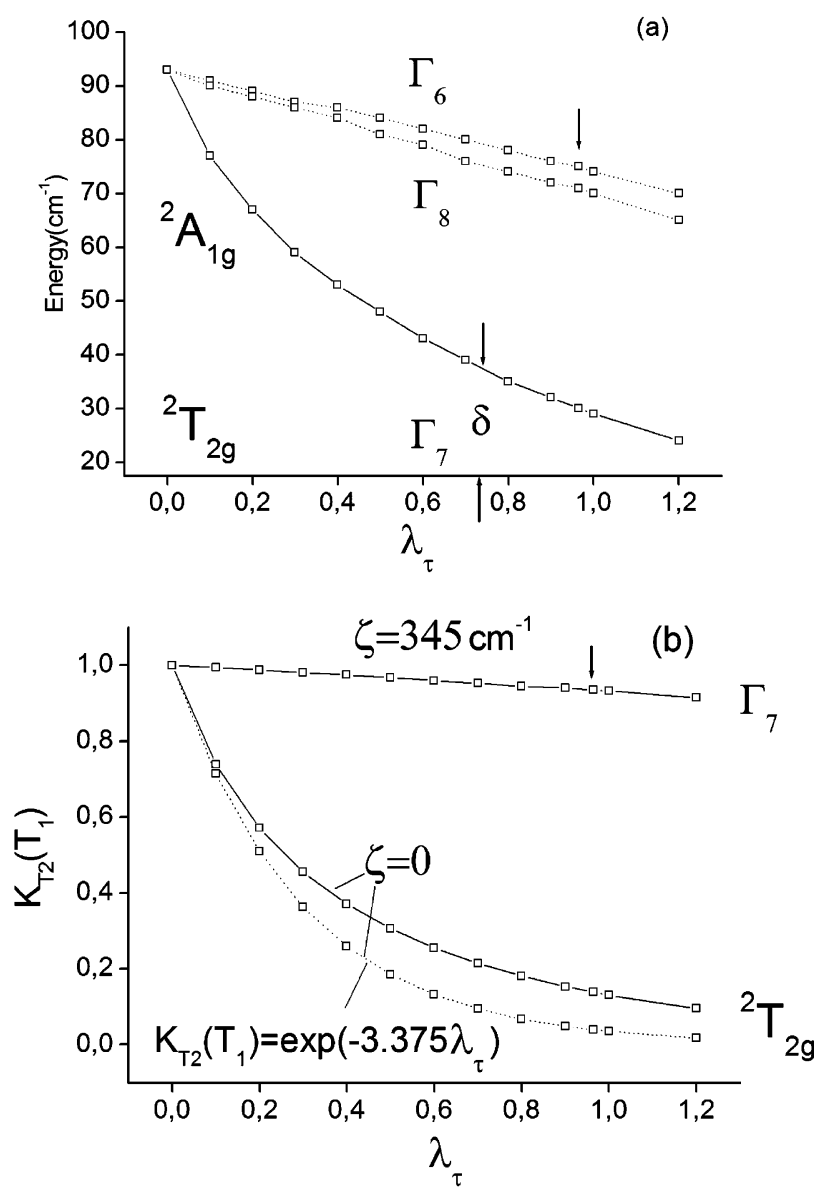

Figure 14. (a) Energies $\left(\mathrm{cm}^{-1}\right)$ of the lowest vibronic states of $\left[\mathrm{Fe}(\mathrm{CN})_{6}\right]^{3-}$ without $\left({ }^{2} \mathrm{~T}_{2 \mathrm{~g}}\right.$ and $\left.{ }^{2} \mathrm{~A}_{1 \mathrm{~g}}\right)$ and with $\left(\Gamma_{7}, \Gamma_{8}, \Gamma_{6}\right)$ spin-orbit coupling. The lowest vibronic state $\left({ }^{2} \mathrm{~T}_{2 \mathrm{~g}}\right.$ or $\left.\Gamma_{7}\right)$ has been taken as an energy reference; the tunneling splitting $\delta$ of the fourfold degenerate vibronic state (strong vibronic coupling limit) is indicated. (b) Vibronic (Ham) reduction factors $K_{\mathrm{T}_{2}}\left(\mathrm{~T}_{1}\right)$ for the angular momentum operator $\left(\mathbf{L}\left(\mathrm{T}_{1}\right)\right)$ in the ground vibronic state of $\left[\mathrm{Fe}(\mathrm{CN})_{6}\right]^{3-}$. The vertical arrows mark the value of $\lambda_{\tau}$ for $\left[\mathrm{Fe}(\mathrm{CN})_{6}\right]^{3-}$ (see Table 5). Solid lines are obtained with a full diagonalization of the vibronic Hamiltonian; dotted lines correspond to the expression obtained with perturbation theory. ${ }^{53}$

The electronic spectrum of $\mathrm{K}_{3}\left[\mathrm{Mn}(\mathrm{CN})_{6}\right]$ has been reported. $22,23,41$ Two sharp transitions at 9216 and $9461 \mathrm{~cm}^{-1}$ with polarizations $\perp$ and $\|$ to the crystal axis (the needle axis) have been observed. ${ }^{22}$ The former was reproduced in a later study ${ }^{25}$ and assigned to the ${ }^{3} \mathrm{~T}_{1 \mathrm{~g}} \rightarrow{ }^{1} \mathrm{~T}_{2 \mathrm{~g}}$ spin-flip transition within the $\mathrm{t}_{2 \mathrm{~g}}{ }^{4}$ ground-state configuration of $\left[\mathrm{Mn}(\mathrm{CN})_{6}\right]^{3-}$. Electronic absorption spectra in the region of the $9191 \mathrm{~cm}^{-1}$ transition at different temperatures are represented in Figure 16. With an increase of temperature two hot bands (at 9116 and $9012 \mathrm{~cm}^{-1}$ ) appear in the spectrum above $11 \mathrm{~K}$. The first is located at $75 \mathrm{~cm}^{-1}$ lower energy; it is quite sharp at $25 \mathrm{~K}$, and it is very probably the second electronic origin from the spin-orbit/ligand field split ${ }^{3} \mathrm{~T}_{1 \mathrm{~g}}$ ground-state multiplet. It has a comparatively intense sideband at $339 \mathrm{~cm}^{-1}$ higher energy, which corresponds to the frequency of the $t_{1 u}$ vibration already observed as a vibronic sideband of the first origin. At still higher temperatures, the spectrum quickly becomes broadened but a third hot band at about $181 \mathrm{~cm}^{-1}$ grows in. We can tentatively assign this to a third component of the ground state. Note that the ratio of the two energies $181 / 75=2.41$ does not obey the Landé interval rule, which implies a ratio of 3 if the three transitions were to be interpreted as originating solely from splitting of the ${ }^{3} \mathrm{~T}_{1 \mathrm{~g}}$ ground term, due to spin-orbit coupling. In analogy to $\mathrm{K}_{3}\left[\mathrm{Fe}(\mathrm{CN})_{6}\right]$, we can assume that $\left[\mathrm{Mn}(\mathrm{CN})_{6}\right]^{3-}$ is trigonally 

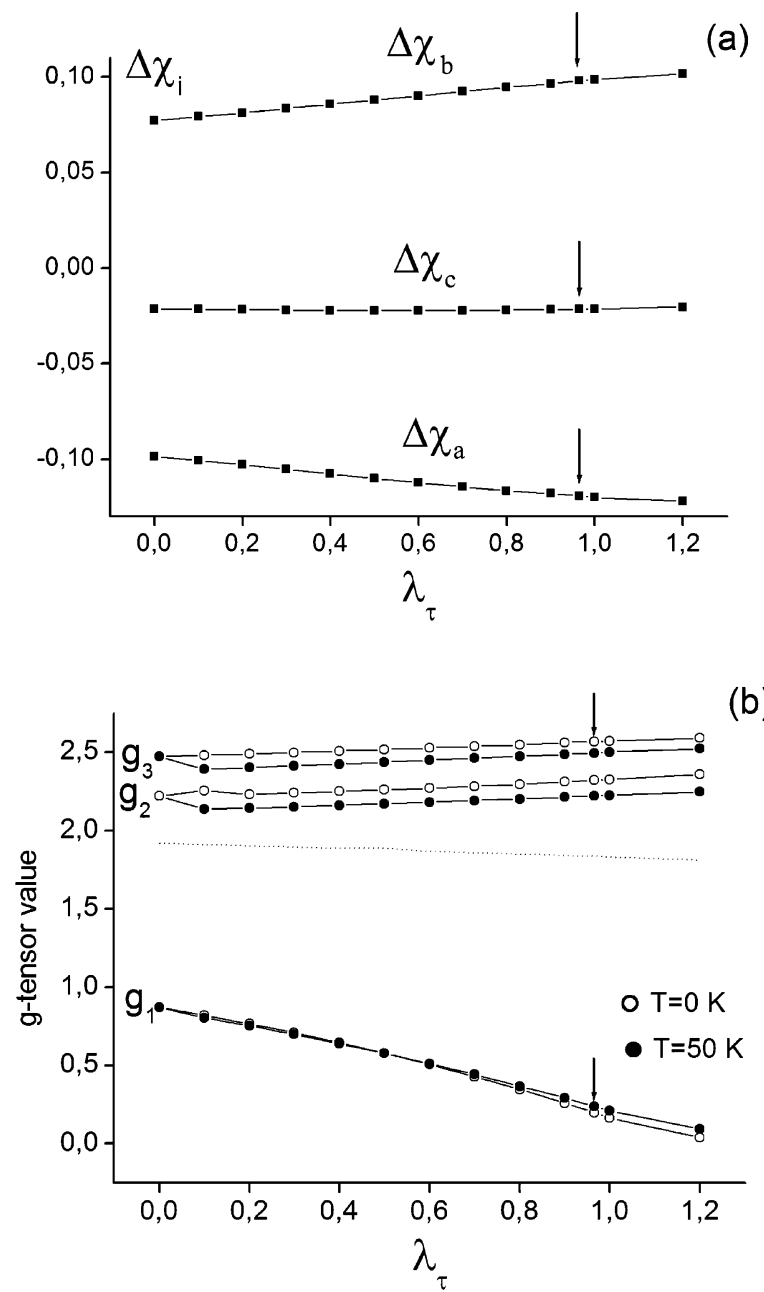

Figure 15. Effect of dynamic JT coupling (linear ${ }^{2} \mathrm{~T}_{2 \mathrm{~g}} \otimes \tau_{2 \mathrm{~g}}$ model) on the anisotropic susceptibilities (a; $T=5 \mathrm{~K}$ ) and $\mathbf{g}$ tensors (b) of $\left[\mathrm{Fe}(\mathrm{CN})_{6}\right]^{3-}$ in dependence of the vibronic coupling strength $\left(\lambda_{\tau}\right)$ in the presence of geometric strain. Values of the strain energies as well as other parameters taken in the calculation are specified in Table 9 (set V). The dotted curve in (b) refers to octahedral $\left[\mathrm{Fe}(\mathrm{CN})_{6}\right]^{3-}$, calculated when excluding the strain. The vertical arrows mark the value of $\lambda_{\tau}$ for $\left[\mathrm{Fe}(\mathrm{CN})_{6}\right]^{3-}$ (see Table 5).

elongated (the compounds are isomorphic). On the basis of the anisotropy of the susceptibility tensor, an axial compression can be ruled out. ${ }^{24}$ We can use the observed ground-state splitting to fit the spin-orbit coupling constant and the angle $\theta$ (all other parameters, specified in Table 7, have been taken as fixed). Results from this calculation are given in Table 10. A value of $\Delta \theta$ of only $-0.44^{\circ}$ along with $\zeta=209 \mathrm{~cm}^{-1}$ can readily account for the experimental results. With these parameters, energies of excited states, split from ${ }^{1} \mathrm{~T}_{2 \mathrm{~g}}$, are calculated in agreement with experiment, and they are consistent with the reported polarizations (Table 10). Finally, a set of all these parameters has been used to calculate the susceptibility tensor; the calculated and experimental data are compared in Figure 17. There is excellent agreement between theory and experiment. We therefore conclude that a trigonally elongated geometry (as in $\left[\mathrm{Fe}(\mathrm{CN})_{6}\right]^{3-}$ with an orbitally nondegenerate ground state) is compatible with the spectroscopic and magnetic behavior of $\left[\mathrm{Mn}(\mathrm{CN})_{6}\right]^{3-}$. As with $\left[\mathrm{Fe}(\mathrm{CN})_{6}\right]^{3-}$, the magnetic anisotropy is found to be extremely sensitive with respect to angular distortions.

\section{Conclusions}

(1) JT coupling in hexacyanometalates with degenerate ${ }^{2} \mathrm{~T}_{2 \mathrm{~g}}$ and ${ }^{3} \mathrm{~T}_{1 \mathrm{~g}}$ ground states $\left(\mathrm{T}_{\mathrm{g}} \otimes\left(\epsilon_{\mathrm{g}}+\tau_{2 \mathrm{~g}}\right)\right.$ coupling) is usually

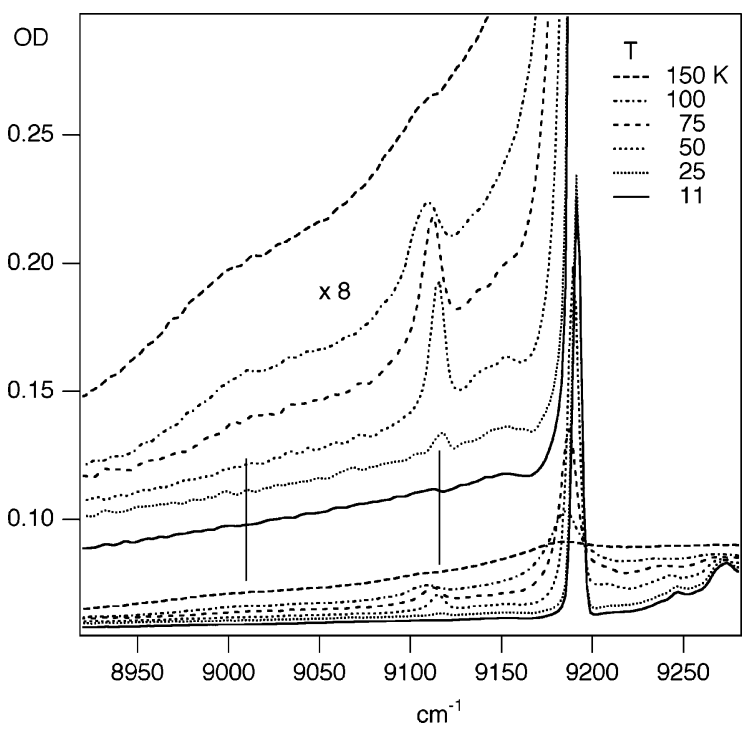

Figure 16. Near-IR spectra in high resolution for $\left[\mathrm{Mn}(\mathrm{CN})_{6}\right]^{3-}$ in the region of the ${ }^{3} \mathrm{~T}_{1 \mathrm{~g}}-{ }^{1} \mathrm{~T}_{2 \mathrm{~g}}$ transition with hot bands which grow upon an increase of temperature.

TABLE 10: Energies of the Lowest Electronic States ${ }^{a}$ Involved in the Spectroscopy and Magnetism of $\left[\mathrm{Mn}(\mathrm{CN})_{6}\right]^{3-}$

\begin{tabular}{|c|c|c|c|c|c|c|}
\hline \multirow[b]{2}{*}{$O_{h}, \zeta=0$} & \multirow{2}{*}{\multicolumn{2}{|c|}{$D_{3 d}, \zeta=0$}} & \multirow{2}{*}{\multicolumn{2}{|c|}{$D_{3 d}{ }^{d} \xi=209$}} & \multicolumn{2}{|c|}{ exptl } \\
\hline & & & & & $b$ & $c$ \\
\hline${ }^{3} \mathrm{~T}_{1 \mathrm{~g}} \quad 0$ & $\begin{array}{l}{ }^{3} \mathrm{~A}_{2 \mathrm{~g}} \\
{ }^{3} \mathrm{E}_{\mathrm{g}}\end{array}$ & $\begin{array}{l}0 \\
159\end{array}$ & $\begin{array}{l}\mathrm{A}_{1 \mathrm{~g}}\left[\mathrm{~A}_{1 \mathrm{~g}}\right] \\
\mathrm{E}_{\mathrm{g}}\left[\mathrm{T}_{1 \mathrm{~g}}\right] \\
\mathrm{A}_{2 \mathrm{~g}}\left[\mathrm{~T}_{1 \mathrm{~g}}\right] \\
\mathrm{A}_{1 \mathrm{~g}}\left[\mathrm{~T}_{2 \mathrm{~g}}, \mathrm{E}_{\mathrm{g}}\right] \\
\mathrm{E}_{\mathrm{g}}\left[\mathrm{T}_{2 \mathrm{~g}}, \mathrm{E}_{\mathrm{g}}\right] \\
\mathrm{E}_{\mathrm{g}}\left[\mathrm{T}_{2 \mathrm{~g}}, \mathrm{E}_{\mathrm{g}}\right]\end{array}$ & $\begin{array}{l}0 \\
75 \\
181 \\
296 \\
331 \\
386\end{array}$ & $\begin{array}{l}0 \\
75 \\
181\end{array}$ & \\
\hline${ }^{1} \mathrm{~T}_{2 \mathrm{~g}} \quad 9096$ & $\begin{array}{l}{ }^{1} \mathrm{E}_{\mathrm{g}} \\
{ }^{1} \mathrm{~A}_{1 \mathrm{~g}}\end{array}$ & $\begin{array}{l}9123 \\
9335\end{array}$ & $\begin{array}{l}\mathrm{Eg}_{\mathrm{g}}\left[\mathrm{T}_{2 \mathrm{~g}}\right] 9250 \\
\mathrm{~A}_{1 \mathrm{~g}}\left[\mathrm{~T}_{2 \mathrm{~g}}\right] 9462\end{array}$ & & $\begin{array}{l}9191 \\
9390\end{array}$ & $\begin{array}{l}9216(\perp)^{e} \\
9461(I \mid)^{e}\end{array}$ \\
\hline
\end{tabular}

${ }^{a} \xi=209 \mathrm{~cm}^{-1}$ and $\theta=54.29^{\circ}$ calculated from a fit to the experimental energies of the $\mathrm{A}_{1 \mathrm{~g}} \rightarrow \mathrm{E}_{\mathrm{g}}\left(75 \mathrm{~cm}^{-1}\right)$ and $\mathrm{A}_{1 \mathrm{~g}} \rightarrow \mathrm{A}_{2 \mathrm{~g}}(181$ $\mathrm{cm}^{-1}$ ) transitions within the ${ }^{3} \mathrm{~T}_{1 \mathrm{~g}}$ octahedral ground state. Other parameters are $B=675, C=3120 \mathrm{~cm}^{-1}, 10 D q=34000 \mathrm{~cm}^{-1}, e_{\sigma}=$ $8976 \mathrm{~cm}^{-1}$, and $e_{\pi}=-1783 \mathrm{~cm}^{-1}$ (see Table 7). The $D_{3 d}$ trigonal splitting of the $\mathrm{t}_{2 \mathrm{~g}}$ orbitals into $\mathrm{a}_{1 \mathrm{~g}}<\mathrm{e}_{\mathrm{g}}$ is $110 \mathrm{~cm}^{-1} .{ }^{b}$ This work. ${ }^{c}$ Reference 22. ${ }^{d}$ The origin from the corresponding term in the $O_{h}$ double group is given in brackets. ${ }^{e}$ Polarization with electric vector $E$ perpendicular $(\perp)$ or parallel (II) to the crystal axis taken to coincide with the needle axis of the dark red crystals.

neglected, because it is a weak effect due to $\pi$-bonding. However, $\pi$-bonding is also responsible for the magnetic properties due to exchange coupling in room-temperature and single-molecule magnets. Since both effects are comparable in magnitude, they need to be accounted for on the same footing when spectroscopic and magnetic properties are modeled and interpreted.

(2) We present a simple method, which allows us to determine all parameters of the $\mathrm{T}_{\mathrm{g}} \otimes\left(\epsilon_{\mathrm{g}}+\tau_{2 \mathrm{~g}}\right)$ JT problem with DFT calculations. First- and second-order vibronic coupling constants can be used to calculate the depth and position of stationary points of $D_{4 h}, D_{3 d}$, and $D_{2 h}$ symmetry on the ground-state potential energy surface and also to assign them to minima and saddle points of different order. There is no way to get the same information from DFT alone, because present implementations of Kohn-Sham DFT do not allow calculations of the energy of the system in the case of orbitally degenerate ground states. In addition, technical problems occur when a scan of the potential energy surface is attempted point by point in low symmetry, where electrons jump between orbitals which are 


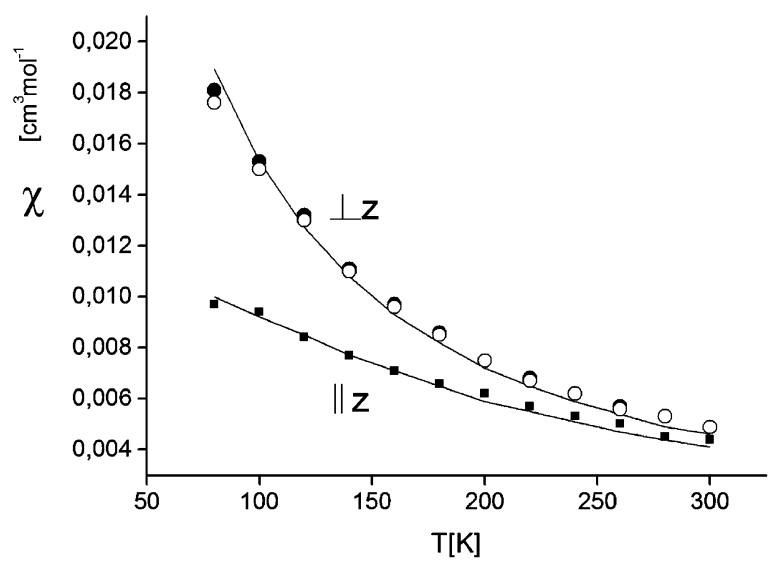

Figure 17. Experimental (black squares, open and full circles) ${ }^{24}$ and calculated (solid line, JT coupling model, trigonal distortion of $\theta=$ $54.29^{\circ}$; see Table 10 for a full list of parameters used) anisotropic magnetic susceptibilities of $\left[\mathrm{Mn}(\mathrm{CN})_{6}\right]^{3-}$. The direction $z$ is parallel to the trigonal $C_{3}$ axis and coincides (within $5^{\circ}$ ) with the crystallographic (a) direction; the molecular $x$ and $y$ axes (represented here by full and open circles, respectively) deviate by only 13 and $7^{\circ}$ from the crystallographic $(b)$ and $(c)$ axes.

different in space but close in energy, and this makes it difficult to define proper electronic configurations.

(3) When spin-orbit coupling is neglected, we find that $D_{3 d^{-}}$ distorted structures represent absolute minima in the case of $\mathrm{M}(\mathrm{CN})_{6}\left(\mathrm{M}=\mathrm{Fe}^{\mathrm{III}}, \mathrm{Mn}^{\mathrm{III}}, \mathrm{Cr}^{\mathrm{II}}, \mathrm{Mn}^{\mathrm{II}}\right)$, while $\left[\mathrm{Ti}(\mathrm{CN})_{6}\right]^{3-}$ is tetragonal $\left(D_{4 h}\right)$. A remarkable trend with a correlation between JT coupling and metal-ligand $\pi$-back-donation is found: $\mathrm{Ti}^{\mathrm{III}}$ $<\mathrm{V}^{\mathrm{III}}<\mathrm{Mn}^{\mathrm{III}}<\mathrm{Fe}^{\mathrm{III}}<\mathrm{Mn}^{\mathrm{II}}<\mathrm{Cr}^{\mathrm{II}}$.

(4) On the basis of a comparison between the vibronic coupling strengths (i.e., the ratios of the JT stabilization energy $\left(E_{\mathrm{JT}}\right)$ and the zero point vibrational energy; $\lambda_{\epsilon}=E_{\mathrm{JT}}\left(D_{4 h}\right) / \hbar \omega_{\epsilon}$ ( $\mathrm{T}_{\mathrm{g}} \otimes \epsilon_{\mathrm{g}}$ coupling), $\lambda_{\tau}=2 E_{\mathrm{JT}}\left(D_{4 h}\right) / 3 \hbar \omega_{\tau}\left(\mathrm{T}_{\mathrm{g}} \otimes \tau_{2 \mathrm{~g}}\right.$ coupling $)$ ) it is found that JT coupling with the $\tau_{2 \mathrm{~g}}$ mode is strong for $\mathrm{Cr}^{\mathrm{II}}$ and $\mathrm{Mn}^{\mathrm{II}}$, moderate for $\mathrm{Mn}^{\mathrm{III}}$ and $\mathrm{Fe}^{\mathrm{III}}$, and weak in all other cases.

(5) The interplay between JT coupling and spin-orbit coupling is found to lead to a shallow $D_{3 d}$ minimum for $\left[\mathrm{Fe}(\mathrm{CN})_{6}\right]^{3-}$ and no distortion for $\left[\mathrm{Mn}(\mathrm{CN})_{6}\right]^{3-}$. However, the ground-state potential energy surfaces of both ions are found to be flat and susceptible to angular distortions. Therefore, we have been able to reproduce the $\mathbf{g}$ and magnetic susceptibility tensors of $\mathrm{K}_{3}\left[\mathrm{Fe}(\mathrm{CN})_{6}\right]$ and the spectra and susceptibility tensor of $\mathrm{K}_{3}\left[\mathrm{Mn}(\mathrm{CN})_{6}\right]$ in terms of statically distorted and straininduced geometries (geometrical strains) and a small trigonal distortion (trigonal strains of only 1 and $0.5^{\circ}$, respectively).

(6) Pseudo JT coupling, due to mixing of the $t_{2 g}$ and $e_{g}$ orbitals via the $\tau_{2 \mathrm{~g}}$ vibrational mode, is found to be of minor importance for $\left[\mathrm{Fe}(\mathrm{CN})_{6}\right]^{3-}$ and possibly also for the other complexes discussed. The reason is the rather high value of the cubic ligand field spitting due to the cyanide ligands, which leads to a partial or a complete suppression of the $t_{2 \mathrm{~g}} \otimes \tau_{2 \mathrm{~g}} \otimes \epsilon_{\mathrm{g}}$ pseudo JT interaction, in contrast to the case for tetrahedral complexes. ${ }^{33}$

(7) Dynamic JT coupling in addition to the structural strain is found in solids and produces interesting effects on the $\mathbf{g}$ tensor values and to a lesser extent on the magnetic susceptibilities with JT active $E_{g}$ or $T_{g}$ ground states. ${ }^{56-65}$ These deserve further experimental studies.

\section{Appendix}

With eqs 10-14 we obtain the following master equations, which relate the parameters of the vibronic coupling Hamiltonian equation (1) with quantities calculated from DFT. (a) From data based on $D_{4 h}$ geometry optimizations (to get $Q_{\theta}^{\mathrm{m}}$ and $Q_{\theta}^{\mathrm{s}}$ ) and a single-point calculation (to get $E_{\mathrm{FC}}{ }^{\mathrm{m}}\left(D_{4 h}\right)$ ):

$$
\begin{gathered}
V_{\epsilon}=\frac{4}{4-r_{\epsilon}} \cdot \frac{E_{\mathrm{FC}}{ }^{\mathrm{m}}\left(D_{4 h}\right)}{Q_{\theta}^{\mathrm{m}}} \\
K_{\epsilon}=\frac{1-r_{\epsilon}}{4-r_{\epsilon}} \cdot \frac{4}{3} \cdot \frac{E_{\mathrm{FC}}{ }^{\mathrm{m}}\left(D_{4 h}\right)}{\left(Q_{\theta}^{\mathrm{m}}\right)^{2}} \\
L_{\epsilon}=\frac{2+r_{\epsilon}}{4-r_{\epsilon}} \cdot \frac{4}{3} \cdot \frac{E_{\mathrm{FC}}{ }^{\mathrm{m}}\left(D_{4 h}\right)}{\left(Q_{\theta}^{\mathrm{m}}\right)^{2}}
\end{gathered}
$$

where $r_{\epsilon}=Q_{\theta}{ }^{\mathrm{m}} / Q_{\theta} \mathrm{s}$.

(b) From structural data based on $D_{3 d}$ geometry optimizations (to get $Q_{\tau}{ }^{\mathrm{m}}$ and $Q_{\tau}{ }^{\mathrm{s}}$ ) and a single-point calculation (to get $E_{\mathrm{FC}}{ }^{\mathrm{m}}$ $\left.\left(D_{3 d}\right)\right)$ :

$$
\begin{gathered}
V_{\tau}=-\frac{2}{r_{\tau}-4} \cdot \frac{E_{\mathrm{FC}}{ }^{\mathrm{m}}\left(D_{3 d}\right)}{Q_{\tau}{ }^{\mathrm{m}}} \\
K_{\tau}=\frac{r_{\tau}-1}{r_{\tau}-4} \cdot \frac{4}{9} \cdot \frac{E_{\mathrm{FC}}{ }^{\mathrm{m}}\left(D_{3 d}\right)}{\left(Q_{\tau}^{\mathrm{m}}\right)^{2}} \\
X_{\tau}=\frac{r_{\tau}+2}{r_{\tau}-4} \cdot \frac{1}{3} \cdot \frac{E_{\mathrm{FC}}{ }^{\mathrm{m}}\left(D_{3 d}\right)}{\left(Q_{\tau}^{\mathrm{m}}\right)^{2}}
\end{gathered}
$$

where $r_{\tau}=Q_{\tau}^{\mathrm{m}} / Q_{\tau} \mathrm{s}$.

(c) From structural data based on $D_{2 h}$ optimization (to get $Q_{\xi}{ }^{\mathrm{m}}$ and $\left.Q_{\theta}{ }^{\mathrm{m}}\right)$ :

$$
\begin{gathered}
W=\frac{V_{\epsilon}+\left(2 K_{\epsilon}-L_{\epsilon}\right) Q_{\theta}{ }^{\mathrm{m}^{\prime}}}{2 Q_{\zeta}^{\mathrm{m}}} \\
L_{\tau}=2 K_{\tau}-2 \frac{V_{\tau}}{Q_{\zeta}^{\mathrm{m}}}-\frac{V_{\epsilon} Q_{\theta}{ }^{\mathrm{m}^{\prime}}}{\left(Q_{\zeta}{ }^{\mathrm{m}}\right)^{2}}-\frac{\left(2 K_{\epsilon}-L_{\epsilon}\right)\left(Q_{\theta}{ }^{\mathrm{m}^{\prime}}\right)^{2}}{\left(Q_{\zeta}{ }^{\mathrm{m}}\right)^{2}}
\end{gathered}
$$

Substitution of $V_{\epsilon}, K_{\epsilon}, L_{\epsilon}$, and $V_{\tau}$ with expressions A.1-A.4 yields

$$
\begin{gathered}
W=\frac{2 E_{\mathrm{FC}}{ }^{\mathrm{m}}\left(D_{4 h}\right)}{Q_{\zeta}^{\mathrm{m}} Q_{\theta}{ }^{\mathrm{m}}} \frac{1-r_{\epsilon} \frac{Q_{\theta}{ }^{\mathrm{m}^{\prime}}}{Q_{\theta}{ }^{\mathrm{m}}}}{4-r_{\epsilon}} \\
L_{\tau}=\frac{4 E_{\mathrm{FC}}{ }^{\mathrm{m}}\left(D_{3 d}\right)}{\left(r_{\tau}-4\right) Q_{\tau}^{\mathrm{m}}}\left[\frac{2}{9} \frac{\left(r_{\tau}-1\right)}{Q_{\tau}^{\mathrm{m}}}+\frac{1}{Q_{\zeta}^{\mathrm{m}}}\right]- \\
\frac{4 E_{\mathrm{FC}}{ }^{\mathrm{m}}\left(D_{4 h}\right)}{\left(4-r_{\epsilon}\right)}\left[\frac{Q_{\theta}{ }^{\mathrm{m}^{\prime}}}{\left(Q_{\zeta}{ }^{\mathrm{m}}\right)^{2} Q_{\theta}{ }^{\mathrm{m}}}-r_{\epsilon}\left(\frac{Q_{\theta}{ }^{\mathrm{m}}}{Q_{\theta}{ }^{\mathrm{m}} Q_{\zeta}{ }^{\mathrm{m}}}\right)^{2}\right]
\end{gathered}
$$

We obtain the following equations for the energies of the Franck-Condon transitions:

$$
E_{\mathrm{FC}}{ }^{\mathrm{m}}\left(D_{2 h}, \mathrm{~b}_{2 \mathrm{~g}} \rightarrow \mathrm{b}_{3 \mathrm{~g}}\right)=2 V_{\tau} Q_{\zeta}{ }^{\mathrm{m}}+2 W Q_{\zeta}{ }^{\mathrm{m}} Q_{\theta}{ }^{\mathrm{m}^{\prime}}
$$




$$
\begin{array}{r}
E_{\mathrm{FC}}{ }^{\mathrm{m}}\left(D_{2 h}, \mathrm{~b}_{2 \mathrm{~g}} \rightarrow \mathrm{a}_{\mathrm{g}}\right)=-\frac{3}{2}\left(V_{\epsilon} Q_{\theta}{ }^{\mathrm{m}^{\prime}}-\frac{1}{2} L_{\epsilon}\left(Q_{\theta}{ }^{\mathrm{m}^{\prime}}\right)^{2}-\right. \\
\left.\frac{1}{2} L_{\tau}\left(Q_{\zeta}^{\mathrm{m}}\right)^{2}\right)+V_{\tau} Q_{\varsigma}^{\mathrm{m}}+W Q_{\varsigma}{ }^{\mathrm{m}} Q_{\theta}{ }^{\mathrm{m}^{\prime}}
\end{array}
$$

and expressed in terms of quantities derived from DFT:

$$
\begin{aligned}
& E_{\mathrm{FC}}{ }^{\mathrm{m}}\left(D_{2 h}, \mathrm{~b}_{2 \mathrm{~g}} \rightarrow \mathrm{b}_{3 \mathrm{~g}}\right)= \\
& \frac{4 E_{\mathrm{FC}}{ }^{\mathrm{m}}\left(D_{3 d}\right) Q_{\zeta}^{\mathrm{m}}}{4-r_{\tau} Q_{\tau}^{\mathrm{m}}}+\frac{4 E_{\mathrm{FC}}{ }^{\mathrm{m}}\left(D_{4 h}\right) Q_{\theta}{ }^{\mathrm{m}^{\prime}}}{4-r_{\epsilon} Q_{\theta}^{\mathrm{m}}}\left(1-r_{\epsilon} \frac{Q_{\theta}{ }^{\mathrm{m}^{\prime}}}{Q_{\theta}^{\mathrm{m}}}\right) \\
& E_{\mathrm{FC}}{ }^{\mathrm{m}}\left(D_{2 h}, \mathrm{~b}_{2 \mathrm{~g}} \rightarrow \mathrm{a}_{\mathrm{g}}\right)= \\
& \frac{E_{\mathrm{FC}}{ }^{\mathrm{m}}\left(D_{3 d}\right) Q_{\zeta}^{\mathrm{m}}}{r_{\tau}-4 Q_{\tau}^{\mathrm{m}}}\left[1+\frac{2}{3}\left(r_{\tau}-1\right) \frac{Q_{\zeta}^{\mathrm{m}}}{Q_{\tau}^{\mathrm{m}}}\right]+ \\
& \frac{E_{\mathrm{FC}}{ }^{\mathrm{m}}\left(D_{4 h}\right) Q_{\theta}^{\mathrm{m}^{\prime}}}{4-r_{\epsilon} Q_{\theta}{ }^{\mathrm{m}}}\left[-7+2\left(1+r_{\epsilon}\right) \frac{Q_{\theta}{ }^{\mathrm{m}^{\prime}}}{Q_{\theta}^{\mathrm{m}}}\right]
\end{aligned}
$$

In the case of linear JT coupling we have

$$
\begin{gathered}
Q_{\theta}{ }^{\mathrm{m}}=\frac{V_{\epsilon}}{K_{\epsilon}} \\
Q_{\theta}^{\mathrm{m}^{\prime}}=-\frac{1 V_{\epsilon}}{2 K_{\epsilon}} \\
Q_{\tau}^{\mathrm{m}}=\frac{2 V_{\tau}}{3 K_{\tau}} \\
Q_{\varsigma}^{\mathrm{m}}=\frac{V_{\tau}}{K_{\tau}}
\end{gathered}
$$

and therefore obtain

$$
\begin{gathered}
\frac{Q_{\theta}{ }^{\mathrm{m}^{\prime}}}{Q_{\theta}{ }^{\mathrm{m}}}=-\frac{1}{2} \\
\frac{Q_{\zeta}^{\mathrm{m}}}{Q_{\tau}^{\mathrm{m}}}=\frac{3}{2} \\
r_{\epsilon}=\frac{Q_{\theta}{ }^{\mathrm{m}}}{Q_{\theta}^{\mathrm{s}}}=-2 \\
r_{\tau}=\frac{Q_{\tau}{ }^{\mathrm{m}}}{Q_{\tau}^{\mathrm{s}}}=-2
\end{gathered}
$$

Substitution into eqs A.13 and A.14 yields

$$
\begin{gathered}
E_{\mathrm{FC}}{ }^{\mathrm{m}}\left(D_{2 h}, \mathrm{~b}_{2 \mathrm{~g}} \rightarrow \mathrm{b}_{3 \mathrm{~g}}\right)=E_{\mathrm{FC}}^{\mathrm{m}}\left(D_{3 d}\right) \\
E_{\mathrm{FC}}^{\mathrm{m}}\left(D_{2 h}, \mathrm{~b}_{2 \mathrm{~g}} \rightarrow \mathrm{a}_{\mathrm{g}}\right)=\frac{1}{2}\left[E_{\mathrm{FC}}^{\mathrm{m}}\left(D_{4 h}\right)+E_{\mathrm{FC}}^{\mathrm{m}}\left(D_{3 d}\right)\right]
\end{gathered}
$$

as given in Table 2 .

Acknowledgment. This study was performed within the priority program SPP 1137 (Molecular Magnetism) of the German Scientific Foundation (DFG). We are grateful for fruitful discussions with various colleagues at the International Symposium of the Jahn-Teller Effect, Trieste, Italy, 2006. Thanks are also due to Prof. D. Reinen (University of Marburg,
Germany) for discussions in the course of this work as well as for careful reading of the manuscript prior to publication.

Supporting Information Available: Text and tables giving computational details and additional derivations mentioned in the text. This material is available free of charge via the Internet at http://pubs.acs.org.

\section{References and Notes}

(1) Teller, E. A historical note. In The Jahn-Teller Effect in Molecules and Crystals; Engelman, R., Ed.; Wiley-Interscience: London, 1972. 220

(2) Jahn, H. A.; Teller, E. Proc. R. Soc. London, Ser. A 1937, 161,

(3) Ruiz, E.; Rodriguez-Fortea, A.; Alvarez, S.; Verdaguer, M. Chem. Eur. J. 2005, 11, 2135.

(4) Atanasov, M.; Comba, P.; Daul, C. A. J. Phys. Chem. A 2006, 110,13332

(5) Reinen, D.; Friebel, C. Struct. Bonding 1979, 37, 1.

(6) Halcrow, M. A. Dalton Trans. 2003, 4375.

(7) Reinen, D.; Atanasov, M. Magn. Reson. Rev. 1991, 15, 167.

(8) Bersuker, I. B.; Polinger, V. Z. Phys. Lett. 1973, 44A, 495.

(9) Bacci, M.; Ranfagni, A.; Fontana, M. P.; Viliani, G. Phys. Rev. B 1975, 11, 3052

(10) Bacci, M.; Ranfagni, A.; Cetica, M.; Viliani, G. Phys. Rev. B 1975, 12,5907

(11) Atanasov, M.; Comba, P. J. Mol. Struct. 2007, 838, 157.

(12) Ceulemans, A.; Beyens, D.; Vanquickenborne, L. G. J. Am. Chem. Soc. 1984, 106, 5824.

(13) Baker, J. M.; Bleaney, B.; Bowers, K. D. Proc. Phys. Soc. London, Sect. B 1956, 69, 1205

(14) Bleaney, B.; O'Brien, M. C. M. Proc. Phys. Soc. London, Sect. B 1956, 69, 1216

(15) Figgis, B. N. Trans. Faraday Soc. 1961, 57, 204

(16) Golding, R. M. Mol. Phys. 1967, 12, 13.

(17) Oosterhuis, W. T.; Lang, G. Phys. Rev. 1969, 178, 439

(18) Figgis, B. N.; Gerloch, M.; Mason, R. Proc. R. Soc. London, Ser. A 1969, 309, 91.

(19) Merrithew, P. B.; Modestino, A. J. J. Am. Chem. Soc. 1972, 94, 3361 .

(20) Figgis, B. N.; Skelton, B. W.; White, A. H. Aust. J. Chem. 1978 31,1195

(21) Baker, J.; Figgis, B. N. Aust. J. Chem. 1982, 35, 265.

(22) Jones, G. D.; Runciman, W. A. Proc. Phys. Soc. (London) 1960, $76,996$.

(23) Mukhrjee, R. K.; Chowdhury, M. Chem. Phys. Lett. 1975, 34, 178

(24) Ghosh, D.; Mukhrjee, R. K. J. Phys. Chem. Solids 1979, 40, 691.

(25) Daul, C. A.; Rauzy, C.; Decurtins, S.; Franz, P.; Hauser, A. Int. J. Quant. Chem. 2005, 101, 753.

(26) Bersuker, I. B. The Jahn-Teller Effect and Vibronic Interactions in Modern Chemistry; Plenum Press: New York, 1984.

(27) Bersuker, I. B. The Jahn-Teller Effect; Cambridge University Press: London, 2006

(28) Griffith, J. S. The Theory of Transition-Metal Ions; Cambridge University Press: London, 1971.

(29) Opik, U.; Pryce, M. H. L. Proc. R. Soc. London, Ser. A 1957, 238 , 425.

(30) Atanasov, M.; Daul, C. A. Chimia 2005, 59, 504

(31) Reinen, D.; Atanasov, M.; Massa, W. Z. Anorg. Allg. Chem. 2006, 632,1375

(32) $Q_{\mathrm{i}}{ }^{\prime}$ are dimensionless normal coordinates, calculated from $Q_{\mathrm{i}}$ (in $\AA$ ) as $Q_{\mathrm{i}}{ }^{\prime}=f Q_{\mathrm{i}}: f=0.1722\left[M\left(\hbar \omega_{\tau}\right)\right]^{1 / 2}$, where $M$ is the reduced mass of the $\tau_{2 \mathrm{~g}}$ vibration $M=R_{\mathrm{tr}}{ }^{2} \cdot\left(m_{\mathrm{C}}+m_{\mathrm{N}}\right) / 4$, with $m_{\mathrm{C}}(=12)$ and $m_{\mathrm{N}}(=14)$ in au, $\hbar \omega_{\tau}$ is the vibrational frequency (in $\mathrm{cm}^{-1}$ ), $R_{\mathrm{tr}}$ is the metal-ligand bond distance (in A). Accordingly, when the vibronic matrix elements are calculated, using the harmonic oscillator wavefunctions $\left(\left\langle n-1\left|Q_{\tau}{ }^{\prime}\right| n\right\rangle=\right.$ $\left.(n / 2)^{1 / 2} ;\left\langle n\left|Q_{\tau}{ }^{\prime}\right| n+1\right\rangle=[(n+1) / 2]^{1 / 2}\right), V_{\tau} Q_{\tau}$ has to be replaced by $V_{\tau}{ }^{\prime} Q_{\tau}{ }^{\prime}$

$\left(V_{\tau}^{\prime}\left(\mathrm{cm}^{-1}\right)=V_{\tau}\left(\mathrm{cm}^{-1} / \AA\right) / f\right.$, which is the same as $V_{\tau}^{\prime}=\sqrt{(3 / 2) E_{\mathrm{JT}}{ }_{3 \mathrm{~d}} \hbar \omega_{\tau}}=$ $(3 / 2) \hbar \omega_{\tau} \sqrt{\lambda_{\tau}}$. One can also show that $\hbar \omega_{\tau}=K_{\tau} / f^{2}$; a different definition of the vibronic coupling strength $k=V_{\tau}^{\prime} / \hbar \omega_{\tau}=(3 / 2) \sqrt{\lambda_{\tau}}$ has been adopted in ref 53, where approximate expressions for $K_{\mathrm{T}_{2}}\left(\mathrm{~T}_{1}\right) \approx \exp \left[-(3 / 2) k^{2}\right]$ and for the $\mathrm{A}_{1}-\mathrm{T}_{2}$ tunneling splitting $\delta \approx 0.88 k^{2} \exp \left(-0.827 k^{2}\right.$ ) (valid for large $k$ values) are given.

(33) Agresti, A.; Ammeter, J. H.; Bacci, M. J. Chem. Phys. 1984, 81 , $1861 ; \mathbf{1 9 8 5}, 82,5299$.

(34) Atanasov, M.; Reinen, D. Adv. Quantum Chem. 2003, 44, 355

(35) Atanasov, M.; Reinen, D. Inorg. Chem. 2005, 44, 5092.

(36) Bérces, A.; Bo, C.; Boerrigter, P. M.; Cavallo, L.; Chong, D. P.; Deng, L.; Dickson, R. M.; Ellis, D. E.; Fan, L.; Fischer, T. H.; Fonseca Guerra, C.; van Gisbergen, S. J. A.; Groeneveld, J. A.; Gritsenko, O. V.; 
Grüning, M.; Harris, F. E.; van den Hoek, P.; Jacobsen, H.; van Kessel, G.; Kootstra, F.; van Lenthe, E.; McCormack, D. A.; Osinga, V. P.; Patchkovskii, S.; Philipsen, P. H. T.; Post, D.; Pye, C. C.; Ravenek, W. Ros, P.; Schipper, P. R. T.; Schreckenbach, G.; Snijders, J. G.; Sola, M. Swart, M.; Swerhone, D.; te Velde, G.; Vernooijs, P.; Versluis, L.; Visser, O.; van Wezenbeek, E.; Wiesenekker, G.; Wolff, S. K.; Woo, T. K.; Baerends, E. J.; Autschbach, J.; Ziegler, T. ADF2006.01 SCM; Theoretical Chemistry, Vrije Universiteit, Amsterdam, The Netherlands, 2006.

(37) Vosko, S. H.; Wilk, L.; Nusair, M. Can. J. Phys. 1980, 58, 1200. 799 .

(38) Klamt, A.; Schürmann, G. J. Chem. Soc., Perkin Trans. 21993

(39) Pye, C. C.; Ziegler, T. Theor. Chim. Acc. 1999, 101, 396.

(40) Lower, J. A.; Fernelius, W. C. Inorg. Synth. 1946, 2, 225

(41) Alexander, J. J.; Gray, H. B. J. Am. Chem. Soc. 1968, 90, 4260

(42) Reinen, D.; Atanasov, M.; Köhler, P. J. Mol. Struct. 2007, 838, 151.

(43) Bacci, M. Chem. Phys. Lett. 1978, 58, 537.

(44) Bacci, M. Chem. Phys. 1979, 40, 237. Because of a different choice for the definition of $Q_{\xi}, Q_{\eta}$, and $Q_{\zeta}$ (i.e. in terms of C-M-C valence bond changes instead of angular displacements of single atoms) the value of $V_{\tau}$, expressed by eq 32 , is smaller by a factor of 2 , in comparison to the expression given in this reference.

(45) Atanasov, M.; Rauzy, C.; Bättig, P.; Daul, C. A. Int. J. Quantum Chem. 2005, 102, 119.

(46) Atanasov, M.; Baerends, E. J.; Baettig, P.; Bruyndonckx, R.; Daul, C. A.; Rauzy, C.; Zbiri, M. Chem. Phys. Lett. 2004, 399, 433.

(47) Buschman, W. E.; Liable-Sands, L.; Rheingold, A. L.; Miller, J. S. Inorg. Chim. Acta 1999, 284, 175.

(48) (a) Vannerberg, N.-G., Acta Chem. Scand. 1970, A24, 2335. (b)

Vannerberg, N.-G. Acta Chem. Scand. 1972, A26, 2863.

(49) Cauzzi, D. A.; Mori, G.; Predieri, G.; Tiripiccio, A.; Cavatorta, F. Inorg. Chim. Acta 1993, 204, 181.

(50) Ljungström, E. Acta Chem. Scand. 1977, A31, 104
(51) It is remarkable that, in contrast to $k_{\mathrm{cov}}=0.79$, a value of $k_{\mathrm{CI}}$ larger than one $\left(k_{\mathrm{CI}}=1.19\right)$ for $\left[\mathrm{Fe}(\mathrm{CN})_{6}\right]^{3-}$ has been calculated using a full $\mathrm{CI}$ calculation (i.e., accounting for the total space of the 256 Slater determinants). This yields $k=k_{\mathrm{cov}} k_{\mathrm{CI}}=0.940\left(K_{\mathrm{T}_{2}}\left(\mathrm{~T}_{1}\right)=1\right)$. This might explain the unusual result that a value of $k=0.913$ was obtained from a fit to magnetic susceptibility data for $\left[\mathrm{N}\left(\mathrm{PPh}_{3}\right)_{2}\right]_{3}\left[\mathrm{Fe}(\mathrm{CN})_{6}\right]$, using static ligand field expressions for cubic symmetry: Atanasov, M.; Comba, P.; Lampeka, Y. D.; Linti, G.; Malcherek, T.; Miletich, R.; Prikhod'ko, A. I. Chem. Eur. J. 2006, 12, 737 .

(52) Ham, F. S. Phys. Rev. 1965, 138, A1727.

(53) Caner, M.; Englman, R. J. Chem. Phys. 1966, 44, 4054.

(54) O'Brien, M. C. M. Phys. Rev. 1969, 187, 407.

(55) Bersuker, I. B.; Polinger, V. Z. Phys. Status Solidi B 1973, 60, 85.

(56) Riley, M. J.; Hitchman, M. A.; Reinen, D. Chem. Phys. 1986, 102

(57) Riley, M. J.; Hitchman, M. A.; Wan Mohammed, A. J. Chem. Phys. 1987, 87, 3766

(58) Riley, M. J. Top. Curr. Chem. 2001, 214, 57.

(59) Ameis, R.; Kremer, S.; Reinen, D. Inorg. Chem. 1985, 24, 2751

(60) Dubicki, L.; Riley, M. J. J. Chem. Phys. 1997, 106, 1669.

(61) Tregenna-Piggott, P. L. W.; O'Brien, M. C. M.; Pilbrow, J. R.; Güdel, H.-U.; Best, S. P.; Noble, C. J. J. Chem. Phys. 1997, 107, 8275.

(62) Tregenna-Piggott, P. L. W.; Noble, C. J.; Pilbrow, J. R. J. Chem. Phys. 2000, 113, 3289.

(63) Tregenna-Piggott, P. L. W.; Güdel, H.-U. Inorg. Chem. 2001, 40 5497

(64) Tregenna-Piggott, P. L. W.; Spichiger, D.; Carver, G.; Frey, B.; Meier, R.; Weihe, H.; Cowan, J. A.; McIntyre, G. J.; Zahn, G.; Barra, A.L. Inorg. Chem. 2004, 43, 8049 .

(65) Tregenna-Piggott, P. L. W.; Carver, G. Inorg. Chem. 2004, 43, 8061.

(66) Reynolds, P. A.; Delfs, C. D.; Figgis, B. N.; Moubaraki, B.; Murray, K. S. Aust. J. Chem. 1992, 45, 1301. 